\title{
Event-based surveillance and response to food- and water-borne disease outbreaks in the European Union
}

Citation for published version (APA):

Gossner, C. M. (2016). Event-based surveillance and response to food-and water-borne disease outbreaks in the European Union. [Doctoral Thesis, Maastricht University]. https://doi.org/10.26481/dis.20160706cg

Document status and date:

Published: 01/01/2016

DOI:

$10.26481 /$ dis.20160706cg

Document Version:

Publisher's PDF, also known as Version of record

\section{Please check the document version of this publication:}

- A submitted manuscript is the version of the article upon submission and before peer-review. There can be important differences between the submitted version and the official published version of record.

People interested in the research are advised to contact the author for the final version of the publication, or visit the DOI to the publisher's website.

- The final author version and the galley proof are versions of the publication after peer review.

- The final published version features the final layout of the paper including the volume, issue and page numbers.

Link to publication

\footnotetext{
General rights rights.

- You may freely distribute the URL identifying the publication in the public portal. please follow below link for the End User Agreement:

www.umlib.nl/taverne-license

Take down policy

If you believe that this document breaches copyright please contact us at:

repository@maastrichtuniversity.nl

providing details and we will investigate your claim.
}

Copyright and moral rights for the publications made accessible in the public portal are retained by the authors and/or other copyright owners and it is a condition of accessing publications that users recognise and abide by the legal requirements associated with these

- Users may download and print one copy of any publication from the public portal for the purpose of private study or research.

- You may not further distribute the material or use it for any profit-making activity or commercial gain

If the publication is distributed under the terms of Article $25 \mathrm{fa}$ of the Dutch Copyright Act, indicated by the "Taverne" license above, 


\title{
Event-based surveillance and response to food- and water- borne disease outbreaks in the European Union
}

\author{
Céline M. Gossner
}

Maastricht, the Netherlands

6 July 2016 

The research presented in this thesis was conducted at the School for Public Health and Primary Care: CAPHRI, Department of Medical Microbiology of Maastricht University. CAPHRI participates in the Netherlands School of Primary Care Research CaRe.

All rights reserved. No part of this thesis may be reproduced, stored, or transmitted in any form or by any means, electronic or mechanical, including photocopy, recording or any information storage or retrieval system, without prior permission of the copyright owner.

Céline M. Gossner is employed by the European Centre for Diseases Prevention and Control (ECDC). The views and opinions of the author expressed herein do not necessarily state or reflect those of the ECDC. The accuracy of the statistical analysis and the findings reported are not the responsibility of ECDC. ECDC is not responsible for conclusions or opinions drawn from the data provided. ECDC is not responsible for the correctness of the data and for data management, data merging and data collation after provision of the data. ECDC shall not be held liable for improper or incorrect use of the data.

(C) Céline M. Gossner, Maastricht 2016

Design and lay-out: Céline M. Gossner

Printed by: Gildeprint

ISBN: 978-94-6233-315-4 


\title{
Event-based surveillance and response to food- and water- borne disease outbreaks in the European Union
}

\author{
DISSERTATION \\ to obtain the degree of Doctor at Maastricht University, \\ on the authority of the Rector Magnificus, \\ Prof.dr. L.L.G. Soete \\ in accordance with the decision of the Board of Deans, \\ to be defended in public \\ on Wednesday 6 July 2016, at 14:00 hours. \\ by Céline M. Gossner
}




\section{Supervisor:}

Prof. dr. C.J.P.A. Hoebe

\section{Co-supervisor:}

Dr. B. de Jong, ECDC, Sweden

\section{Assessment Committee:}

Prof. dr. P.H.M. Savelkoul (chair)

Prof. dr. H. Bosma

Prof. dr. K. Horstman

Prof. dr. J.H. Richardus, Erasmus MC Rotterdam

Dr. Y. van Duijnhoven, Public Health Service Amsterdam 
Pour ma fille Tuva Louise... 


\section{TABLE OF CONTENT}

Section I General introduction ...................................................................

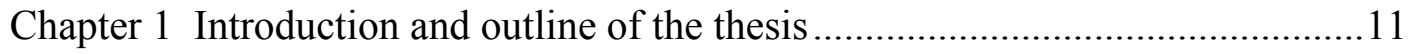

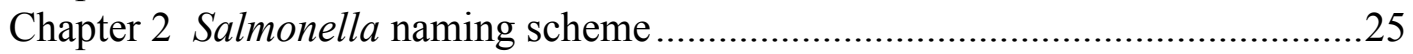

Section II Event-based surveillance through the EPidemic intelligence Information System for Food- and Water-borne Diseases and zoonoses (EPISFWD)

Chapter 3 Description of the EPidemic intelligence Information System for Foodand Water-borne Diseases and zoonoses (EPIS-FWD)

Chapter 4 Analysis of the data collected through the EPidemic intelligence Information System for Food- and Water-borne Diseases and zoonoses (EPISFWD)

Section III Detection and response to food- and water-borne disease outbreaks in the European Union.

Chapter 5 Nationwide outbreak of monophasic Salmonella Typhimurium in

France, 2011

Chapter 6 Multi-country outbreaks of Hepatitis A virus infection in the European

Union, 2013.

Chapter 7 Using surveillance data to respond to multi-country outbreaks of Hepatitis A virus infection in the European Union.

Section IV Detection and response to food- and water-borne disease outbreaks beyond the European Union level and closure of outbreaks.

Chapter 8 Detection and response to food- and water-borne disease outbreaks with a worldwide scope

Chapter 9 Closure of food- and water-borne disease outbreaks

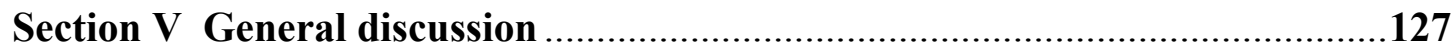

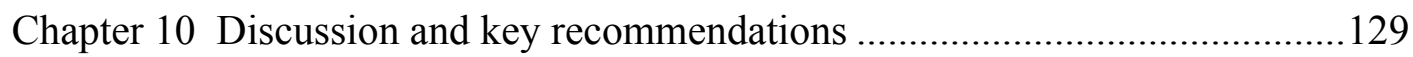

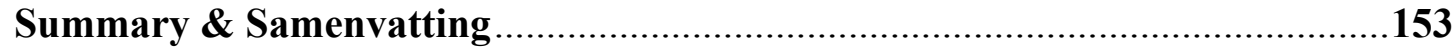

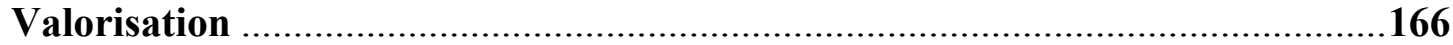

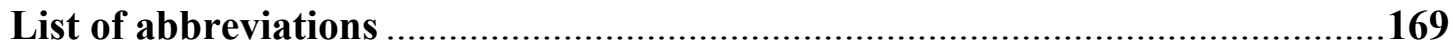

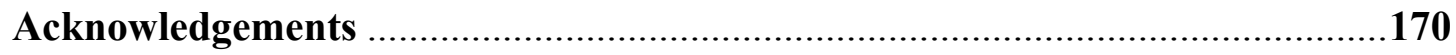

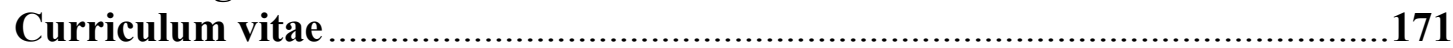





\section{Health}

Sallmonella public number

\section{Reporting cont Disoase Names \\ Campylobacter \\ Cases \\ Serotypes FWD Intrormation $F$ Heod Geographical Water Outbreaks Country commens Water Outbreaks country mann} Scheme Enterica Country Population Infection

SECTION I

GENERAL INTRODUCTION * 
Section I provides an introduction to this thesis, describing the general concepts of surveillance and outbreak response to food- and water-borne diseases in the EU.

Chapter 1 introduces some basics on surveillance and outbreak response, presents the scope of this thesis, and provides an overview of the most common pathogens and epidemiological situation regarding food- and water-borne disease infections and outbreaks in the EU.

Chapter 2 describes the Salmonella naming scheme and its impacts on public health microbiology. 


\section{Chapter 1}

\section{INTRODUCTION AND}

OUTLINE OF THE THESIS 


\section{INTRODUCTION TO FOOD- AND WATER-BORNE DISEASES AND OUTBREAKS}

Food- and water-borne diseases (FWDs) regroup more than 200 diseases that are transmitted predominantly through the ingestion of contaminated food or water. Diseases ranges from diarrhoea to cancers and may lead to long-lasting disability and death. The World Health Organization (WHO) estimates that two million people are dying every year from food- and water-borne diarrhoeal diseases worldwide. The majority of the FWDs are caused by biological agents including bacteria, viruses, parasites and prions but FWDs can also be caused by chemical or physical agents [1].

According to WHO, a disease outbreak is "the occurrence of cases of disease in excess of what would normally be expected in a defined community, geographical area or season. An outbreak may occur in a restricted geographical area, or may extend over several countries. It may last for a few days or weeks, or for several years.

A single case of a communicable disease long absent from a population, or caused by an agent (e.g. bacterium or virus) not previously recognized in that community or area, or the emergence of a previously unknown disease, may also constitute an outbreak and should be reported and investigated [2]."

FWD outbreaks may have a considerable impact on public health but also economic repercussion on the industry. For instance, when cholera re-entered Peru in 1991, it not only caused the death of 3000 people but also affected the export of seafood from Peru. The country suffered from a trade embargo and tourism decreased. According to estimations this had a cost of more than US\$ 770 million to the Peruvian economy in one year [3]. A more recent example in the European Union (EU) is commonly known as the "Spanish cucumber" scandal. Initial field investigations of the largest shiga-toxin-producing Escherichia coli (STEC) O104:H4 outbreak that started in Germany in May 2011, suggested that raw food items, such as tomatoes, cucumbers or leaf salad were the source of infection [4]. While further investigations identified sprouts as the most likely vehicle of infection, German officials had already, prematurely, reported that imported cucumbers from Spain were the vehicle of infection [5]. According to the European agricultural union - General Committee for Agricultural Cooperation in the EU (Copa-Cogeca), this premature and erroneous announcement caused an estimated loss for EU farmers in the fruit and vegetable sector of at least EUR 812 million in the first two weeks after announcement [6].

Contamination of food products may occur at all stages of the food chain: primary production (at the farms, using untreated water), processing plants (contaminated machines), distribution, point-of-sell, restaurant or at home (infected food handler or cross contamination of products). Contamination is often the result of an accidental malpractice but may, in rare occasion, also be the result of a bioterror attack $[7,8]$ or fraud [9].

As international trade of food items and movements of people (i.e. travels) are constantly increasing, the likelihood of having dispersed multi-country FWD outbreaks is increasing too. In this context, it is crucial to ensure that surveillance and response systems in place at the supra-national level can capture those outbreaks and allow a timely and coordinated response. 


\section{CONCEPT OF PUBLIC HEALTH SURVEILLANCE AND OUTBREAK RESPONSE}

According to WHO, public health surveillance is "the continuous, systematic collection, analysis and interpretation of health-related data needed for the planning, implementation, and evaluation of public health practice" [10]. In this thesis, surveillance is divided into two categories: event-based surveillance and indicatorbased surveillance.

WHO defines event-based surveillance as "the organized collection, monitoring, assessment and interpretation of mainly unstructured ad hoc information regarding health events or risks, which may represent an acute risk to human health" [11]. Sources of information include media reports, blogs, social media, private industries press releases, official and unofficial reports or press releases from local, national and international authorities from the public health sectors or other sectors such as animal health, food safety, environment etc. All this information is aggregated and filtered to produce signals that are verified and validated with the competent authorities to define whether they are events (Figure 1; Table 1). All events are analysed using background information to define whether they could become threats for which response activities would then be needed.

Event-based surveillance is commonly opposed to indicator-based surveillance. The latter is defined by WHO as "the systematic (regular) collection, monitoring, analysis and interpretation of structured data, i.e. of indicators produced by a number of wellidentified, mostly health-based, formal sources" [11]. At the EU level, the data collected for public health purpose includes epidemiological information about human cases, microbiological information on isolates, animal vectors (e.g. mosquitoes, rodents) distribution and abundance, human population and mortality rates, climate records, etc. All this information is computed and analysed to give indicators that, after verification, may become a threat (Figure 1; Table 1).

Threats detected through event-based surveillance and indicator-based surveillance are continuously assessed in order to provide the necessary tools to risk managers to implement the appropriate control measures. 


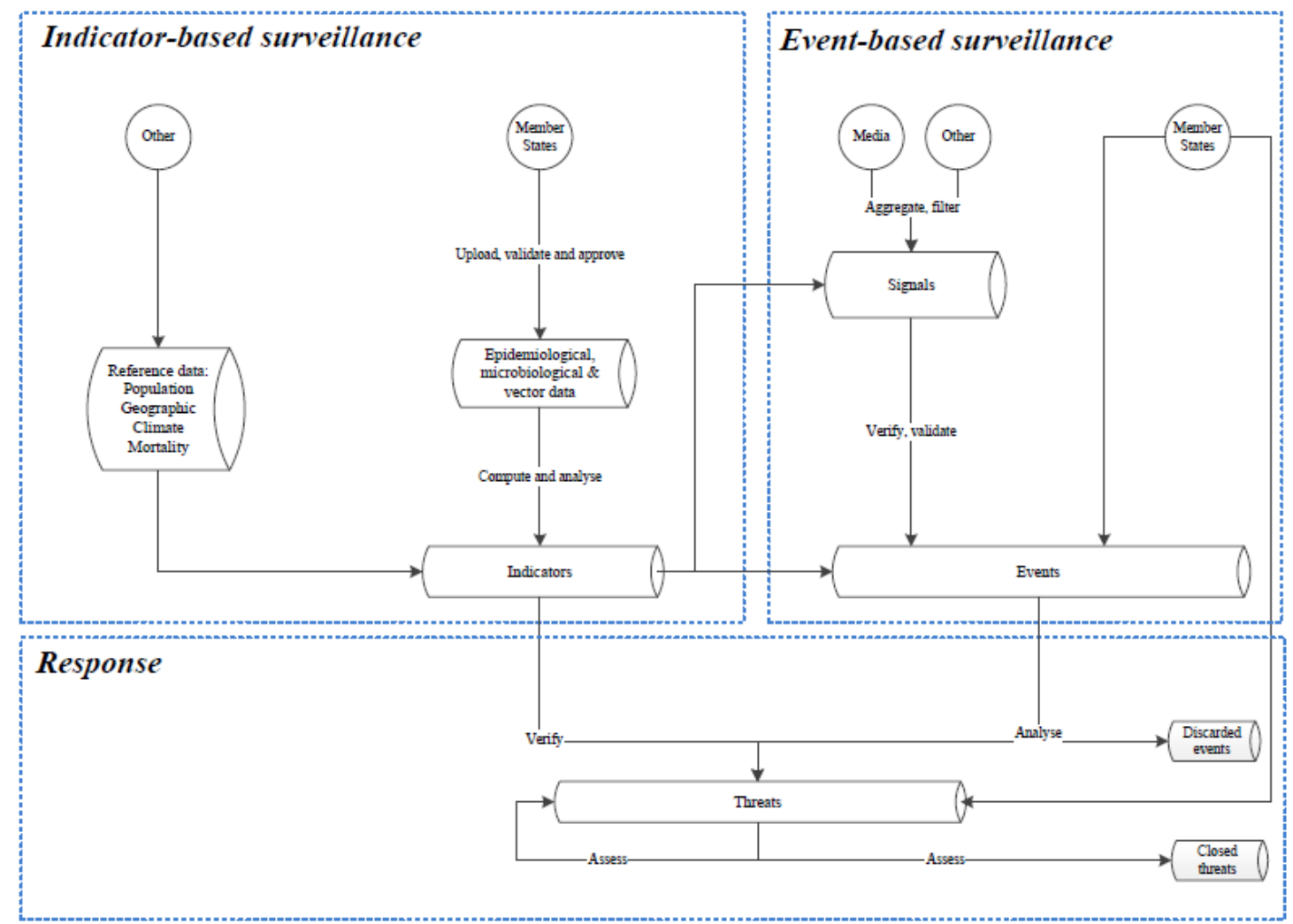

Figure 1. Surveillance and response framework

Table 1. Glossary of surveillance and response framework

\begin{tabular}{|c|c|c|}
\hline Term & Definition & Examples \\
\hline Signal & $\begin{array}{l}\text { Indication that there might be an unusual or } \\
\text { unexpected incident }\end{array}$ & $\begin{array}{l}\text { Rumour from a blog or } \\
\text { media article }\end{array}$ \\
\hline Event & $\begin{array}{l}\text { Unusual or unexpected incident confirmed } \\
\text { by competent authority }\end{array}$ & $\begin{array}{l}\text { Outbreak reported by a } \\
\text { country and which could } \\
\text { potentially affect other } \\
\text { countries }\end{array}$ \\
\hline Indicator & $\begin{array}{l}\text { Result of a computation and analysis of data } \\
\text { collected through indicator-based } \\
\text { surveillance }\end{array}$ & Increase in trend \\
\hline Threat & $\begin{array}{l}\text { Confirmed unusual or unexpected event that } \\
\text { pose a threat to public health }\end{array}$ & Multi-country outbreak \\
\hline
\end{tabular}

Outbreak response includes all activities that support the assessment and investigations of an outbreak. Response activities may for instance include the coordination of the production of a risk assessment, the provision of expertise, the deployment of assistance team on the field, the establishment, coordination and activation of expert networks (e.g. laboratories, disease specific experts), the development of guidelines and procedures, and the training of experts.

The outbreak response ends when the outbreak is considered closed and the outbreak report, including final recommendations, is issued. An outbreak is commonly declared over when the number of cases being reported returns to baseline levels or when two or more incubation periods have passed with no new primary cases reported [12, 13]. 


\section{FOOD- AND WATER-BORNE DISEASE INFECTIONS IN THE EU}

According to the EU Decision 2000/96/EC [14] and 2003/534/EC [15], 52 diseases and conditions are subject to mandatory notification to the EU level. Among those notifiable diseases, 17 are FWD: botulism, brucellosis, campylobacteriosis, cholera, cryptosporidiosis, echinococcosis, giardiasis, hepatitis A, listeriosis, salmonellosis, shigellosis, toxoplasmosis, trichinellosis, typhoid and paratyphoid fever, variant Creutzfeldt-Jakob disease, STEC infection, and yersiniosis.

In the EU, campylobacteriosis and salmonellosis are the most commonly reported gastro-intestinal illnesses, with respectively 236851 and 87805 confirmed human cases in 2014 [16]. Those two diseases accounted for 84\% (324 656/385 770) of all FWD cases notifiable at the EU level in 2014. In number of cases, giardiasis and hepatitis A infections were the third and fourth most reported diseases with respectively 16986 and 13603 cases reported in 2014.

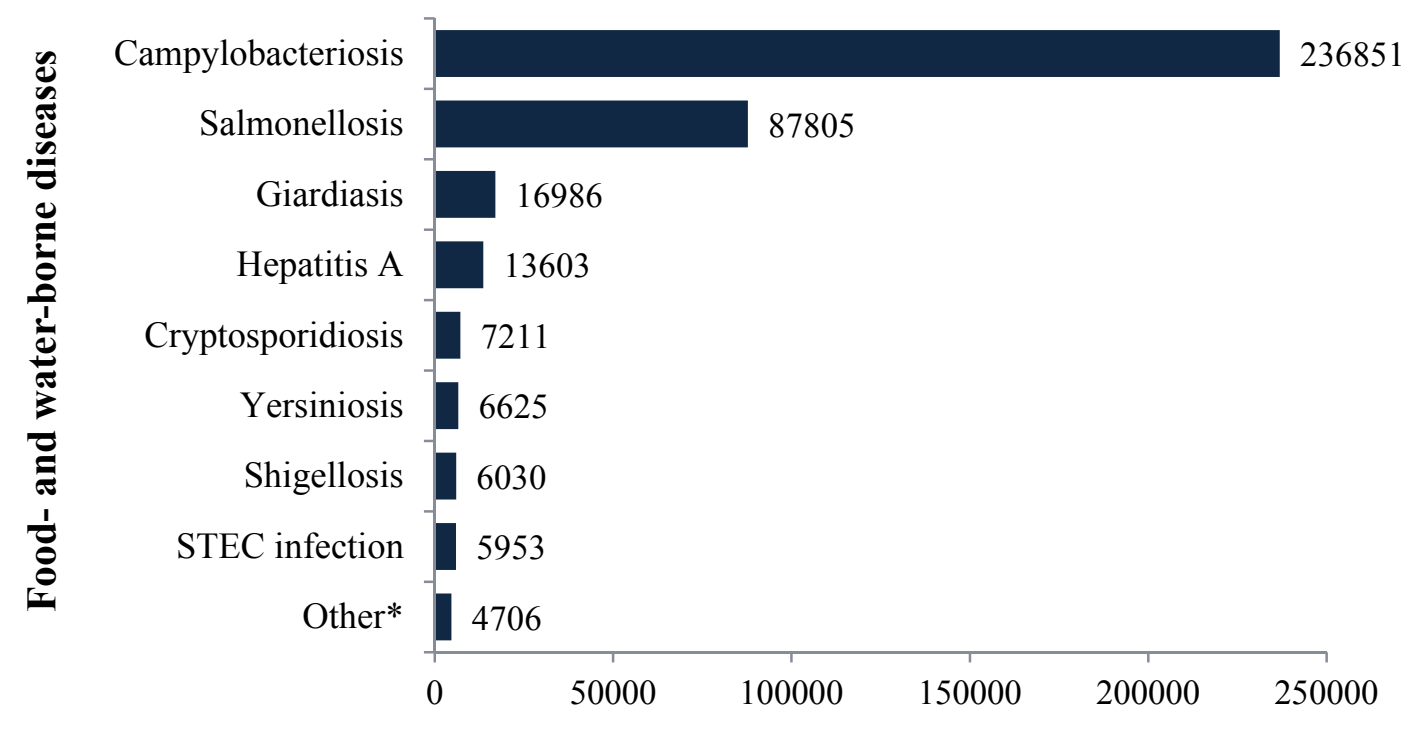

Number of confirmed cases

*Botulism, brucellosis, cholera, echinococcosis, listeriosis, toxoplasmosis (congenital), trichinellosis, typhoid/paratyphoid fever and Variant Creutzfeldt-Jakob disease

Figure 2. Number of confirmed cases of food- and water-borne infections reported in 2014 in the European Union [16]

\section{Campylobacter and campylobacteriosis}

Campylobacter is a bacterium that can cause illness both in humans and in animals. There are 17 species and six subspecies [17]. Most human cases are caused by the species Campylobacter jejuni, Campylobacter coli and Campylobacter Lari [17, 18]. Campylobacter grows best in micro-aerobic atmosphere (with less oxygen than in the atmosphere) and can be easily killed by drying or oxygen [19]. Freezing reduces the number of bacteria in raw food [19].

Most cases of campylobacteriosis are sporadic cases but outbreaks can also be observed. Infections occur mainly from handling or ingestion of contaminated food (mostly raw or undercooked poultry meat) or water [17, 19]. Swimming in 
contaminated water and direct contact with infected animals (i.e. dogs and cats) are also risk factor for infection [20].

Outbreaks have often been associated with consumption of unpasteurized dairy products, contaminated water and poultry [19]. Human-to-human transmission is rare [19].

The infectious dose is very low (fewer than 500 organisms) [19] which indicates that the ingestion of a very limited amount of contaminated food can lead to infection.

After an incubation period of two to five days, the patient experience severe abdominal pain, watery and/or bloody diarrhoea, fever, headache and nausea. Those symptoms are usually self-limiting. Severe complications (i.e. reactive arthritis, Guillain-Barré syndrome) are rare [19].

Germany (70 530), the United Kingdom (66 790) and the Czech Republic (20 750) were the countries reporting the most (67\%) confirmed cases of campylobacteriosis in the EU. The overall rate of infection was 60.02 cases per 100000 inhabitants in the EU (range 1.28 to 197.39), which was higher than in 2013 (54.86) and 2012 (55.62) [16].

\section{Salmonella and salmonellosis}

Salmonella is a bacterium that can cause illness in human and in animals. More than 2500 species (called "serotypes") are currently described [21-23].

Salmonella grows best at temperature between 10 and $48{ }^{\circ} \mathrm{C}$ and is killed by heat treatments (e.g. pasteurization) [24]. Salmonella requires some water to survive and grow but it can survive for some time in dry food surfaces. The bacteria can grow with or without oxygen.

Salmonella can cause both sporadic cases and outbreaks and are usually transmitted to humans by ingesting food products contaminated by animal faeces for instance at the farm level or during slaughtering. While contaminated food items are often of animal origin (e.g. beef, poultry, milk, eggs), other food items like vegetables can be contaminated. An infected food handler may also spread the bacteria. Pets including reptiles are known risk factors [25].

The incubation period lasts for 12 to 72 hours, after which the patient develops diarrhoea, fever and abdominal cramps. In most cases, the disease is self-limiting after four to seven days. Complications (e.g. septicaemia, reactive joint inflammation) may occur and in some cases can lead to the death of the patient. Elderly, infants, and immuno-compromised individuals are more likely to have a severe illness [25].

In 2014, the most commonly reported serotypes in the EU were Salmonella Typhimurium and Salmonella Enteritidis [16]. Germany is the country reporting the most confirmed cases in the EU in 2014 ( $\mathrm{n}=15$ 916, 18\%). The highest confirmed case rates were reported in the Czech Republic (126.09 cases per 100000 population) and Slovakia (75.30). At the EU level, the rate of infection has been steadily decreasing between 2008 and 2013 (from 31.41 to 20.04) but increased in 2014 (23.20) [16]. The decline observed between 2008 and 2013 has been mostly attributed to successful control programs implemented by the veterinary sector [17]. 


\section{$\underline{\text { Giardia and giardiasis }}$}

Giardia is a parasite that can infect animals and humans. Infection occurs after ingestion of contaminated food, water, soil or by person-to-person transmission or even animal-to-person [17, 26]. Giardia cyst (hard shells containing Giardia) can survive for long period in the environment. Outbreaks due to ingestion of contaminated drinking water that has been inadequately treated are frequently reported [16].

Incubation period may last up to three weeks [26]. Cases can be asymptomatic or develop fatigue and bloating followed by diarrhoea [17].

In 2014, 16986 confirmed cases of giardiasis were reported in the EU [atlas], and the overall rate is 5.42 cases per 100000 inhabitants. This rate has been relatively constant over the past seven years. The highest rates of confirmed cases were observed in Bulgaria (23.89 per 100 000) and Estonia (16.80 per 100 000) [16].

\section{Hepatitis A virus and hepatitis A infection}

Hepatitis A virus (HAV) is part of the Picornaviridae family. Three out of the six genotype identified infects humans [27]. The virus survives in the environment; it is resistant to the most commonly used food preservation methods (i.e. drying, freezing) [28].

Hepatitis A is an acute viral infection of the liver. Humans are the main reservoir of the virus which is spread mostly through the faecal-oral route via person-to-person contact or ingestion of contaminated food or water; in rare cases, transmission can also occur via infected blood [29].

The incubation period is 30 days ranging from 15 to 50 days. Infection in young children is usually asymptomatic. In adult, hepatitis A is mild and self-limiting but may, in rare occasions, cause fulminant hepatitis and liver failure. Immunity after infection is life-long and infection is effectively prevented by vaccination $[17,30]$.

In 2014, 13603 confirmed cases of hepatitis A were reported in the EU [16], and the overall rate is 3.06 cases per 100000 inhabitants. Romania was the country reporting the highest rate of infection (33.32), followed by Hungary (15.67) [16].

\section{OUTBREAKS OF FOOD- AND WATER-BORNE DISEASES IN THE EU}

In 2013, there were 5196 food-borne outbreaks in the EU, which is a decrease of $3.2 \%$ compared to $2012(\mathrm{n}=5363)$. These outbreaks accounted for 40726 human cases among which 5935 were hospitalized and 10 had a fatal outcome [31].

The overall reporting rate in 2013 was 1.19 outbreaks per 100000 population. Latvia had the highest reporting rate (29.55), followed by Slovakia (8.46) [31] (Figure 3). 


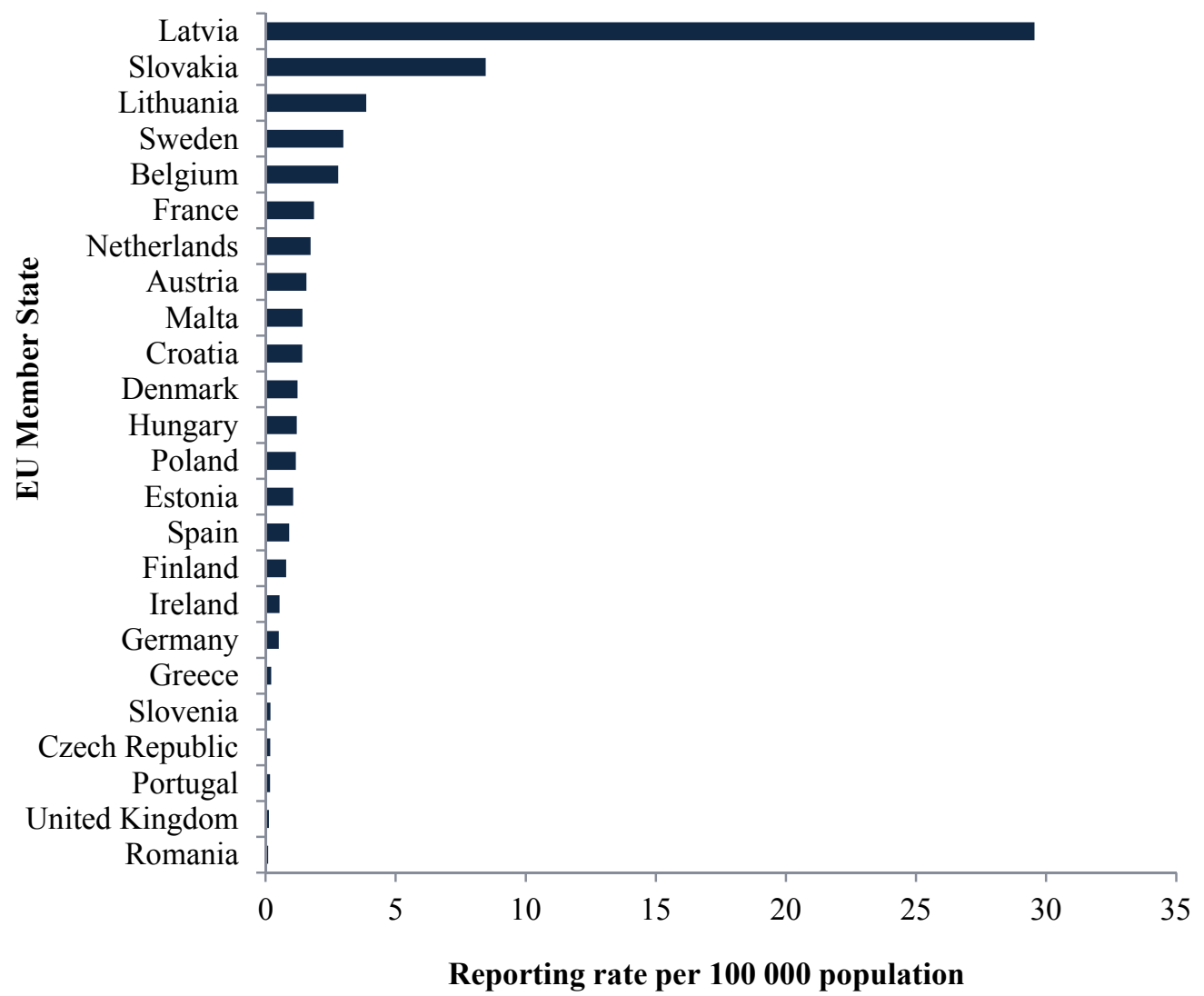

Figure 3. Reporting outbreak rate per 100000 population in European Union Member States in 2013 [31]

Salmonella was the most frequently detected causative agent $(\mathrm{n}=1168 ; 22.5 \%$ of outbreaks), followed by viruses $(n=942 ; 18.1 \%)$, bacterial toxins $(n=834 ; 16.1 \%)$ and Campylobacter ( $\mathrm{n}=414 ; 8.0 \%)$. In $28.9 \%$ of the reported outbreaks the causative agent was unknown ( $\mathrm{n}=1$ 502) [31] (Table 2).

The number of outbreaks in 2013 is lower than in 2012. The number of outbreaks due to Salmonella and Campylobacter decreased by $23.8 \%$ and $17.4 \%$ respectively. The number of outbreaks due to viruses and bacterial toxins increased by $24.6 \%$ and $7.3 \%$ compared to 2012 [31] (Table 2). 
Table 2. Causative agents in all food-borne outbreaks in the EU, 2012-2013 [31, 32]

\begin{tabular}{|l|c|c|c|}
\hline Causative agent & $\begin{array}{c}\text { Number of } \\
\text { outbreaks in } \\
\mathbf{2 0 1 2}\end{array}$ & $\begin{array}{c}\text { Number of } \\
\text { outbreaks in } \\
\mathbf{2 0 1 3}\end{array}$ & $\begin{array}{c}\text { Percentage of } \\
\text { outbreaks in } \\
\mathbf{2 0 1 3}\end{array}$ \\
\hline Salmonella & 1533 & 1168 & $22.5 \%$ \\
\hline Bacterial toxins & 777 & 834 & $16.1 \%$ \\
\hline Viruses & 756 & 942 & $18.1 \%$ \\
\hline Campylobacter & 501 & 414 & $8.0 \%$ \\
\hline Other causative agents & 137 & 132 & $2.5 \%$ \\
\hline Other bacterial agents & 80 & 80 & $1.5 \%$ \\
\hline Escherichia coli, pathogenic & 51 & 74 & $1.4 \%$ \\
\hline Parasites & 38 & 41 & $0.8 \%$ \\
\hline Yersinia & 12 & 8 & $0.2 \%$ \\
\hline Unknown & 1478 & 1502 & $28.9 \%$ \\
\hline EU total & $\mathbf{5 3 6 3}$ & $\mathbf{5 1 9 6}$ & $\mathbf{1 0 0 \%}$ \\
\hline
\end{tabular}

Note: Bacterial toxins include toxins produced by Bacillus, Clostridium and Staphylococcus. Foodborne viruses include calicivirus, hepatitis A virus, flavivirus, rotavirus and other unspecified viruses. Other causative agents include mushroom toxins, marine biotoxins, histamine, mycotoxins, atropine and other unspecified agents. Parasites include primarily Trichinella, but also Cryptosporidium, Giardia, Anisakis and other unspecified parasites. Other bacterial agents include Listeria, Brucella, Shigella, Vibrio and Francisella. Pathogenic Escherichia coli includes also STEC.

\section{BURDEN OF FOOD-BORNE DISEASES}

The Food-borne Disease Burden Epidemiology Reference Group (FERG) established in 2007 by WHO estimated the burden of food-borne diseases for 31 food-borne hazards among which Campylobacter, Salmonella, HAV, Echinococcus and Dioxins. The group concluded that in 2010, the global burden of food-borne diseases was 33 million Disability Adjusted Life Years (DALYs), which is comparable to the burden of diseases such as HIV/AIDS, malaria and tuberculosis [33].

The group has not yet published the results for the EU. However the zone referenced as EUR $A^{*}$ in the publication "World Health Organization global estimates and regional comparisons of the burden of food-borne disease in 2010" [33], which includes 20 of the EU Member States, could serve as a proxy to estimate the burden in the EU. In the zone EUR A, FERG study concluded that the median rate of foodborne DALYs in 2010 was 41 per 100000 population (95\% uncertainty intervals [29, 64]), which ranks the EU among the regions with the lowest rate of food-borne DALYs in the world. Non-typhoidal Salmonella enterica and Campylobacter are the two pathogens causing the higher burden on the population, with median rates of food-borne DALYs of 12 (95\% uncertainty intervals [7, 18]) and 10 (95\% uncertainty intervals $[6,14])$ per 100000 population respectively. Giardia and HAV contribute respectively to 0.03 (95\% uncertainty intervals $[0,0.1])$ and $0.8(95 \%$ uncertainty intervals $[0.03,2])$ DALYs per 100000 population.

\footnotetext{
* Andorra, Austria, Belgium, Croatia, Cyprus, Czech Republic, Denmark, Finland, France, Germany, Greece, Iceland, Ireland, Israel, Italy, Luxembourg, Malta, Monaco, Netherlands, Norway, Portugal, San Marino, Slovenia, Spain, Sweden, Switzerland and the United Kingdom
} 


\section{SCOPE AND OUTLINE OF THE THESIS}

This thesis focuses primarily on FWDs that are of biological origin and that affect the EU.

The aim of the thesis is to provide an understanding of FWD surveillance and outbreak response in the EU and to investigate possible ways to strengthen related processes and information technology systems.

Section I provides an introduction to this thesis, describing the general concepts of surveillance and outbreak response to food- and water-borne diseases in the EU. Chapter 1 introduces some basics on surveillance and outbreak response, presents the scope of this thesis, and provides an overview of the most common pathogens and epidemiological situation regarding FWD diseases infections and outbreaks in the EU. Chapter 2 describes the Salmonella naming scheme and its impacts on public health microbiology.

Section II introduces the EPidemic intelligence Information System for Food- and Water-borne Diseases and zoonoses (EPIS-FWD) as a EU tool for event-based. Chapter 3 briefly describes the two major updates made in 2013 to EPIS-FWD in order to strengthen inter-sectorial collaboration. Chapter 4 provides an in-depth analysis of the FWD events assessed by ECDC between 2008 and 2013 and highlights the impact of the introduction of EPIS-FWD in 2010 on the information exchange between public health authorities.

Section III gathers examples of food-borne disease outbreaks to present the process of outbreak detection and response, including investigation mechanisms and development of a response strategy. Chapter $\mathbf{5}$ describes a national outbreak of salmonellosis that occurred in France in 2011 which highlights how outbreak detection, investigation and reporting to the international level are conducted in the EU Member States. Using three multi-country outbreaks of hepatitis A that occurred simultaneously in 2013, chapter 6 presents how EPIS-FWD supports the rapid detection of multi-country outbreaks and the collection of epidemiological and microbiological data used for the investigations. In addition, chapter 6 highlights the importance of international collaboration but also cross-sectorial collaboration.

As a response to the wave of food related hepatitis A outbreaks described in chapter 6, the European Centre for Disease Prevention and Control (ECDC) launched a review of the hepatitis A epidemiological situation in the EU. Chapter 7 demonstrates how surveillance data is supporting such mid-term outbreak response, underlying the limitations encountered.

Section IV extends the scope of outbreak detection and response beyond the EU level and provides guidance on closure of FWD outbreaks. Using one of the largest deliberate food contamination incidents ever described, chapter 8 illustrates the complexity of international trade of food products and ingredients and how the response to such global food safety incident is coordinated by WHO.

Declaring the end of a FWD multi-country outbreak is a key step of an outbreak investigation that is unfortunately often neglected. Chapter 9 provides criteria to guide the decision to declare FWD multi-country outbreaks over.

Section $\mathbf{V}$ is a general discussion to this thesis. Chapter $\mathbf{1 0}$ discusses the main findings presented earlier in this thesis, highlights some of the limitations of the FWD 
surveillance and response mechanisms, and provides some avenues for strengthening such mechanisms. 


\section{REFERENCES}

1. World Health Organization. Food safety - Fact sheet N³99, November 2014. [Accessed 12 May 2015]; Available from:

http://www.who.int/mediacentre/factsheets/fs399/en/.

2. World Health Organization. Health topics, Disease outbreaks. 2015

[Accessed 31 March 2015]; Available from:

http://www.who.int/topics/disease_outbreaks/en/.

3. World Health Organization. Global infectious disease surveillance - Fact sheet $\mathrm{N}^{\circ} 200$ [Accessed 15 May 2015]; Available from:

http://www.who.int/mediacentre/factsheets/fs200/en/.

4. Frank C, Faber MS, Askar M, Bernard H, Fruth A, Gilsdorf A, et al. Large and ongoing outbreak of haemolytic uraemic syndrome, Germany, May 2011. Euro Surveill. 2011;16(21).

5. E. coli cucumber scare: Spain angry at German claims. BBC. 31 May 2011. Archived from the original on 1 June 2011. [Accessed 20 July 2015]. Available from: http://www.bbc.com/news/world-europe-13605910.

6. Commission staff working document. Lessons learned from the 2011 outbreak of Shiga toxin-producing Escherichia coli

(STEC) O104:H4 in sprouted seeds. SANCO/13004/2011. Available from: http://ec.europa.eu/food/food/biosafety/salmonella/docs/cswd lessons learned_en.pdf

7. Kolavic SA, Kimura A, Simons SL, Slutsker L, Barth S, Haley CE. An outbreak of Shigella dysenteriae type 2 among laboratory workers due to intentional food contamination. JAMA. 1997 Aug 6;278(5):396-8.

8. Torok TJ, Tauxe RV, Wise RP, Livengood JR, Sokolow R, Mauvais S, et al. A large community outbreak of salmonellosis caused by intentional contamination of restaurant salad bars. JAMA. 1997 Aug 6;278(5):389-95.

9. European Commission, DG Health and Consumers. Horse meat: one year after - Actions announced and delivered! [Accessed 9 June 2105]; Available from: http://ec.europa.eu/food/food/horsemeat/.

10. World Health Organization. Health topics, Public health surveillance. 2015 [Accessed 31 March 2015]; Available from: http://www.who.int/topics/public health surveillance/en/.

11. World Health Organization. Early detection, assessment and response to acute public health events: Implementation of Early Warning and Response with a focus on Event-Based Surveillance 2004.

12. Council to Improve Foodborne Outbreak Response (CIFOR). Guidelines for Foodborne Disease Outbreak Response. Atlanta: Council of State and Territorial Epidemiologists; 2009;

http://www.cifor.us/documents/CIFORGuidelinesforFoodborneDiseaseOutbreakResp onse.pdf.

13. Queensland government. Queensland Health Foodborne Illness Outbreak Management Guidelines 2006;

http://www.health.qld.gov.au/ph/documents/cdb/31572.pdf. 
14. European Commission. Commission decision 2000/96/EC of 22 December 1999 on the communicable diseases to be progressively covered by the Community network under Decision No 2119/98/EC of the European Parliament and of the Council. Official Journal of the European Union. Luxembourg: Publications Office of the European Union. 3.2.2000:L28/50. Available from: http://eur-lex.europa.eu/legalcontent/EN/TXT/PDF/?uri=CELEX:32000D0096\&from=EN.

15. European Commission. Commission decision 2003/534/EC of 17 July 2003 amending Decision No 2119/98/EC of the European Parliament and of the Council and Decision 2000/96/EC as regards communicable diseases listed in those decisions and amending Decision 2002/253/EC as regards the case definitions for communicable diseases. Official Journal of the European Union. Luxembourg: Publications Office of the European Union. 23.7.2003:L184/35. Available from: http://eurlex.europa.eu/LexUriServ/LexUriServ.do?uri=OJ:L:2003:184:0035:0039:EN:PDF.

16. European Centre for Disease Prevention and Control. Surveillance atlas of infectious diseases; Available from: http://atlas.ecdc.europa.eu/public/index.aspx

17. European Centre for Disease Prevention and Control. Annual epidemiological report 2014 - food- and waterborne diseases and zoonoses. Stockholm: ECDC; 2014.

18. World Health Organization. Campylobacter, Fact sheet N²55. 2011 [updated October 2011; Accessed 10 June 2015]; Available from: http://www.who.int/mediacentre/factsheets/fs255/en/.

19. Centers for Disease Control and Prevention. Campylobacter - General Information. Atlanta: CDC; 2014 [1 April 2015]; Available from: http://www.cdc.gov/nczved/divisions/dfbmd/diseases/campylobacter/.

20. European Centre for Disease Prevention and Control. Campylobacteriosis. [1 April 2015]; Available from:

http://ecdc.europa.eu/en/healthtopics/campylobacteriosis/Pages/index.aspx.

21. Grimont PAD, Weill FX. Antigenic formulae of the Salmonella serovars, 9th ed. Paris: World Health Organization Collaborating Center for Reference and Research on Salmonella, Institut Pasteur2007.

22. Guibourdenche M, Roggentin P, Mikoleit M, Fields PI, Bockemühl J, Grimont PA, et al. Supplement 2003-2007 (No. 47) to the White-Kauffmann-Le Minor scheme Res Microbiol. 2010;161(1):26-9. doi: 10.1016/j.resmic.2009.10.002.

23. Issenhuth-Jeanjean S, Roggentin P, Mikoleit M, Guibourdenche M, de Pinna E, Nair S, et al. Supplement 2008-2010 (no. 48) to the White-Kauffmann-Le Minor scheme. Res Microbiol 2014;165(7):526-30. doi:10.1016/j.resmic.2014.07.004.

24. Food safety watch. Salmonella. [updated Last updated 2 February 2013; Accessed 10 June 2015]; Available from: http://www.foodsafetywatch.org/factsheets/salmonella/.

25. Centers for Disease Control and Prevention. Salmonellosis - General information. Atlanta: CDC; [1 April 2015]; Available from: http://www.cdc.gov/nczved/divisions/dfbmd/diseases/salmonellosis/\#what.

26. Centers for Disease Control and Prevention. Giardia - Epidemiology \& Risk Factors. Atlanta: CDC; [1 April 2015]; Available from: http://www.cdc.gov/parasites/giardia/epi.html. 
27. Desbois D, Couturier E, Mackiewicz V, Graube A, Letort MJ, Dussaix E, et al. Epidemiology and genetic characterization of hepatitis A virus genotype IIA. J Clin Microbiol. 2010 Sep;48(9):3306-15.

28. Baert L, Debevere J, Uyttendaele M. The efficacy of preservation methods to inactivate foodborne viruses. Int J Food Microbiol. 2009 May 31;131(2-3):83-94.

29. WHO position paper on hepatitis A vaccines. Wkly Epidemiol Rec. 2012;87(28/29):261-76. PMID:22905367June 2012.

30. Schiff ER. Atypical clinical manifestations of hepatitis A. Vaccine. 1992;10 Suppl 1:S18-20.

31. European Food Safety Authority, European Centre for Disease Prevention and Control. The European Union Summary Report on Trends and Sources of Zoonoses, Zoonotic Agents and Food-borne Outbreaks in 2013. EFSA Journal. 2015;13(1):3991, 165 pp. doi:10.2903/j.efsa.2015.3991

32. European Food Safety Authority, European Centre for Disease Prevention and Control. The European Union summary report on trends and sources of zoonoses, zoonotic agents and food-borne outbreaks in 2012. EFSA Journal. 2014;12(2):3547. $312 \mathrm{pp}$. Available from: http://www.efsa.europa.eu/en/efsajournal/pub/3547.htm doi:10.2903/j.efsa.2014.3547

33. Havelaar AH, Kirk MD, Torgerson PR, Gibb HJ, Hald T, Lake RJ, et al. World Health Organization Global Estimates and Regional Comparisons of the Burden of Foodborne Disease in 2010. PLoS Med. 2015;12(12):e1001923. doi:10.1371/journal.pmed.1001923 


\section{Chapter 2}

\section{SALMONELLA NAMING SCHEME}




\section{Around the WORLd in 1475 Salmonella Geo-}

SEROTYPES

Emerg Infect Dis. 2016 Jul. Available online: http://dx.doi.org/10.3201/eid2207.141678

Céline M. Gossner, Simon Le Hello, Birgitta de Jong, Per Rolfhamre, Daniel Faensen, François-Xavier Weill and Johan Giesecke

It's easy to remember Salmonella serotypes names, isn't it? Surely, this is because the naming system of Salmonella serotypes is by far the most scientist friendly.

Traditionally, most Salmonella serotypes have been named after geographic locations. We decided to explore the geographic locations to which Salmonella serotypes refer and describe some unexpected twists in the naming scheme. We found that $93 \%$ ( $\mathrm{n}=$ 1,475 ) of the 1,585 serotypes could be categorized as geo-serotypes; that is, the name refers to a geographic location. The 3 countries with the most geo-serotypes are Germany, the United Kingdom, and the United States. Other serotype names refer to the name of a person, animal, tribe, or food item or are a composite of symptoms and host.

The Salmonella serotypes naming scheme has had a valuable effect on public health microbiology, and in the current era of fast development of whole-genome sequencing, it should remain a reference. 
What do the cities of Paris, Pisa, and Toronto have in common? Yes, all 3 are famous for their towers but what else? You don't know? Let's see if this will help you: what do the states of Colorado, Florida, and Ohio in the United States have in common with the 3 cities above? No idea? If we tell you Salmonella serotypes... If you still don't know, by the end of this essay you will, without a doubt, be able to answer these questions.

Salmonella was first isolated from a human sample in 1884 by bacteriologist Georg Gaffky and later identified as Salmonella enterica subspecies enterica serotype Typhi. The following year, the veterinary surgeon Daniel Elmer Salmon (whose name was later given to the Salmonella genus) and microbiologist Theobald Smith isolated $S$. enterica ser. Choleraesuis from a swine sample, while searching for the agent causing cholera in hogs [1]. Since then, a plethora of Salmonella names was given to strains with new serotypes; that is, new combinations of flagellar $(\mathrm{H})$ and/or somatic $(\mathrm{O})$ antigens. In 1934, a first list of 44 validated Salmonella serotypes, called the Kauffmann-White scheme, was published [2].

The naming scheme of serotypes (also called serovars) evolved over time. At the beginning of the 20th century, serotype names referred to clinical syndromes either in humans (e.g., enteritidis, typhi, paratyphi) or in animals (e.g., abortus-ovis, abortusequi, typhi-murium, cholerae-suis). The host specificity was correct for some serotypes (e.g., abortus-ovis, abortus-equi) but proved to be wrong for many others (e.g., typhi-murium, cholerae-suis) [2].

By the mid-1930s, Fritz Kauffmann was heading the World Health Organization Collaborating Centre for Reference and Research on Salmonella at the Statens Serum Institut, Copenhagen, Denmark. While there, he began to name new serotypes according to the geographic origin of the isolated strain. After Kauffmann's retirement in 1965, Léon Le Minor became director of the World Health Organization Collaborating Centre at the Institut Pasteur, Paris, France [3], and he perpetuated the serotype naming scheme established by Kauffmann.

Kauffmann considered each serotype as a species and, consequently, in the old literature, the serotype names were italicized (e.g., typhi). DNA-DNA hybridization, which arrived in the 1980s, showed otherwise: only 2 species ( $S$. enterica and $S$. bongori) were found to be in the genus Salmonella. This discovery led to a longstanding debate until, in 2005, the Judicial Commission of the International Committee for Systematics of Prokaryotes made the decision to recognize the new nomenclature [4]. Consequently, the serotype names must no longer be italicized and the first letter must be capitalized (e.g., Typhi). Names are only given to subspecies enterica serotypes, which represent $99.5 \%$ of all Salmonella strains. The remaining Salmonella strains are named after their antigenic formula [2].

Currently, >2,500 Salmonella serotypes have been described and listed in the "bible" of Salmonella serovars: the White-Kauffmann-Le Minor (WKL) scheme [2]. Last revised in January 2007, WKL has since been completed, with 1 supplement published in 2010 [5] and another in 2014 [6]. Listed in the WKL scheme are 1,585 serotypes of $S$. enterica subsp. enterica.

We decided to assess the geographic locations for which subspecies enterica serotypes are named and describe some unexpected twists in the naming scheme. First, we searched for published articles and books that recorded the first isolation of specific Salmonella serotypes [7-12]. A large part of this exploration relied on the 
extensive work of the microbiologist Eckehart Kelterborn, who cataloged the history of Salmonella serotypes first isolations in 2 books: Salmonella-species: First Isolations, Names and Occurrence [7] and Catalogue of Salmonella First Isolations 1965-1984 [8]. Then, we used the open GeoNames database [13] and Google Maps [14] to find the geographic locations corresponding with the serotype names.

Of the 1,585 serotypes of $S$. enterica subsp. enterica that we considered, 1,475 (93\%) are geo-serotypes (i.e., the name is associated with a geographic location); $95(6 \%)$ have names related to a nongeographic origin (e.g., person, animal); and 15 (1\%) have names of unknown origin. Geo-serotypes include serotypes for which there is a clear reference in the literature of the first isolation and link to a geographic location and for which there is no clear reference in the literature but the name is most likely associated with a geographic location with the same name. For instance, a serotype that was first described in a patient returning from France and to which was given the name of a French city was considered as a possible geo-serotype (unless contradictory information was found). The geo-serotypes were named after continents, countries, regions, islands, cities, neighborhoods, streets, gardens, rivers, lakes, and hills but also after university auditoriums, laboratories, hospitals, kibbutzim, markets, and mines.

Four geo-serotypes are linked to a broad region or continent: Africana, Antarctica, Orientalis, and Westafrica. Remarkably, serotype Antarctica was first isolated from an Emperor penguin in 1977 in the South Pole continent. The remaining 1,471 geoserotypes can be directly associated with 1 country. The 10 countries with the most geo-serotypes are Germany ( $\mathrm{n}=181$; e.g., Berlin, Brandenburg, Heidelberg); the United Kingdom ( $\mathrm{n}=167$; e.g., Chester, Derby, Stanley); the United States $(\mathrm{n}=148$; e.g., Brooklyn, Chicago, Saintpaul); Nigeria ( $\mathrm{n}=74$; e.g., Abuja, Ibadan, Lagos, Nigeria); France ( $\mathrm{n}=70$; e.g., Avignon, Lyon, Marseille); Togo ( $\mathrm{n}=58$; e.g., Adime, Lome, Djame); the Democratic Republic of the Congo $(n=58$; e.g., Leopoldville, Mbandaka, Zaire); Senegal ( $n=55$; e.g., Dakar, Kedougou, Saboya); Sweden ( $\mathrm{n}=39$; e.g., Goeteborg, Lund, Stockholm); and Ghana ( $\mathrm{n}=39$; e.g., Accra, Ashanti, Victoriaborg, Goldcoast) (Figure 1, 2). 


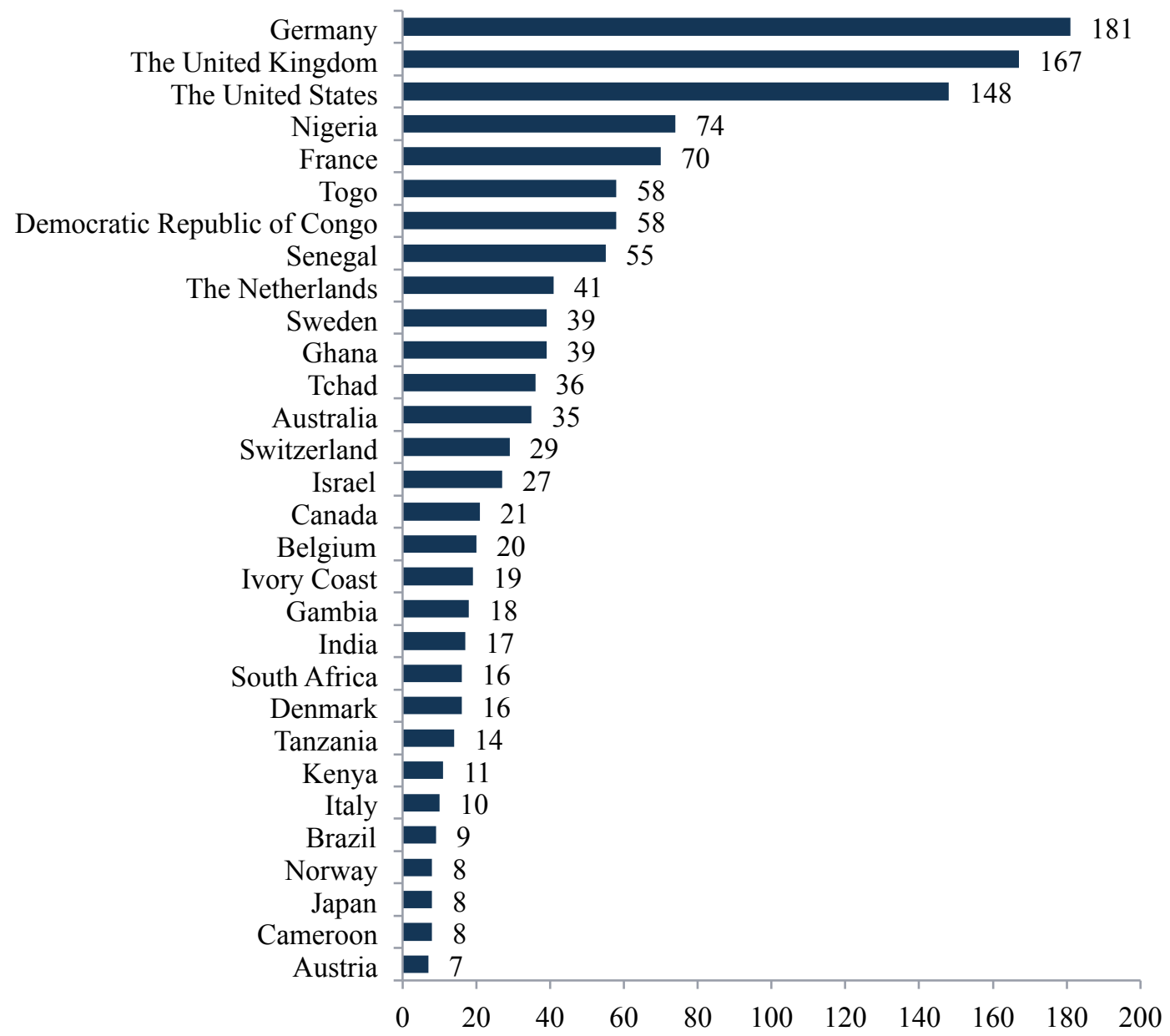

Figure 1. Top 30 countries with the highest number of associated Salmonella geoserotypes $(n=1,259)$.

Among the 1,474 Salmonella geo-serotypes that could be attached to a continent (Orientalis was excluded), the names of $43 \%$ are related to Europe and the names of $34 \%$ are related to Africa (Figure 2). 


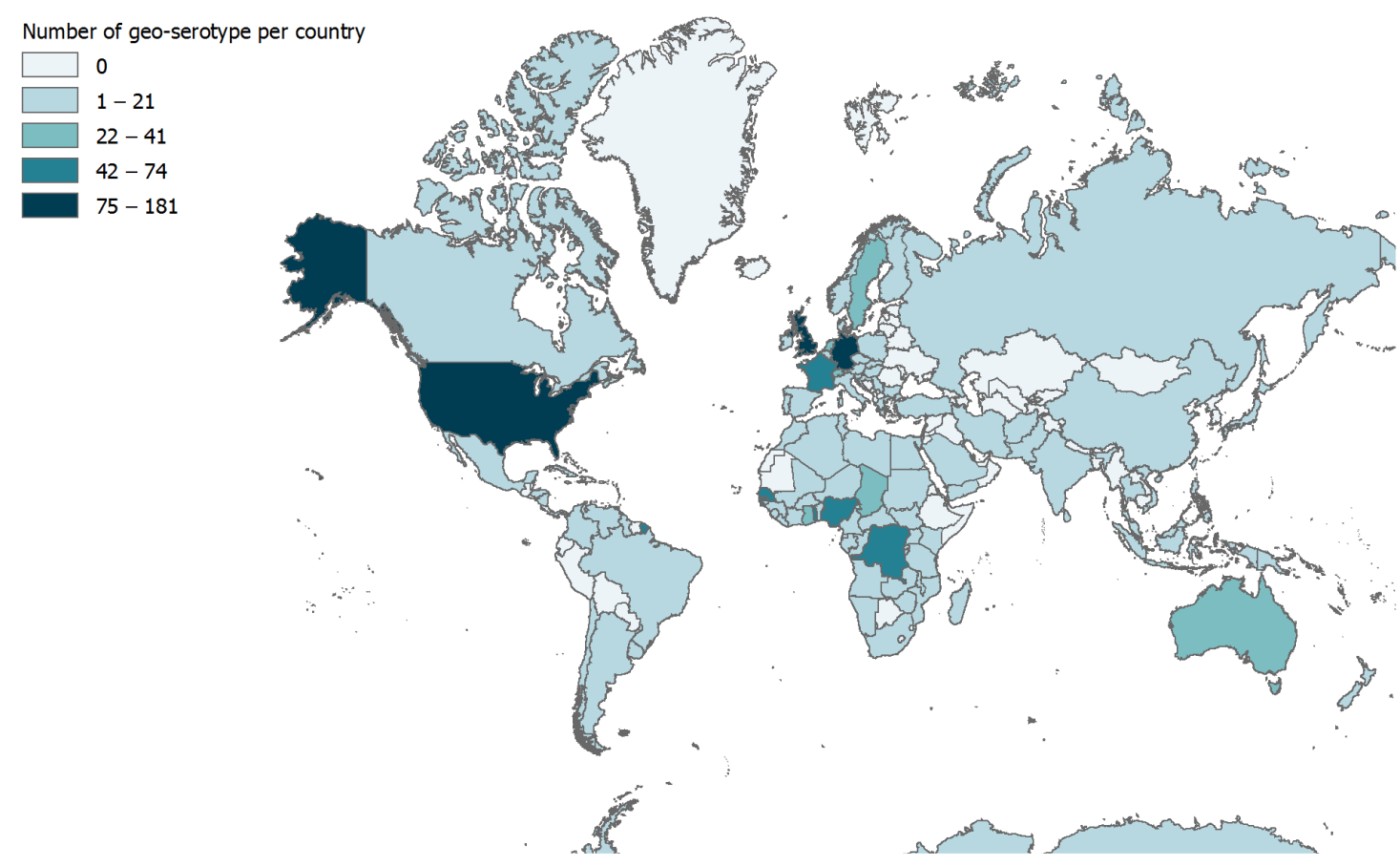

Figure 2. Worldwide geographic distribution of Salmonella geo-serotypes $(n=1,472)$.

The geo-serotypes Africana, Orientalis, and Westafrica were excluded. Administrative boundaries copyright by Eurographics and the United Nations Food and Agricultural Organization.

A total of 41 geo-serotypes (3\%) were named after a country, which includes current and former names of countries. Among the geo-serotypes with country names are Australia, Brazil, Bulgaria, Malaysia, and Tanzania. Singapore is represented twice, with Singapore and Sinchew, the Chinese name for Singapore. Cubana and Papuana also count as country names because they derive from Cuba and Papua New Guinea.

Fifty geo-serotypes (3\%) were named after a capital city (current capital names, former capital names, and former capitals). Let's revise our knowledge of capitals! Bangkok, Thailand; Brazzaville, Republic of Congo; Caracas, Venezuela; and Stockholm, Sweden, are current capitals. Bonn was the capital of West Germany from 1949 to 1990; Berlin is the current capital of Germany. In addition, Tananarive is the previous name of Antananarivo, the capital of Madagascar. The capital of France is named in different ways: Paris, Lutetia (the Latin name of Paris), Picpus, Vaugirard, Miromesnil, and Portedeslilas (4 metro stations), and Morillons (a street where the food safety laboratory was located). The serotype London was isolated in the city of Reading in the United Kingdom from a patient whose last name began with the letter "L." Because the serotype Reading already existed, this serotype was named London by extension of the patient's name.

Twenty-four states of the United States gave their names to serotypes, among which are Alabama, California, Colorado, Florida, Kentucky, Michigan, Ohio, Texas, and Utah. The states/regions of Ontario and Quebec in Canada, Nordrhein in Germany, Ashanti in Ghana, and Demerara-Mahaica in Guiana also gave their names to serotypes. 
Through the years, $\approx 300$ serotypes have been removed from the WKL scheme because they were shown to belong to other subspecies or the variant was no longer recognized. Among them, 11 referred to names of capital cities (Bern, Cairo, Buenosaires, Helsinki, Khartoum, Nairobi, Sofia, Windhoek, Zagreb, Manila, Kinshasa); 4 referred to names of countries (Angola, Argentina, Congo, Rhodesiense); and 3 referred to states of the United States (Oregon, Arkansas, Illinois). Although the serotype Buenosaires was removed from the WKL scheme, Bonariensis, the Latin name of Buenos Aires, was entered [2,15].

Instead of a location, some serotypes take their name from the name of the patient (e.g., Agbeni, Ayinde); a laboratory employee (e.g., Bamboye, Souza); an animal owner (e.g., Sarajane); the patient's tribe (e.g., Azteca, Lokomo, Yoruba); a ship (e.g., Maron); the animal type or the food item in which the strain was isolated (e.g., Agama [lizards], Epicrates [boa], Djinten [cumin spice], Egusi [seeds]); a combination of symptoms and host (e.g., Abortusovis, Typhimurium, Typhisuis); and the Latin name of the vehicle (e.g., Aqua [water], Carno [meat], Os [bone]) . Would you think that the serotype Heron is called after the bird? That would be too easy. The strain was isolated in 1962 from a turtle by a biologist called Madam Heron [7].

Who says that biologists have no sense of humor? The serotype Hiduddify is named after a fictional island [8]. The story goes as follows: In 1941, a Swede named Einar Pettersson-Skämtkvist escaped from a Japanese prisoner of war camp to arrive to the yet undiscovered island of Hiduddify, which was home of a unique ecosystem. The island was inhabited by the Rhinogradentia, mammals of a new order that were using their nose as mean of locomotion [16]. This unique discovery was described in 1961 in a book by German zoologist Gerolf Steiner under the pseudonym Harald Stümpke. The entire story remains today a major hoax in the field of biology [17].

Serotype Grumpensis refers to grumpy, the name given to the owner of the guinea pig from which the strain was isolated [7]. Ironically, the serotype Fortune refers to luck [7], which is certainly not the emotion felt by the person with a diagnosis of Salmonella infection!

In 1961, the laboratory of Colindale in the United Kingdom isolated, for the first time, serotype Egusi in egusi seeds. The same year, Colindale identified another new serotype in egusi seeds and, consequently, it was named Egusitoo [7]. Serotype Jukestown was named by a doctor who was passionate about the juke box who lived in Georgetown, Guiana [7]. Isolated in Chicago, the serotype Mjordan refers to the famous basketball player of the Chicago Bulls, Michael Jordan (unpub. data). Finally, other serotypes are portmanteaus or acronyms: Anfo (animal food), Ank (address not known), Ceyco (Ceylonese coconut), Chincol (Chinese egg, Colindale), Echa (egron and chamoiseau [family names of scientists who discovered this serotype]), and Inpraw (Indian prawns) [8].

Most of the 1,585 Salmonella serotypes are named after a geographic location. The list of countries that have named the most geo-serotypes correlates well with countries with strong laboratory capacities in Europe and the Americas and with countries in Africa (generally former European colonies) where some laboratory capacities (e.g., an Institut Pasteur) or close links with a laboratory in Europe had been established.

A naming scheme based on tangible names (e.g., cities, countries) has obvious advantages, such as making it easier to communicate about and pinpoint outbreaks. It is much easier to remember a label like "Agona" than the formula 


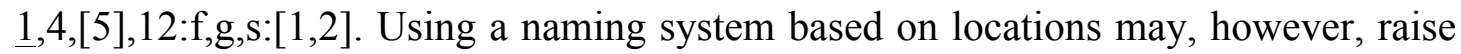
some sensitivity. National or local authorities may not appreciate the association of their area with a pathogen, especially when large foodborne outbreaks are highly publicized by the media. The same applies for serotype names based on the name of a food product. For instance, outbreaks of S. enterica ser. Djinten (cumin spice) are certainly not a good selling pitch for cumin producers/distributors. Therefore, serotype names should be interpreted with caution, and consumers should be reminded that no direct relationship exists between the serotype name and the prevalence of cases in the specific location or by the consumption of a specific product. The likelihood of acquiring $S$. enterica ser. Heidelberg infection in the city of Heidelberg, Germany, is probably no higher than the chance of acquiring the same infection in Miami, Florida, USA. Studying the correlation between serotypes' names and places of infection could be intriguing.

The affiliation of a new variant to a previously recognized serotype may have more implications than a simple name attribution. Although the monophasic variant $1,4,[5], 12: 1:-$ emerged in the 2000 s, only in 2010 was it officially recognized as part of serotype Typhimurium by the European Union [18]. Because of its atypical antigenic formula, this variant avoided for years all European Union laws applying to $S$. enterica ser. Typhimurium. It is certainly a proof of natural selection against European Union legislation.

The introduction of DNA-based methods targeting neutral markers such as multilocus sequence typing demonstrated that most of Salmonella serotypes span multiple, genetically unrelated clusters [19]. Therefore, as multilocus sequence typing and, ultimately, sequence-based typing methods based on entire genomes are more discriminatory than serotyping, the serotype-based nomenclature will ideally be complemented by a genome sequence-based typing scheme [19]. A genome type/serotype dictionary should be developed to maintain the link with the serotyping nomenclature, to continue building on $>80$ years of accumulated data, and to ensure a smooth transition for countries or regions in the world that will not switch to wholegenome sequencing as fast as others.

To answer the question posed at the beginning of this article-indeed, Paris, Pisa, Toronto, Colorado, Florida, and Ohio have all given their name to Salmonella serotypes. As promised, the material provided in this short review on the Salmonella naming scheme will help you interpret and decipher Salmonella names. 


\section{REFERENCES}

1. Mastroeni P, Maskell D, editors. Salmonella infections: clinical, immunological and molecular aspects. Cambridge (UK): Cambridge University Press; 2006.

2. Grimont PAD, Weill FX. Antigenic formulae of the Salmonella serovars, 9th ed. Paris: World Health Organization Collaborating Center for Reference and Research on Salmonella, Institut Pasteur; 2007.

3. Institut Pasteur. Salmonella. Centre Collaborateur de l'OMS (CCOMS) de Référence et de Recherche pour lesSalmonella [cited 2016 Feb

17]. http://www.pasteur.fr/fr/sante/centres-collaborateurs-l-oms-ccoms/salmonella

4. De Vos P, Truper HG, Tindall BJ. Judicial Commission of the International Committee on Systematics of Prokaryotes Xth International (IUMS) Congress of Bacteriology and Applied Microbiology. Minutes of the meetings, 28, 29 and 31 July and 1 August 2002, Paris, France. Int J Syst Evol Microbiol. 2005;55:525-32.

5. Guibourdenche M, Roggentin P, Mikoleit M, Fields PI, Bockemühl J, Grimont PA, Supplement 2003-2007 (no. 47) to the White-Kauffmann-Le Minor scheme. Res Microbiol. 2010;161:26-9.

6. Issenhuth-Jeanjean S, Roggentin P, Mikoleit M, Guibourdenche M, de Pinna E, Nair S, Supplement 2008-2010 (no. 48) to the White-Kauffmann-Le Minor scheme. Res Microbiol. 2014;165:526-30.

7. Kelterborn E. Salmonella-species. First isolations, names and occurrence [in German]. Leipzig (Germany): Hirzel; 1967.

8. Kelterborn E. Catalogue of Salmonella first isolations, 1965-1984. Boston, Dordrecht (the Netherlands): Nijhoff;1987.

9. Lapage SP, Taylor J, Nicewonger CR, Phillips AG. New serotypes of Salmonella identified before 1964 at the Salmonella reference laboratory, Colindale. Int J Syst Bacteriol. 1966;16:253-98.

10. Ikumapayi UN, Antonio M, Sonne-Hansen J, Biney E, Enwere G, Okoko B, Molecular epidemiology of community-acquired invasive non-typhoidal Salmonella among children aged 29 months in rural Gambia and discovery of a new serovar, Salmonella enterica Dingiri. J Med Microbiol. 2007;56:1479-84.

11. McDougal DL, Treleaven BE, Renshaw EC Jr. New Salmonella serotype: Salmonella enteritidis serotype Grandhaven (30(1):r:1,2). J Clin Microbiol. 1982;16:197-9.

12. Monzón C, O'Shanahan L, Echeita MA, Usera MA, Popoff MY. [A new serotype of Salmonella: Grancanaria]. Enferm Infecc Microbiol Clin. 1993;11:228-9.

13. GeoNames. 2014 [cited 2 Oct 2014]. http://www.geonames.org/

14. Google Maps. 2014 [cited 1 Oct 2014].

https://www.google.se/maps/preview?source=newuser-ws

15. Kauffmann F. Entero-bacteriaceae, 2nd ed. Copenhagen: E. Munksgaard; 1954.

16. Stümpke H. Bau und Leben der Rhinogradentia. Stuttgart (Germany): Fischer Verlag; 1961. 
17. Lewin RA. Humor in the scientific literature. Bioscience. 1983;33:266-8.

18. EFSA Panel on Biological Hazards (BIOHAZ). Scientific opinion on monitoring and assessment of the public health risk of "Salmonella Typhimuriumlike" strains. EFSA. 2010;8:1826 [cited 2016 May 11].

http://www.efsa.europa.eu/sites/default/files/scientific_output/files/main_documents/1 826.pdf

19. Achtman M, Wain J, Weill FX, Nair S, Zhou Z, Sangal V, Multilocus sequence typing as a replacement for serotyping in Salmonella enterica. PLoS Pathog. 2012;8:e1002776. 
Network Messages Risk Surveillance

\section{Infection}

\section{RASFF System}

EPIS Outbr

Salmonella

Number Cases
Range EWRS EU/EEA

Countries

Reportē

Multicountry ECDC

\section{SECTION II}

Diseases

EVENT-BASED SURVEILLANCE* THROUGH THE EPIDEMIC INTELLIGENCE INFORMATION SYSTEM FOR FOOD-AND WATER-BORNE DISEASES AND ZOONOSES (EPIS-FWD) 
Section II introduces EPIS-FWD as a EU tool for event-based.

Chapter 3 briefly describes the two major updates made in 2013 to EPIS-FWD in order to strengthen inter-sectorial collaboration.

Chapter 4 provides an in-depth analysis of the FWD events assessed by ECDC between 2008 and 2013 and highlights the impact of the introduction of EPIS-FWD in 2010 on the information exchange between public health authorities. 


\section{Chapter 3}

\section{DESCRIPTION OF THE}

EPIDEMIC INTELLIGENCE

INFORMATION SYSTEM FOR

FOOD- AND W ATER-BORNE

DISEASES AND ZOONOSES

(EPIS-FWD) 
ECDC LAUNCHES THE SECOND VERSION OF THE EPIS-FWD PLATFORM

Euro Surveill. 2013;18(27):pii=20517. Available online: http://www.eurosurveillance.org/ViewArticle.aspx?ArticleId=20517

Céline M. Gossner

On 8 July 2013, the European Centre for Disease Prevention and Control (ECDC) will launch a new version of the Epidemic intelligence Information System for food- and waterborne diseases (EPIS-FWD) with new features that will contribute to multidisciplinary collaboration during FWD outbreak investigations.

As part of its mandate, ECDC identifies, assesses and communicates threats to human health from FWD [1]. ECDC launched in 2010 the first EPIS-FWD, a restricted web-based communication platform bringing together multidisciplinary experts to ensure the early detection and coordination of the response to multistate outbreaks through the timely sharing of cross-sectorial information [2, 3]. Based on Microsoft SharePoint technology, this system gathers more than 350 epidemiologists, microbiologists but also policymakers and risk managers. The majority of them are from the 27 European Union (EU) Member States and the three European Economic Area (EEA) countries (Iceland, Norway and Lichtenstein); however, experts from Australia, Canada, Japan, New Zealand, South Africa, Switzerland, Turkey and the United States also contribute actively to the information exchange (as a follow-up of Enter-net [3]). For the past three years, EPIS-FWD has proved to be successful in strengthening the collaboration between stakeholders and also in ensuring the timely detection and smooth coordination of the response to food-borne outbreaks $[4,5]$.

The second version of the EPIS-FWD platform will include, among other things, two new features. The first is the Molecular Typing Cluster Investigations (MTCI), an area dedicated to the assessment of microbiological clusters of Salmonella, Shiga toxin-producing Escherichia coli (STEC) and Listeria monocytogenes infections detected through The European Surveillance System (TESSy). This area is targeted at microbiologists from the EU/EEA countries while the information will be available to epidemiologists from all the affected countries. The second new feature consists of the Urgent Inquiries and Urgent Inquiries associated forums, which are the outbreak alert and investigation tools. The Urgent Inquiries are by default open to the entire EPIS-FWD network (all 38 present members of the network). The Urgent Inquiries associated forums are dedicated areas linked to the Urgent Inquiries to share information about the outbreak investigation among a restricted number of experts. For each forum, experts from the network are invited to contribute. In addition, nominated experts outside the EPIS-FWD network, such as food-safety experts, veterinarians, environmental experts, from the network countries or any expert or organisation outside the network can also be invited to join in a timely manner. These forums may 
include discussions, questionnaires, working documents for co-editing and line listings. These restricted forums should facilitate the exchange of information between the countries and sectors. In addition, the new version of the EPIS-FWD platform encompasses a geographic information system allowing the display of cases up to the Nomenclature of Units for Territorial Statistics (NUTS) level 3 [6].

EPIS-FWD is part of the EU-wide systems to combat food-borne diseases. Effort should be made to integrate EPIS-FWD with systems such as TESSy, the Rapid Alert System for Food and Feed (RASFF) and the Early Warning and Response System (EWRS), with the aim of strengthening multidisciplinary collaboration and consequently preventing the occurrence of human infections. 


\section{REFERENCES}

1. European Parliament, Council of the European Union. Regulation (EC) No 851/2004 of the European Parliament and of the Council of 21 April 2004 establishing a European centre for disease prevention and control. Official Journal of the European Union. Luxembourg: Publications Office of the European Union. 30.4.2004:L 142. Available from:http://ecdc.europa.eu/en/aboutus/Key\%20Documents/0404_KD_Regulation_est ablishing_ECDC.pdf

2. European Centre for Disease Prevention and Control (ECDC). Epidemic Intelligence Information System for food- and water borne diseases in the European Union. Stockholm: ECDC. [Accessed 03 June 2013]. Available from: http://external.ecdc.europa.eu/EPIS FWD/.

3. European Centre for Disease Prevention and Control (ECDC). Enter-net. [Accessed 29 May 2013]. Available from: http://ecdc.europa.eu/en/activities/surveillance/pages/enter-net.aspx.

4. Yde M, Naranjo M, Mattheus W, Stragier P, Pochet B, Beulens K, et al. Usefulness of the European Epidemic Intelligence Information System in the management of an outbreak of listeriosis, Belgium, 2011. Euro Surveill. 2012;17(38):pii=20279. Available from: http://www.eurosurveillance.org/ViewArticle.aspx?ArticleId=20279

5. Friesema IH, de Jong AE, Fitz James IA, Heck ME, van den Kerkhof JH, Notermans DW, et al. Outbreak of Salmonella Thompson in the Netherlands since July 2012. Euro Surveill. 2012;17(43):pii=20303. Available from: http://www.eurosurveillance.org/ViewArticle.aspx?ArticleId=20303

6. European Commission. Eurostat. Nomenclature of territorial units for statistics. [Accessed 29 May 2013]. Available from:

http://epp.eurostat.ec.europa.eu/portal/page/portal/nuts_nomenclature/introduction 


\section{Chapter 4}

Analysis OF THE DATA COLLECTED THROUGH THE EPIDEMIC INTELLIGENCE INFORMATION SYSTEM FOR FOOD- AND W ATER-BORNE Diseases AND zOONOSES (EPIS-FWD) 


\title{
EVENT-BASED SURVEILLANCE OF FOOD- AND WATERBORNE DISEASES IN EUROPE: 'URGENT INQUIRIES' (OUTBREAK ALERTS) DURING 2008 TO 2013
}

\author{
Euro Surveill. 2015;20(25):pii=21166. Available online: \\ http://www.eurosurveillance.org/images/dynamic/EE/V20N25/art21166.pdf
}

Céline M. Gossner, Birgitta de Jong, Christian J. Hoebe, Denis Coulombier, European Food and Waterborne Diseases Study Group.

During 2008 to 2013, 215 outbreak alerts, also known as 'urgent inquiries' (UI), for food- and waterborne diseases were launched in Europe, the majority of them (135; $63 \%$ ) being related to salmonellosis. For $110(51 \%)$ UI, a potential food vehicle of infection was identified, with vegetables being the most reported category $(34 ; 31 \%)$. A total of $28 \%(n=60)$ of the outbreaks reported had an international dimension, involving at least two countries (mean: 4; standard deviation: 2; range: 2-14). Participating countries posted 2,343 messages (initial posts and replies, excluding updates), with a median of 11 messages per urgent inquiry (range: 1-28). Of 60 multicountry UI, 50 involved between two and four countries. The UI allowed early detection of multicountry outbreaks, facilitated the identification of the suspected vehicles and consequently contributed to the timely implementation of control measures. The introduction of an epidemic intelligence information system platform in 2010 has strengthened the role of the Food- and Waterborne Diseases and Zoonoses network in facilitating timely exchange of information between public health authorities of the participating countries. 


\section{INTRODUCTION}

Collecting laboratory-based surveillance data of food-borne pathogens, with the aim of detecting and responding to multicountry outbreaks, has long been established in the European Union (EU). Created in 1994, Salm-Net was the first European network for Salmonella surveillance [1], which was replaced in 1997 by Enter-net, covering surveillance of Salmonella and Shiga toxin-producing Escherichia coli (STEC) O157, with the addition of Campylobacter in 2004 [2]. Looking beyond EU borders, the network was extended to include experts from the current countries of the EU (excluding Croatia), plus Australia, Canada, Iceland, Japan, New Zealand, Norway, South Africa and Switzerland [2]. In 2007, Enter-net activities were transferred to the European Centre for Disease Prevention and Control (ECDC) and the network was renamed the Food- and Waterborne Diseases and Zoonoses (FWD) network [3]. The network scope was broadened to cover six priority diseases: salmonellosis, campylobacteriosis, STEC infections, listeriosis, shigellosis and yersiniosis. The network was also extended to encompass Lichtenstein, Turkey and the United States (US). Thus, during 2008 to 2013, 38 countries in five continents were included in the network.

One of the key activities inherited from Enter-net was an internationally agreed procedure to share outbreak alerts, so-called urgent inquiries (UI), among network members. UI are launched by participating countries or ECDC after observing an unusual increase in the number of food- and waterborne infections having potential for international spread. The main objective of the UI is to allow the detection of multicountry outbreaks and thereafter facilitate the investigations. While UI were communicated initially by fax and email, ECDC launched a web-based restrictedaccess communication platform, the Epidemic Intelligence Information System for FWD (EPIS-FWD) in March 2010, allowing nominated participants from public health authorities to post and access information in a structured format [4,5] (Table 1).

Table 1. Event-based surveillance systems ${ }^{\mathrm{a}}$ for food- and waterborne diseases in the European Union/European Economic Area

\begin{tabular}{|c|c|c|c|}
\hline System & Coordinating body & Role of the systems & Participants \\
\hline $\begin{array}{l}\text { Epidemic Intelligence } \\
\text { Information System, } \\
\text { for Food- and } \\
\text { Waterborne Diseases } \\
\text { and Zoonoses (EPIS- } \\
\text { FWD) }\end{array}$ & $\begin{array}{l}\text { European Centre for } \\
\text { Disease Prevention and } \\
\text { Control (ECDC) }\end{array}$ & $\begin{array}{l}\text { Detection of } \\
\text { multicountry food- and } \\
\text { waterborne diseases } \\
\text { outbreaks and } \\
\text { assessment of the risk }\end{array}$ & $\begin{array}{l}\text { Public health } \\
\text { authorities in EU/EEA } \\
\text { countries plus } \\
\text { Australia, Canada, } \\
\text { Iceland, Japan, New } \\
\text { Zealand, Norway, } \\
\text { South Africa and } \\
\text { Switzerland }\end{array}$ \\
\hline $\begin{array}{l}\text { Early Warning and } \\
\text { Response System } \\
\text { (EWRS) }\end{array}$ & European Commission & $\begin{array}{l}\text { Risk management of } \\
\text { international or } \\
\text { unexpected events }\end{array}$ & $\begin{array}{l}\text { Public health } \\
\text { authorities in EU/EEA } \\
\text { countries }\end{array}$ \\
\hline $\begin{array}{l}\text { Rapid Alert System for } \\
\text { Food and Feed } \\
\text { (RASFF) }\end{array}$ & European Commission & $\begin{array}{l}\text { Risk management of } \\
\text { serious risk to human } \\
\text { health deriving from } \\
\text { food and feed }\end{array}$ & $\begin{array}{l}\text { Food safety authorities } \\
\text { in EU/EEA countries } \\
\text { and specific agreement } \\
\text { with non-EU/EEA } \\
\text { countries }\end{array}$ \\
\hline
\end{tabular}

EU/EEA: European Union/European Economic Area

A mean of 5,392 (standard deviation (SD): 173) FWD outbreaks were reported annually during the study period in the EU and European Economic Area (EEA) 
countries [6-11]. About 95\% of these outbreaks are point source outbreaks, i.e. where exposure happened at only one place, often a result from mishandling of food in restaurants or at home and leading to small and localised outbreaks. Only a small proportion of these outbreaks have the potential to affect multiple countries and those are the ones that the UI aim to capture. While participation in the UI system is voluntary, EU/EEA countries must report international or unexpected events to the Early Warning and Response System (EWRS) and through the International Health Regulations (IHR) [12,13] (Table 1). Events for which there is evidence that cases in different countries are linked and/or that a food vehicle is identified and potentially exported or imported and/or foreign travellers may have been exposed should be reported to the EWRS. Similarly, EU/EEA food authorities should notify the European Commission and other food authorities through the Rapid Alert System for Food and Feed (RASFF) about serious risks to human health deriving from food or feed [14] (Table 1). Since 2003, yearly reporting of investigated FWD outbreaks to the European Food Safety Authority (EFSA) has been mandatory for EU/EEA countries [15].

The objective of this study was to describe the UI during 2008 to 2013, to measure the performance of the UI as an event-based surveillance system to detect multicountry outbreaks, and to analyse them in a more global EU/EEA surveillance context while looking at the link with other reporting systems. In addition, we aimed to evaluate the acceptability of the EPIS-FWD as a supporting platform.

\section{METHODS}

We extracted UI details exchanged by fax and email and through EPIS-FWD from January 2008 to December 2013. For each urgent inquiry, we collated the following variables on a spreadsheet: disease, pathogen, date of launch of the UI and initiating country of the UI, number of cases and vehicle of infection. Epidemiological (person, place and time) and microbiological information (laboratory results) were used to identify a possible multicountry dimension of an outbreak. UI for which different countries reported cases with indistinguishable pulsed-field gel electrophoresis (PFGE) pattern, same multiple-locus variable-number of tandem-repeats analysis (MLVA) profile or similar RNA sequence within a defined time period were considered possible multicountry outbreaks. For rare Salmonella serotypes, serotype information was sufficient to define if cases might be part of a multicountry outbreak. Vehicles of infections were divided in two categories: 'unknown' and 'suspected or confirmed'. EU/EEA countries were grouped into four geographical regions according to the United Nations, Department of Economic and Social Affairs [16]: eastern, northern, southern and western Europe (Figure 1). To further define the characteristics of the UI, we collected complementary information from peerreviewed articles, outbreak reports, press releases, and ECDC and EFSA reports, by searching on national public health websites, ECDC and EFSA websites, PubMed and Google with keywords relevant to the disease being studied. We also asked countries to update the information in EPIS-FWD. 

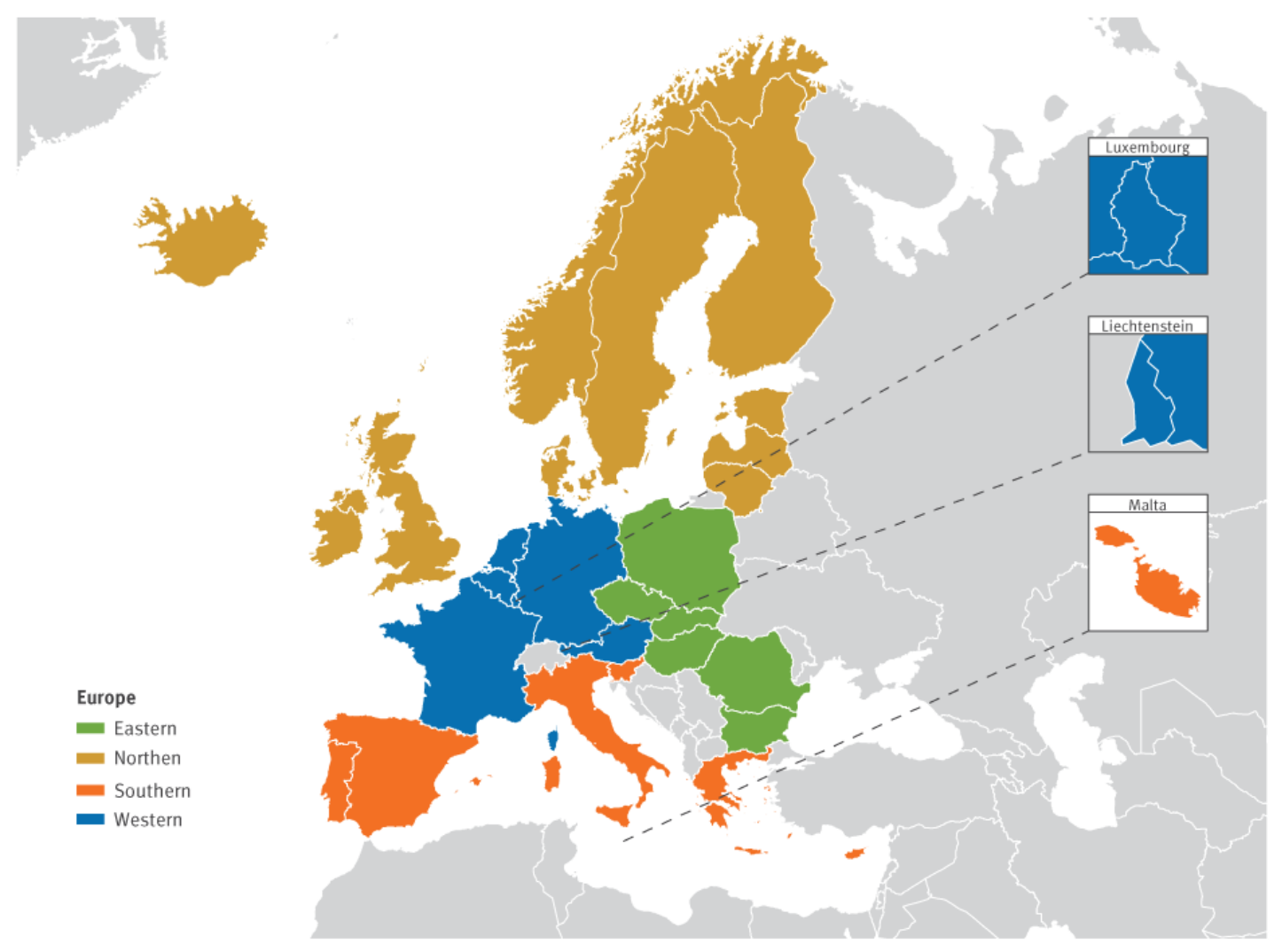

Figure 1. Geographical classification of European Union/European Economic Area countries

Source of the classification: United Nations, Department of Economic and Social Affairs [16].

The data were analysed with Microsoft Excel 2010 and Stata 12.1. Seasonality was analysed using a five-month moving average. Significance of the difference in proportions was tested using chi-squared test.

We assessed the performance of the UI system through the following: the activity of the participating countries; the threshold for launching UI (number of cases triggering the UI); and the capacity of the system to detect multicountry outbreaks (percentage of UI that were multicountry outbreaks was taken as a proxy measure for this). We evaluated the acceptability of the EPIS-FWD through the comparison of UI characteristics before and after the introduction of the platform. We consulted the EWRS and RASFF platforms to identify whether UI-associated notifications were issued. As this study focuses on EU systems, IHR notifications were not included in the analysis.

\section{ReSULTS}

\section{General characteristics of urgent inquiries}

Between January 2008 and December 2013, 215 UI were issued by participating countries (Figure 2). The number of UI fluctuated over the years, with 32 UI in 2008, 27 in 2009, 33 in 2010, 49 in 2011, 32 in 2012 and 42 in 2013. 


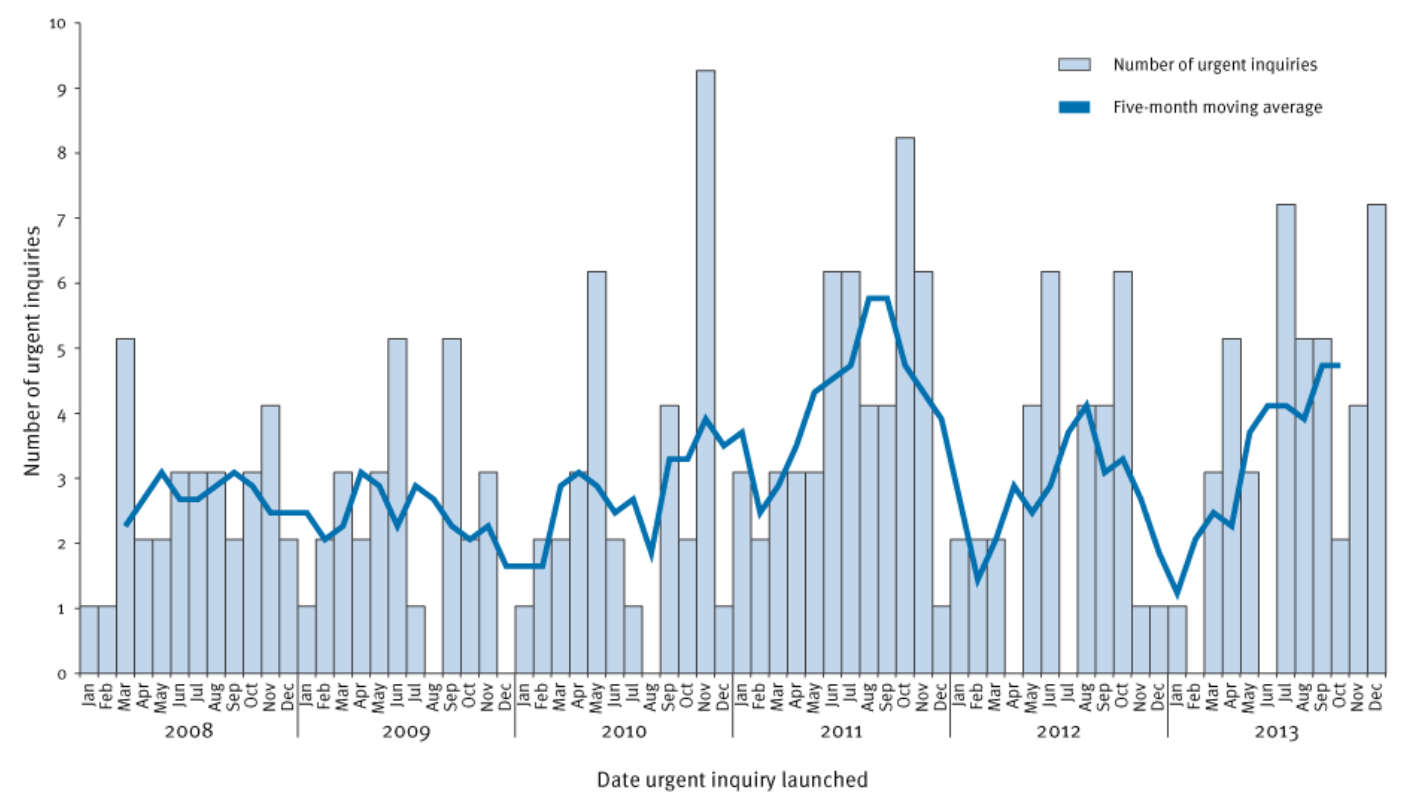

Figure 2. Number of urgent inquiries and five-month moving average, by month, participating countries of the northern hemisphere ${ }^{a}, 2008-13(n=214)$

a Current countries of the European Union/European Economic Area (excluding Croatia), plus Canada, Japan, Switzerland, Turkey and the United States.

The moving average highlights some seasonality in the northern hemisphere, with peaks during spring and summer. One peak in November 2010 did not follow this seasonal pattern. In addition, a larger peak was visible in the summer and autumn of 2011, with 34 UI launched between June and November.

A total of 20 of 30 EU/EEA countries, four of eight non-EU/EEA countries and ECDC initiated the UI. Only one urgent inquiry was launched by a country from the southern hemisphere. Countries in northern and western Europe launched the majority of the UI, with 117 (54\%) and 54 UIs (25\%), respectively (Figure 3). The countries from northern and western Europe launched respectively 31 and 13 multicountry UI. 


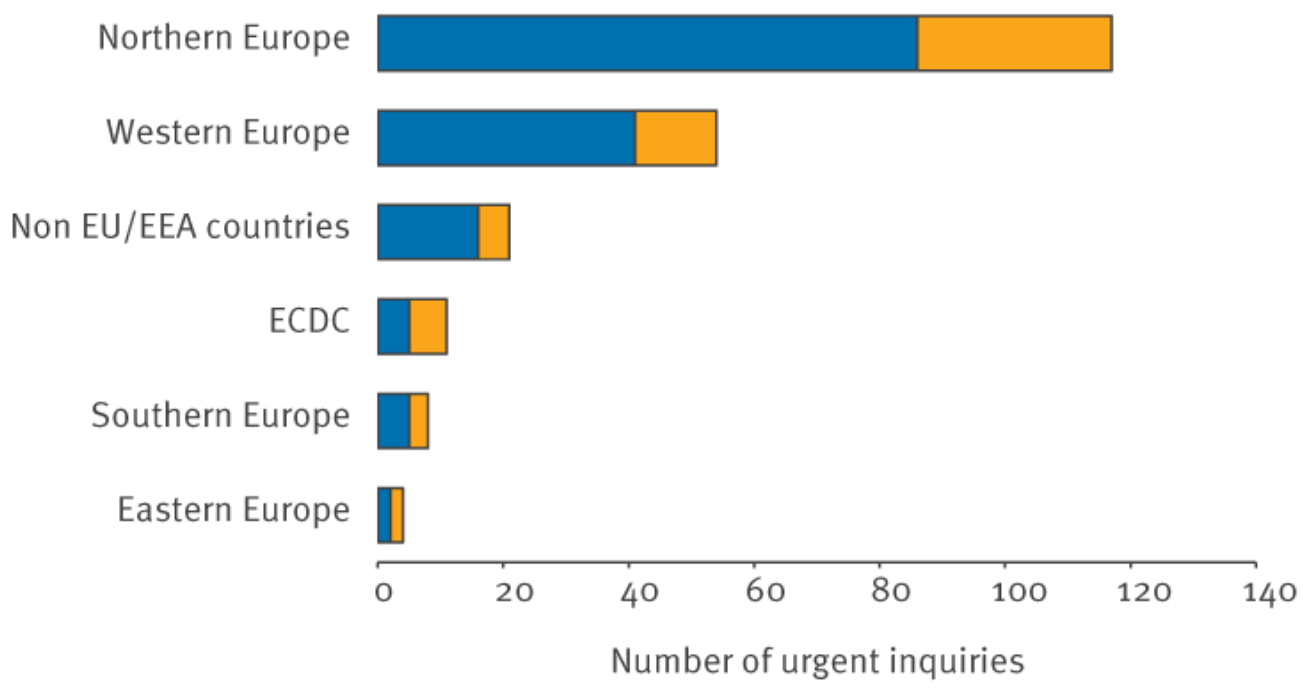

Single country Multicountry

Figure 3. Single country and multicountry urgent inquiries initiated by participating countries $^{\mathrm{a}}$ and the European Centre for Disease Prevention and Control, 2008-13 $(n=215)$

ECDC: European Centre for Disease Prevention and Control; EU/ EEA: European Union/European Economic Area.

a Current countries of the EU/EEA (excluding Croatia), plus Australia, Canada, Japan, New Zealand, South Africa, Switzerland, Turkey and the United States. Geographical classification of EU/ EEA countries according to the categories of the United Nations, Department of Economic and Social Affairs [16].

The majority of the UI were posted by the United Kingdom $(n=27)$, France $(n=21)$ and Denmark $(n=20)$. Among the participating non-EU/EEA countries, the US posted the most UI $(\mathrm{n}=18)$. One of the UI was launched by ECDC on behalf of Israel.

The rate of UI per million inhabitants in EU/EEA countries shows a pattern, with countries in northern Europe posting the most UI, followed in order by countries in western, eastern and southern Europe (Figure 4). 


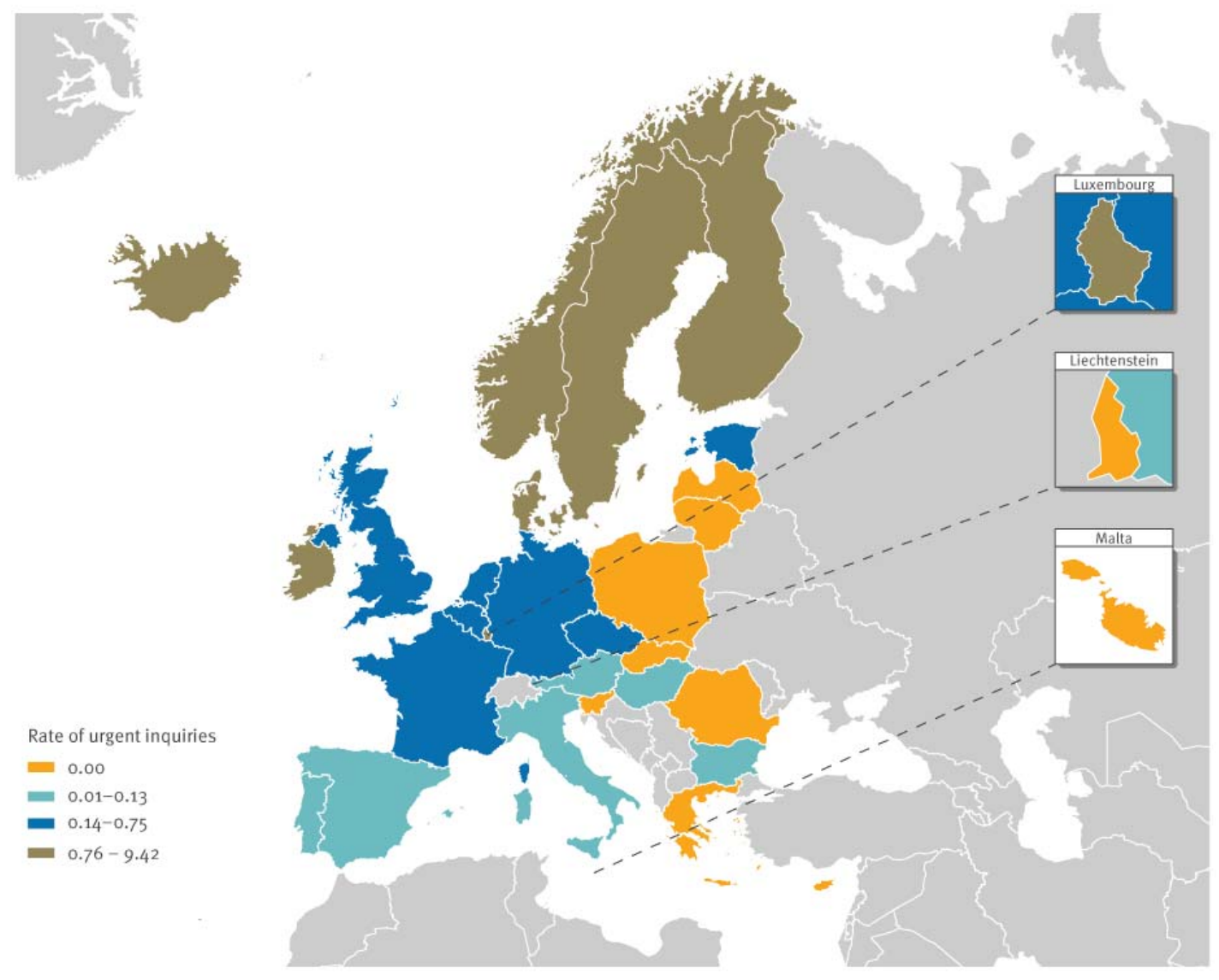

Figure 4. Rate of urgent inquiries per million inhabitants in European Union/European Economic Area countries, 2008-13 $(n=215)$

Divided by quantile. Source of population estimates: Eurostat 2011 [22]. Geographical classification of European Union/European Economic Area countries according to the categories of the United Nations, Department of Economic and Social Affairs [16].

Participating countries posted 2,343 messages (initial posts and replies, excluding updates), with a median of 11 messages per urgent inquiry (range: 1-28). After launch of EPIS-FWD in 2010, the number of messages posted increased. From 272 and 235 messages in 2008 and 2009 respectively, the number of messages rose to 315 in 2010 , 582 in 2011, 450 in 2012 and 485 in 2013. The mean number of messages per urgent inquiry increased from 2008 to 2012, and decreased in 2013 (Figure 5). 


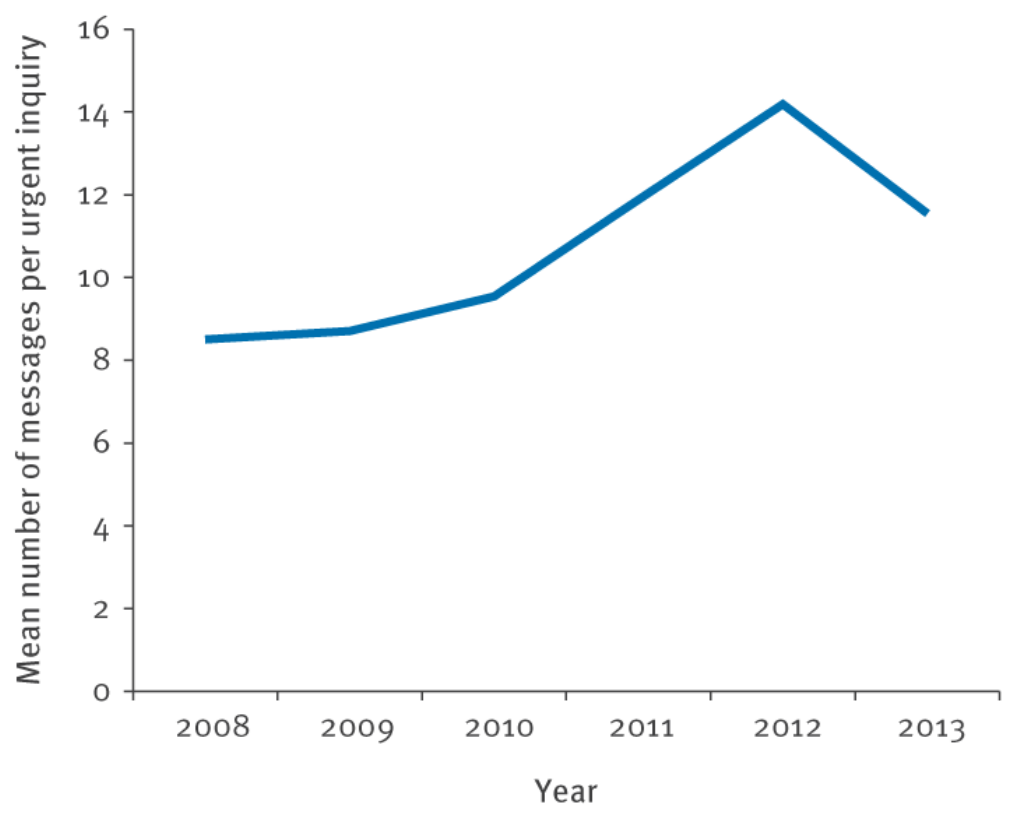

Figure 5. Mean number of messages ${ }^{a}$ per urgent inquiry per year, participating countries $^{\mathrm{b}}$, 2008-13

${ }^{a}$ Comprises initial posts and replies, excluding updates.

${ }^{b}$ Current countries of the EU/EEA (excluding Croatia), plus Australia, Canada, Japan, New Zealand, South Africa, Switzerland, Turkey and the United States.

\section{Pathogens and vehicles of infection}

A total of 15 diseases and intoxication syndromes were reported (Table 2). Salmonellosis and STEC infection represented $63 \%(n=135)$ and $15 \%(n=32)$ of the UI, respectively. A total of 50 Salmonella serotypes were reported: the two most commonly reported were $S$. Typhimurium $(\mathrm{n}=34)$, including its monophasic variants 1,4,[5],12:i:-, and $S$. Enteritidis $(\mathrm{n}=22)$. Seven STEC serogroups were reported, of which serogroup O157 was the most predominant $(n=20 / 32)$. Other serogroups reported included O26, O27, O104, O121, O145 and O177. 
Table 2. Urgent inquiries launched per disease or intoxication syndrome, participating countries ${ }^{\mathrm{a}}, 2008-13(\mathrm{n}=\mathbf{2 1 5})$

\begin{tabular}{|l|c|}
\hline Disease or intoxication syndrome & Number of urgent inquiries \\
\hline Salmonellosis & 135 \\
\hline Shiga toxin-producing Escherichia coli infection & 32 \\
\hline Listeriosis & 11 \\
\hline Shigellosis & 7 \\
\hline Hepatitis A & 7 \\
\hline Cryptosporidiosis & 5 \\
\hline Norovirus infection & 4 \\
\hline Cholera & 3 \\
\hline Botulism & 3 \\
\hline Food poisoning due to toxins & 2 \\
\hline Yersiniosis & 2 \\
\hline Trichinellosis & 1 \\
\hline Paratyphoid fever & 1 \\
\hline Cyclosporiasis & 1 \\
\hline Brucellosis & 1 \\
\hline Total & $\mathbf{2 1 5}$
\end{tabular}

${ }^{a}$ Current countries of the European Union/European Economic Area (excluding Croatia), plus Australia, Canada, Japan, New Zealand, South Africa, Switzerland, Turkey and the United States.

For 110 UI (51\%), a food vehicle of infection was either suspected or confirmed, through descriptive and/or analytical epidemiological studies. This proportion was relatively stable between 2008 and 2013 (range: 36-67\%). For 93 UI, the vehicle or origin of infection remained unknown. For seven UI, the infection was due to direct contact with animals; for four, it was water; and for one, it was a laboratory-acquired infection [17].

Three waterborne outbreaks were related to cholera in countries outside the EU where European travellers were at risk of infection and the remaining outbreak was a local outbreak of cryptosporidiosis after contamination of the drinking water.

The most commonly reported food vehicles were vegetables $(n=34)$, followed by pork $(n=14)$, beef $(n=12)$, eggs $(n=7)$, cereal products $(n=7)$ and fruit $(n=7)$ (Figure 6). A large increase in number of UI related to vegetables was observed in 2011, followed by a decrease in 2012 and 2013. There were fewer UI related to pork in 2012-13 compared with the 2008-11 (except 2009, when there was no urgent inquiry related to pork). 


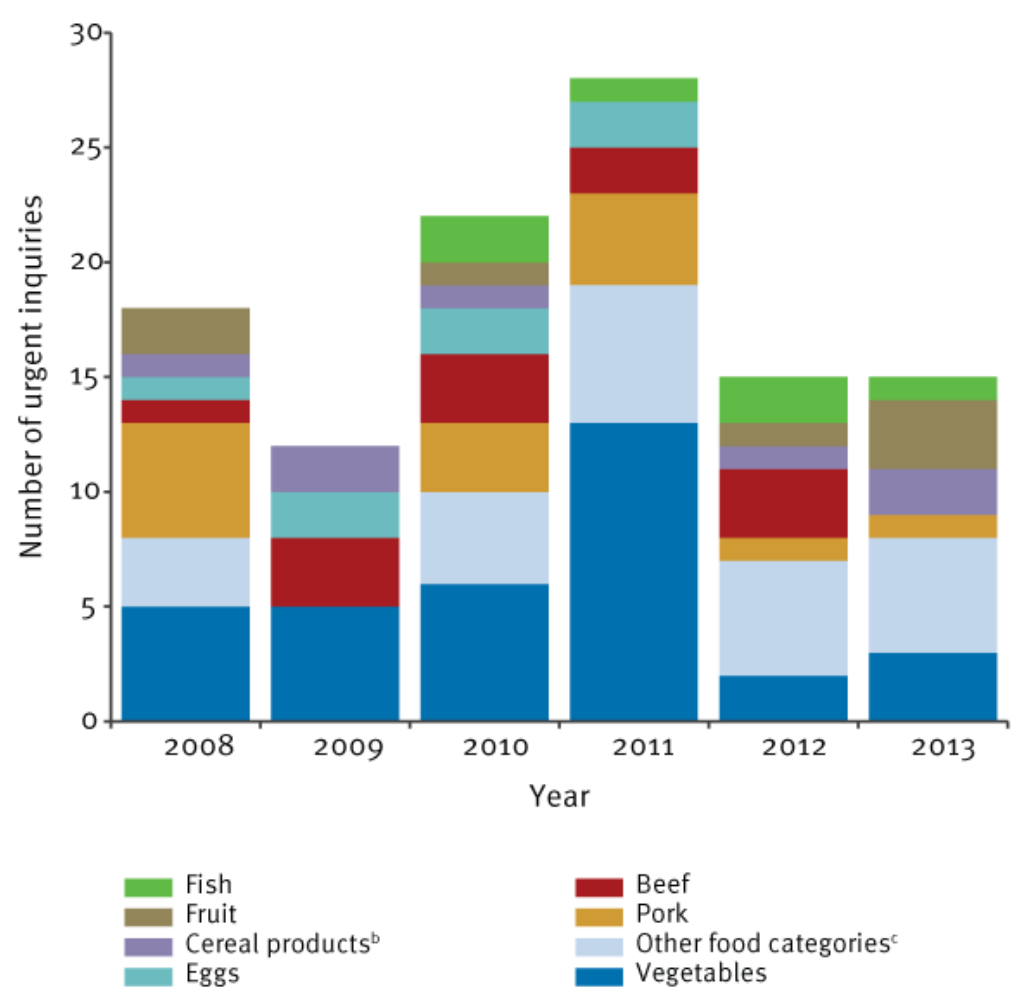

Figure 6. Urgent inquiries by categories of food vehicle of infection, participating countries $^{\text {a }}, 2008-13(n=110)$

a Current countries of the European Union/European Economic Area (excluding Croatia), plus Australia, Canada, Japan, New Zealand, South Africa, Switzerland, Turkey and the United States.

${ }^{b}$ Cereal products includes rice and seeds/pulses.

${ }^{c}$ Other food categories include crustaceans, shellfish, molluscs, herbs and spices, mixed or buffet meals, canned food products, turkey meat, sweets and chocolate, infant formula, pet food, dietary supplements and other or unspecified poultry meat.

\section{Affected countries and exposure}

Most of the UI $(155,72 \%)$ involved a single country, meaning that no linked cases could be identified by ECDC in other countries. The mean number of country involved in multicountry UI was four (SD: 2; range: 2-14). Of the 60 multicountry UI, 50 involved between two and four countries. In 10 UI, at least five countries were involved per urgent inquiry, including an outbreak of S. Stanley infections in the EU in 2012 [18] and hepatitis A associated with travel to Egypt in 2013 [19]. Multicountry outbreaks were primarily due to the distribution of a contaminated product to multiple countries (35 outbreaks) and to the travel of people to a common country/place of infection (19 outbreaks). International trade of infected animals was reported in two UI. For four UI, the information available was insufficient to define the exposure.

A total of $31 / 117(26 \%)$ of the UI launched by countries in northern Europe were multicountry outbreaks (Figure 3). A similar proportion of multicountry outbreaks was observed among countries of western Europe (13/54) and non-EU/EEA countries 
$(5 / 21)$. For countries in southern and eastern Europe, numbers of UI were too small to obtain a meaningful comparisons for these regions. No region was, however, statistically significantly more likely to launch UI that became multicountry.

\section{Number of cases triggering an urgent inquiry}

For 76 UI (35\%), the trigger for posting the UI was less than 10 human cases and for 19 UI (9\%) the trigger was above 100 cases (median: 15; range: $0-8,138)$. Six UI were launched after identification of a contaminated food product, without any human cases initially reported. The UI launched with the highest number of cases $(8,138$ cases) was related to a large outbreak of cholera in Haiti in 2010 and can be considered as an outlier [20].

Of the 76 UI with a trigger below 10 cases, 42 and 16 were posted by countries in northern and western Europe, respectively.

The median number of cases triggering the UI decreased over the years: 29; range 31,375 (in 2008), 18; range: 0-600 (2009), 20; range: 2-8,138 (2010), 9; range 0-250 (2011), 12; range 1-267 (2012) and 11; range 0-391 (2013). A total of 19 UI with a trigger below 10 cases and 6/19 UI with a trigger above 100 cases appeared to be multicountry outbreaks. The mean number of cases triggering UI differed by disease; for instance, for listeriosis, salmonellosis and STEC infection, respectively, the mean was 14 (SD: 16), 59 (SD: 170) and 21 (SD: 46).

No statistically significant associations were observed between the geographical regions, the number of cases triggering the UI and the multicountry aspect of the UI.

\section{Links with other alert systems}

For 41 UI, an EWRS was launched: 26 UI were launched before an EWRS message was issued, eight were posted after an EWRS message was issued and seven were posted the same day. For the last two situations, the UI were used to collect epidemiological and microbiological information to assess the situation better, but implied that information was scattered between the two platforms.

For 26 of the 60 multicountry outbreaks, an EWRS message was launched. Between 2008 and 2013, 105 EWRS messages were issued about FWD events, among which 36 were multicountry events. The majority of the EWRS messages on FWD related to salmonellosis $(n=29)$, botulism $(n=13)$ and hepatitis A $(n=13)$. A total of $44(42 \%)$ and $56(53 \%)$ of those 105 EWRS messages reported the risk of a contaminated food product potentially distributed internationally and the risk of travellers getting infected while abroad (including infection on cruise ships), respectively. Among the 64 EWRS on FWD events that were not reported as UI, two salmonellosis outbreaks could potentially have been investigated first through UI: one reported by the European Commission on behalf of Switzerland in 2008 and one outbreak connected to campsites and restaurants in southern Sweden in 2010.

For 46 UI, at least one RASFF notification was issued. For 14 of the 27 UI that involved at least one EU/EEA country, were linked to the distribution of a contaminated product and for which a vehicle of infection was suspected or confirmed, a RASFF notification was issued. For 22 events, the UI were launched 
first; for 20 events, the RASFF notification was launched first; and for four events, they were launched the same day.

\section{DisCUSSION}

\section{Key performance of urgent inquiries}

With a mean of three UI per month (SD: 2) between 2008 and 2013, an increasing number of messages exchanged, and a decreasing median number of cases triggering the UI, the UI are a well-established system that is increasingly trusted by the participating countries. More information is shared and outbreaks are likely to be reported at an earlier stage. Since 2010, EPIS-FWD has facilitated the exchange of information.

The number of messages exchanged among participating countries did not seem to be an indicator for having multicountry outbreaks. The majority of the replies to UI were to report negative findings and/or provide background information useful for the investigations.

Looking at the moving average (Figure 2), two main peaks in number of UI were observed: the first in November 2010 is unexplained; for the peak observed from June to November 2011, it is possible that following media attention on the outbreak of STEC O104:H4 infection in Germany in 2011, network members increased the sensitivity of their surveillance systems and decreased the threshold to launch UI.

UI are slightly marked by the seasons. While outbreaks related to mishandling of food (home or restaurant) are quite affected by the seasons - with faster growth of microorganisms in warmer temperatures and inadequate cooking or contamination of food at barbeques or parties - outbreaks related to distribution of contaminated commercial food items are likely to be less affected by the seasons, but rather by breach of contamination barriers in the production chain, resulting in less marked seasonal patterns.

A total of 10 EU/EEA countries did not launch any UI during the study period. Considering the difference in number and rate of UI launched by participating countries, the threshold to launch UI appears to be extremely variable, with the countries in northern and western Europe having the lowest threshold for posting an UI. This is confirmed by the fact that the majority of the UI triggered by less than 10 cases were launched by countries of these two regions. Considering the absence of association between the region and multicountry aspect of the UI, it is suspected that outbreaks, including multicountry outbreaks, were under-reported in countries of eastern and southern Europe. The UI system is dependent on the capacity and willingness of participating countries to launch and reply to an UI. While the focus of the UI is to detect multicountry outbreaks, the majority of the UI involved one single country. It was not possible to identify the criteria that make UI become multicountry investigations.

The threshold number of cases to launch UI differed with the reported disease, with UI for listeriosis and STEC infections having a lower threshold than, for instance, salmonellosis. This could be explained by the relative severity of the diseases.

Two thirds of the multicountry outbreaks were due to the distribution of a contaminated product and one third were related to travel to one country or place of infection. Multicountry waterborne outbreaks are likely to be travel related. For both 
distribution of contaminated products and travel-related outbreaks, it is through the gathering and cross-matching of information that the multicountry dimension of an outbreak can be identified. As there was no association between number of cases as a threshold of UI and being a multicountry outbreak, all clusters/outbreaks with potential international spread should be reported, even if detected at a late stage.

The reasons for the striking variations in UI reporting are unclear. Structural and cultural differences in the organisation of national public health systems are possible explanations. There are striking variations between countries with respect to their surveillance systems, including their laboratory capacity for detection, identification and typing of gastrointestinal pathogens. Some countries, therefore, have very limited capacity to detect and investigate outbreak signals [21]. Considering the important variation in the number of UI launched per countries and the number of their replies, ECDC should further encourage all countries to participate actively in the system. Negative responses are also of practical value to a national outbreak control team, as they actively confirm that other countries have not detected associated cases.

The active participation of non-EU/EEA countries confirms the perceived added value of the UI. While not part of the network, Israel used the UI through ECDC to investigate a national outbreak in 2011. Such requests from countries outside the network should be evaluated and, as much as possible, facilitated by ECDC.

\section{Representativeness of urgent inquiries regarding outbreaks occurring in the European Union/European Economic Area}

The majority of the outbreaks reported to EFSA during the study period were caused by Salmonella spp. [6-11] and similarly Salmonella was the leading pathogen for which UI were launched. This was expected, as laboratories commonly test for and report this pathogen, and serotyping and molecular typing can be very effective in detecting case clusters. Salmonella has a propensity to cause both point source and persistent source outbreaks, the latter being potentially cross-border outbreaks through food or animal trade. STEC and Listeria were the number two and three pathogens reported in UI, respectively, while outbreaks caused by these pathogens were least often reported to EFSA. STEC infection and Listeria outbreaks were infrequent in comparison with Salmonella outbreaks; however, the seriousness of the diseases, coupled with the availability of discriminative molecular typing methods mean that they are more likely to be reported.

UI may be particularly valuable for Listeria outbreaks because the disease does not have a high attack rate and listeriosis outbreaks are frequently due to consumption of manufactured products potentially distributed internationally (e.g. cheese, fish) rather than mishandling of food in restaurants or households as for Salmonella. Therefore, dispersed outbreaks are much more likely to be detected through the pooling of case information at the EU/EEA level [5].

While campylobacteriosis was the most commonly reported food-borne disease in the EU/EEA during the study period (mean: 212,987 cases (SD: 11,916); 471 outbreaks (SD: 89) [6-11], no UI were launched during the period studied. Campylobacter samples are not subtyped routinely and no discriminative and reliable subtyping system exists so dispersed, continuous outbreaks are therefore unlikely to be detected.

Whereas vegetables were the predominant vehicles of infection reported in the UI, eggs were the main food vehicle category reported to EFSA [6-11], representing up to 
$18.5 \%$ of the outbreaks in 2013 [10]. One hypothesis is that eggs are more likely to be associated with point source outbreaks, such as in households or restaurants. It should be noted that the proportion of outbreaks due to vegetables reported to EFSA increased, from $1.9 \%$ in 2008 to $4.4 \%$ in 2013 (with a peak of $8.7 \%$ in 2010) [6-11]. The outbreak of STEC infection in Germany in 2011 potentially encouraged countries to report outbreaks linked to vegetables, which might explain the increase in number of vegetable-related UI that year. No explanation was identified for the peak in 2010.

\section{Links with other event-based surveillance systems}

Despite the existence of criteria for mandatory notifications, outbreaks reported as UI were inconsistently notified through EWRS and RASFF. This does not imply, however, that appropriate measures were not effectively implemented. All EWRS contact points have access to EPIS-FWD so that public health risk managers are kept informed.

ECDC, together with the European Commission, should develop guidance for reporting in the various existing risk assessment (EPIS-FWD) and risk management (EWRS and RASFF) platforms and should be more proactive in ensuring that EU/EEA countries report appropriately to these platforms. No RASFF notifications were issued for half of the UI that involved at least one EU/EEA country and were linked to the distribution of a contaminated product and for which a vehicle of infection was suspected or confirmed. A possible explanation for the lack of RASFF notification is that for these UI, a vehicle was suspected but no specific product or brand could be identified.

Despite a new version of EPIS-FWD, launched in July 2013, allowing any expert to be granted access to specific UI, food safety authorities still do not have default access to the platform. In the future, providing food safety authorities access to EPISFWD and creating an IT connection between EPIS-FWD and EWRS, and eventually RASFF, could be foreseen in order to streamline the exchange of information and ensure constant interaction between risk assessment and risk management.

In 2013, as ECDC established a molecular typing surveillance system for Salmonella, Listeria and STEC, a new version of EPIS-FWD was launched, integrating the management of clusters detected through molecular surveillance. With the development of molecular typing methods and their use in EU/EEA countries, ECDC will detect more and more multicountry microbiological clusters. Microbiological clusters considered to be relevant will be the trigger for ECDC to launch UI and therefore the number of UI is expected to rise in the coming years.

\section{CONCLUSION}

The UI proved to be successful in facilitating the detection of multicountry FWD outbreaks and became a key element of event-based surveillance of FWD outbreaks in the EU/EEA.

The introduction of the EPIS-FWD platform in 2010 has strengthened the role of the FWD network in facilitating the timely exchange of information between countries. Combined with data collected by EFSA on outbreaks, the UI give a good overview of the characteristics of FWD outbreaks reported at the EU/EEA level. 
Our analysis shows the need to strengthen coordination between the risk assessors and risk managers at the EU/EEA level, particularly when reporting events to EPIS-FWD, EWRS and RASFF. This could be supported through the development of crosssectoral guidelines for outbreak reporting.

As it was not possible to define any criteria that identify which events reported as UI would become multicountry outbreaks, guidelines for posting an UI should not be restrictive and participating countries should be encouraged to post an UI as soon as they detect any unusual FWD event.

Additional studies should be conducted in order to further assess the capacity of UI to detect multicountry outbreaks and to evaluate the impact of UI on the geographical spread of outbreaks and the resolution of outbreak sources. 


\section{Members of THE EuROPEAN FoOd ANd WATERborne Diseases STUdy Group}

Agency for Health and Food Safety, Vienna, Austria (C. Kornschober, D. Schmid); Scientific Institute of Public Health, Brussels, Belgium (S. Quoilin); National Center of Infectious and Parasitic Diseases, Sofia, Bulgaria (K. Parmakova); National Reference Laboratory for Enteric Pathogens, Sofia, Bulgaria (P. Petrov); Ministry of health, Nicosia, Cyprus (M. Koliou); National Institute of Public Health, Prague, Czech Republic (R. Kralova, M. Marejkova); Statens Serum Institut, Copenhagen, Denmark (S. Ethelberg, L. Müller, M. Torpdahl, E. Møller Nielsen); Health Board, Tallinn, Estonia (J. Epstein, I. Dontsenko); National Institute for Health and Welfare, Helsinki, Finland (T. Lienemann, R. Rimhanen-Finne, M. Kuusi, A. Siitonen); French Institute for Public Health Surveillance, St Maurice, France (N. Jourdan-Da Silva, L. King); Institut Pasteur, Paris, France (S. Le Hello, A. Leclercq); Robert Koch Institute, Berlin, Germany (H. Bernard, C. Frank, D. Werber); National Reference Centre for Salmonella and other Enteric pathogens, Robert Koch Institute, Wernigerode, Germany (W. Rabsch); Hellenic Center for Disease Control \& Prevention, Attica, Greece (K. Mellou); National Centre for Epidemiology, Budapest, Hungary (K. Krisztalovics, J. Pászti); Centre for health security and communicable disease control, Reykjavik, Iceland (G. Sigmundsdottir, H. Hardardottir); Health Protection Surveillance Centre, Dublin, Ireland (P. Garvey, P. McKeown); National Salmonella, Shigella and Listeria Reference Laboratory, University Hospital, Galway, Ireland (M. Cormican); National Verocytotoxin E. coli Laboratory, Cherry Orchard Hospital, Dublin, Ireland (E. McNamara); Istituto Superiore di Sanità, Roma, Italy (G. Scavia, I. Luzzi); Centre for Disease Prevention and Control, Riga, Latvia (R. Korotinska); Centre for Communicable diseases and AIDS, Vilnius, Lithuania (G. Zagrebneviene); Health Promotion and Disease Prevention Directorate, Msida, Malta (A. Gatt); Norwegian Institute of Public Health, Oslo, Norway (K. Nygård, L. Vold, L.C. Thorstensen Brandal, A.L. Wester); Institute of Environmental Science and Research, Upper Hutt, New Zealand (M. Dufour); National Institute of Public Health, Bucharest, Romania (L. Zota); Public Health Authority, Bratislava, Slovak Republic (J. Mikas); National Institute of Public Health, Ljubljana, Slovenia (E. Grilc); Institute of Health Carlos III, Madrid, Spain (C. Varela Martínez, S. Herrera León); National Institute for Communicable Diseases, Johannesburg, South Africa (K. H Keddy); School of Public Health, University of the Witwatersrand, Johannesburg, South Africa (K. H Keddy); Swedish Institute for Communicable Disease Control, Stockholm, Sweden (S. Ivarsson, M. Löfdahl, C. Jernberg, I. Hedenström); National Institute for Public Health and the Environment, Bilthoven, the Netherlands (I. Friesema, L. Verhoef, W. van Pelt and M. Heck); Public Health England, London, United Kingdom (C. Lane, T. Peters, A. Awofisayo); Health Protection Scotland, Glasgow, United Kingdom (S. Brownlie); Centers for Disease Control and Prevention, Atlanta, United States (P. Gerner-Smidt). 


\section{REFERENCES}

1. Fisher IS. Salm-Net: a network for human salmonella surveillance in Europe. Euro Surveill. 1995;0(0):7-8. PMID:12631753

2. International surveillance network for the enteric infections - Salmonella, VTEC O157 and Campylobacter. Enter-net annual report 2005. Surveillance of enteric pathogens in Europe and beyond. London: Enter-net surveillance hub, Health Protection Agency; 2007. Available from:http://staging.ecdedmz.europa.eu/en/publications/Publications/316 annual_repo $\underline{\text { rt2005.pdf }}$

3. European Centre for Disease Prevention and Control (ECDC). Surveillance of six priority food- and waterborne diseases in the EU/EEA, 2006 - 2009. Stockholm: ECDC; 2013. Available

from:http://www.ecdc.europa.eu/en/publications/Publications/food-and-waterbornediseases-surveillance-report.pdf

4. Gossner C. ECDC launches the second version of the EPIS-FWD platform. Euro Surveill. 2013;18(27). PMID:23870080

5. Yde M, Naranjo M, Mattheus W, Stragier P, Pochet B, Beulens K, et al. Usefulness of the European Epidemic Intelligence Information System in the management of an outbreak of listeriosis, Belgium, 2011. Euro Surveill. 2012;17(38). PMID:23040965

6. European Food Safety Authority, European Centre for Disease Prevention and Control. The European Union summary report on trends and sources of zoonoses, zoonotic agents and food-borne outbreaks in 2011. EFSA Journal. 2013;11(4):3129. $250 \mathrm{pp}$. Available from: http://www.efsa.europa.eu/en/efsajournal/pub/3129.htm doi:10.2903/j.efsa.2013.3129

7. European Food Safety Authority, European Centre for Disease Prevention and Control. The European Union summary report on trends and sources of zoonoses, zoonotic agents and food-borne outbreaks in 2010. EFSA Journal. 2012;10(3):2597. 442pp. Available from: http://www.efsa.europa.eu/en/efsajournal/pub/2597.htm doi:10.2903/j.efsa.2012.2597

8. European Food Safety Authority, European Centre for Disease Prevention and Control. The European Union summary report on trends and sources of zoonoses, zoonotic agents and food-borne outbreaks in 2009. EFSA Journal. 2011;9(3):2090. $378 \mathrm{pp}$. Available from: http://www.efsa.europa.eu/en/efsajournal/pub/2090.htm doi:10.2903/j.efsa.2011.2090

9. European Food Safety Authority, European Centre for Disease Prevention and Control. The Community summary report on trends and sources of zoonoses, zoonotic agents and foodborne outbreaks in the European Union in 2008. EFSA Journal.

2010;8(1):1496. 410 pp. Available

from:http://www.efsa.europa.eu/en/efsajournal/pub/1496.htm doi:10.2903/j.efsa.2010.1496

10. European Food Safety Authority, European Centre for Disease Prevention and Control. The European Union summary report on trends and sources of zoonoses, zoonotic agents and food-borne outbreaks in 2013. EFSA Journal. 2015;13(1):3991. $162 \mathrm{pp}$. Available from: http://www.efsa.europa.eu/en/efsajournal/pub/3991.htm doi:10.2903/j.efsa.2015.3991 
11. European Food Safety Authority, European Centre for Disease Prevention and Control. The European Union summary report on trends and sources of zoonoses, zoonotic agents and food-borne outbreaks in 2012. EFSA Journal. 2014;12(2):3547. 312 pp. Available from: http://www.efsa.europa.eu/en/efsajournal/pub/3547.htm doi:10.2903/j.efsa.2014.3547

12. European Commission. Commission decision of 10 July 2009 amending Decision 2000/57/EC on the early warning and response system for the prevention and control of communicable diseases under Decision No 2119/98/EC of the European Parliament and of the Council. 2009/547/EC. Official Journal of the European Union. Luxembourg: Publications Office of the European Union. 14.7.2009:L181. Available from: http://eurlex.europa.eu/LexUriServ/LexUriServ.do?uri=OJ:L:2009:181:0057:0060:EN:PDF

13. World Health Organization (WHO). International Health Regulations (2005). 2nd ed. Geneva: WHO; 2008. Available from: http://whqlibdoc.who.int/publications/2008/9789241580410 eng.pdf

14. Regulation (EC) No 178/2002 of the European Parliament and of the Council of 28 January 2002 laying down the general principles and requirements of food law, establishing the European Food Safety Authority and laying down procedures in matters of food safety. Official Journal of the European Union. Luxembourg: Publications Office of the European Union. 1.2.2002:L31. Available from: Available from: http://eur-

lex.europa.eu/LexUriServ/LexUriServ.do?uri=OJ:L:2002:031:0001:0024:EN:PDF

15. Directive 2003/99/EC of the European Parliament and of the Council of 17 November 2003 on the monitoring of zoonoses and zoonotic agents, amending Council Decision 90/424/EEC and repealing Council Directive 92/117/EEC. Official Journal of the European Union. Luxembourg: Publications Office of the European Union. 12.12.2003:L325. Available from: Available from: http://eurlex.europa.eu/LexUriServ/LexUriServ.do?uri=OJ:L:2003:325:0031:0040:EN:PDF

16. United Nations, Department of Economic and Social Affairs. Composition of macro geographical (continental) regions, geographical sub-regions, and selected economic and other groupings. New York, NY: United Nations, Department of Economic and Social Affairs; revised 31 Oct 2013. [Accessed 3 Feb 2014]. Available from:https://unstats.un.org/unsd/methods/m49/m49regin.htm\#europe

17. Centers for Disease Control and Prevention (CDC). Human Salmonella Typhimurium infections associated with exposure to clinical and teaching microbiology laboratories. Atlanta, GA: CDC; 17 Jan 2012. [Accessed 15 Feb 2014]. Available from: http://www.cdc.gov/salmonella/typhimuriumlaboratory/011712/index.html

18. European Centre for Disease Prevention and Control (ECDC), European Food Safety Authority (EFSA). Multi-country outbreak of Salmonella Stanley infections update. Joint ECDC/EFSA rapid risk assessment. Stockholm: ECDC; 20 Sep 2012. [Accessed 15 Feb 2014]. Available from:http://ecdc.europa.eu/en/publications/publications/20120921_rra_stanley_salmo nella.pdf

19. MacDonald E, Steens A, Stene-Johansen K, Gillesberg Lassen S, Midgley S, Lawrence J, et al. Increase in hepatitis A in tourists from Denmark, England, 
Germany, the Netherlands, Norway and Sweden returning from Egypt, November 2012 to March 2013. Euro Surveill. 2013;18(17):20468. PMID:23647624

20. Pan American Health Organization (PAHO). Epidemiological alert: update on cholera in Haiti. Washington, DC: PAHO; 7 Nov 2010. [Accessed 28 Feb 2014]. Available

from:http://www2.paho.org/hq/dmdocuments/2010/epi_alert2010 7_November_Ch olera_Outbreak.pdf

21. European Centre for Disease Prevention and Control (ECDC). Survey of National Reference Laboratory (NRL) capacity for six food-and waterborne diseases in EU/EEA countries. Stockholm: ECDC; 2012. Available from:http://www.ecdc.europa.eu/en/publications/publications/survey-nrl-capacity-forfood-waterborne-agents.pdf

22. European Statistical System (ESS). EU 2011 population and housing census. Luxembourg: ESS. [Accessed 18 Jun 2015]. Available

from: https://ec.europa.eu/CensusHub2/query.do?step $=$ selectHyperCube\&qhc $=$ false 


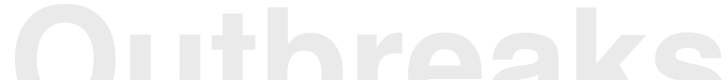

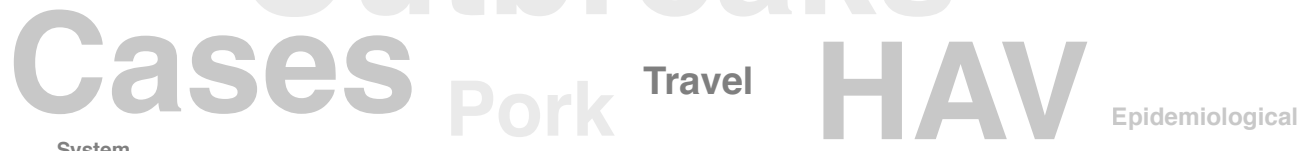 System EU/EEA Chain December Food EU/EEA Supermarket Travellers Reported ${ }^{\text {Supermad }}$ Dried
Berries Infection Countries} Information Control Vaccination Risk
Endemicity
Investigation Diseases

Salmonella

\section{SECTION III}

DETECTION AND RESPONSE *

TO FOOD- AND WATER-BORNE

DISEASE OUTBREAKS IN THE

EUROPEAN UNION 
Section III gathers examples of food-borne disease outbreaks to present the process of outbreak detection and response, including investigation mechanisms and development of a response strategy.

Chapter 5 describes a national outbreak of salmonellosis that occurred in France in 2011 which highlights how outbreak detection, investigation and reporting to the international level are conducted in the EU Member States.

Using three multi-country outbreaks of hepatitis A that occurred simultaneously in 2013, chapter 6 presents how EPIS-FWD supports the rapid detection of multicountry outbreaks and the collection of epidemiological and microbiological data used for the investigations. In addition, chapter 6 highlights the importance of international collaboration but also cross-sectorial collaboration.

As a response to the wave of food related hepatitis A outbreaks described in chapter 6, ECDC launched a review of the hepatitis A epidemiological situation in the EU. Chapter 7 demonstrates how surveillance data is supporting such mid-term outbreak response, underlying the limitations encountered. 


\section{Chapter 5}

NATIONWIDE OUTBREAK OF MONOPHASIC SALMONELLA TyPHIMURIUM IN FRANCE, 2011 
NATIONWIDE OUTBREAK OF SALMONELLA ENTERICA SEROTYPE 4,[5],12:I:- INFECTION ASSOCIATED WITH CONSUMPTION OF DRIED PORK SAUSAGE, FRANCE, NOVEMBER TO DECEMBER 2011

Euro Surveill. 2012;17(5):pii=20071. Available online: http://www.eurosurveillance.org/ViewArticle.aspx?ArticleId=20071

Céline M. Gossner, Dieter van Cauteren, Simon Le Hello, François-Xavier Weill, Elodie Terrien, Sabrina Tessier, Claire Janin, Anne Brisabois, Virginie Dusch, Véronique Vaillant, Nathalie Jourdan-da Silva

An outbreak of the monophasic variant of Salmonella enterica serotype 4,[5],12:i:occurred in November and December 2011 in France. Epidemiological investigation and food investigation with the help of supermarket loyalty cards suggested dried pork sausage from one producer as the most likely source of the outbreak. Despite the absence of positive food samples, control measures including withdrawal and recall were implemented. 


\section{OUTBREAK DESCRIPTION}

On 7 December 2011, the National Reference Centre for Salmonella (NRC) alerted the French Public Health Institute (InVS) about a two-fold increase of Salmonella enterica serotype 4,[5],12:i:- since the first week of November. Between 31 October and 18 December (week 44 to week 50), a total of 337 cases were identified (Figure 1). The median age was 10 years (range: $0-90$ years) with about $30 \%$ of children under five. A majority of women were affected (female to male sex ratio: 1.22). Cases were reported throughout France (Figure 2).

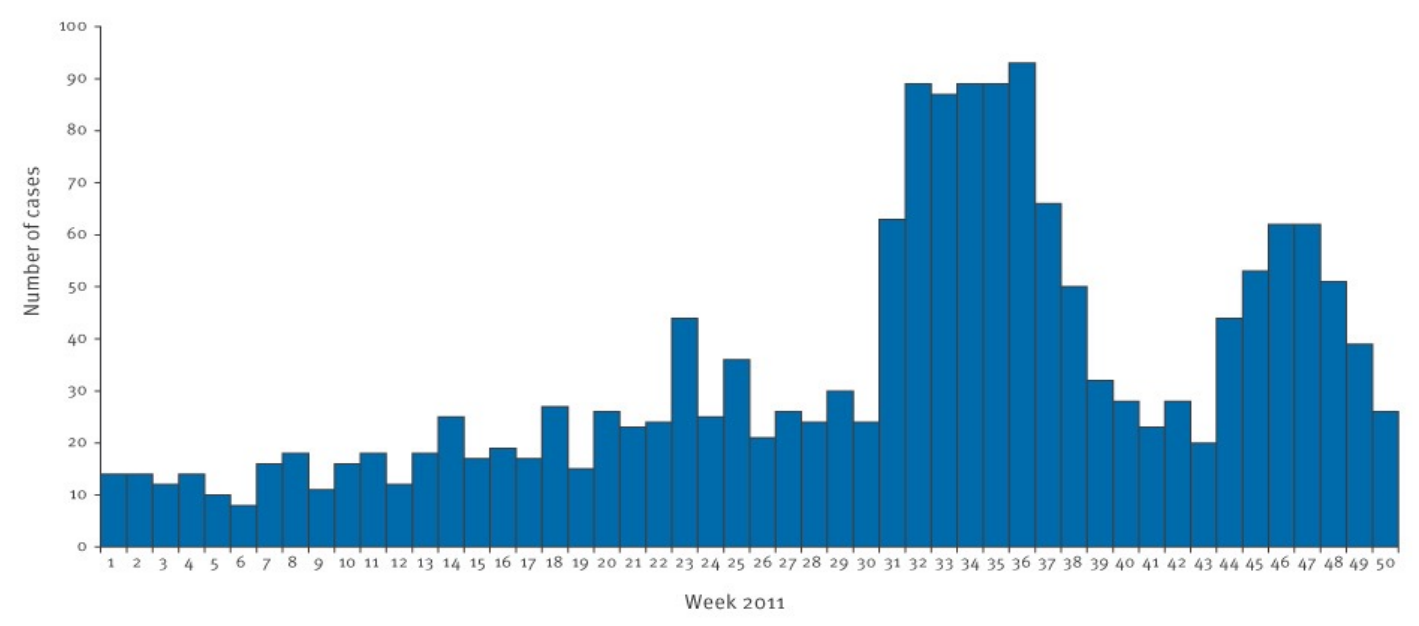

Figure 1. Salmonella enterica 4,[5],12:i:- cases reported by the National Reference Centre, by week of isolation at the primary laboratory, France, 2011 $(n=1,721)$ 


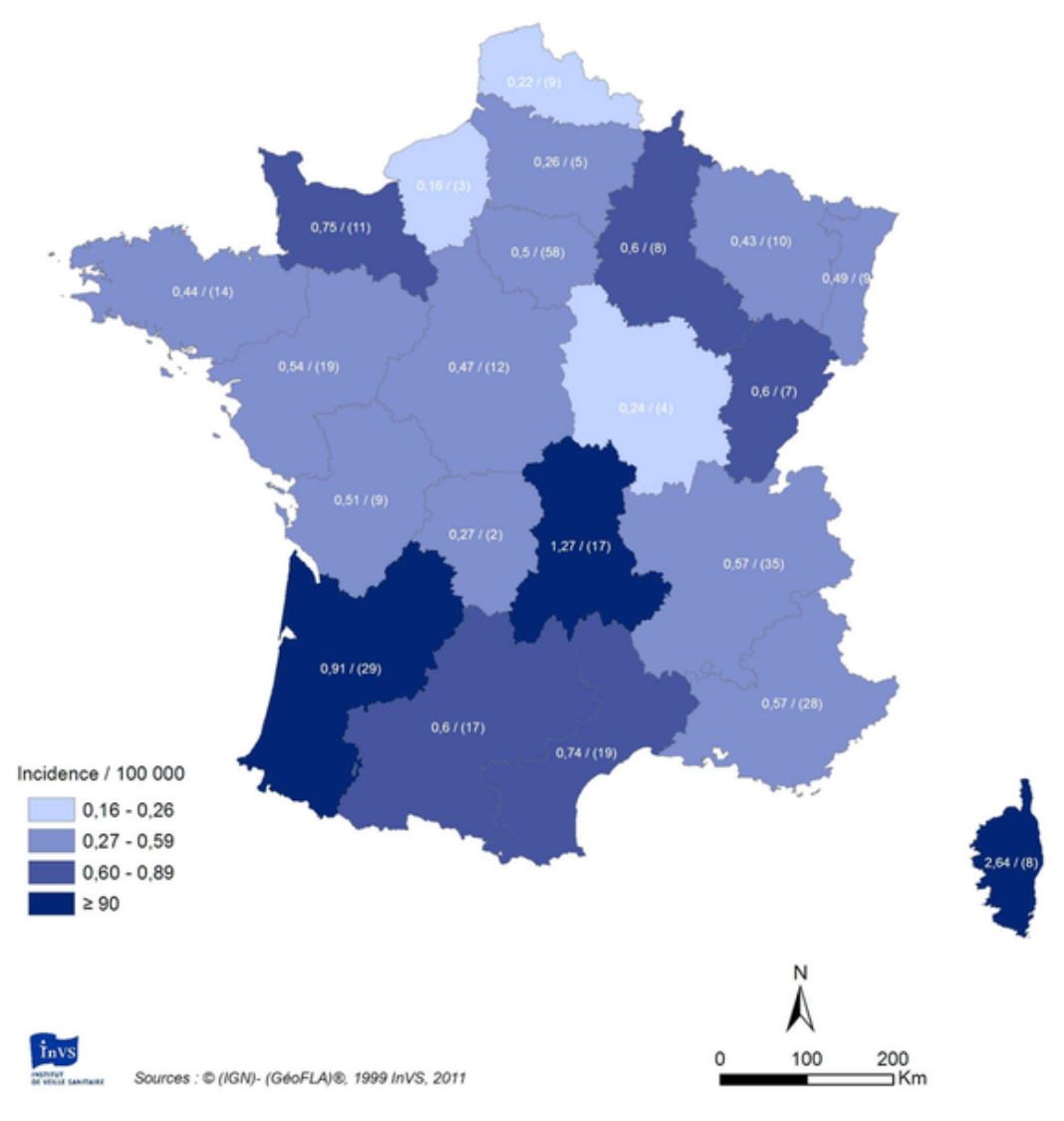

Figure 2. Incidence rate, per $\mathbf{1 0 0 , 0 0 0}$ inhabitants and per region, of Salmonella enterica 4,[5],12:i:- cases isolated by the National Reference Centre, 31 October to 18 December 2011, France $(n=337)$

An epidemic of Salmonella enterica 4,[5],12:i:- was already observed about three months prior to this outbreak. Between 1 August and 9 October, 682 cases were reported (Figure 1), of whom 100 cases were interviewed at the time but no common vehicle of infection could be identified. In comparison, 212 cases with this serotype had been isolated during the same period in 2010 .

These two consecutive outbreaks appeared in a context of emergence of monophasic variants of Salmonella Typhimurium all over Europe in humans, animals and food products [1,2]. Surveillance data from the French Agency for Food, Environmental and Occupational Health and Safety (Anses), showed that this 4,[5],12:i:- variant had been identified in multiple animal and food samples including pork and beef [3]. While this serotype was rarely identified before the mid-1990s, it is now among the most reported Salmonella serotype in the European Union [2,4-7, and personal communication, European Centre for Disease prevention and Control, 17 Jan 2011]. In France, serotype 4,[5],12:i:- ranks third among strains isolated from the pork industry (pork carcasses, pork meat and processed pork meat products ("charcuterie") in 2011.

An outbreak investigation team composed of experts from the InVS, NRC, Anses and the French Directorate General for Food (DGAL) was set up and launched simultaneously epidemiological, microbiological and food investigations to define the extend of the outbreak and identify the vehicle of transmission. 


\section{EPIDEMIOLOGICAL AND MICROBIOLOGICAL INVESTIGATIONS}

\section{Epidemiological investigation}

A case was defined as a person resident in France, who had clinical sign of Salmonella infection and for whom monophasic Salmonella enterica serotype 4,[5],12:i:- was isolated from blood, stool or urine samples after week 44, i.e from 31 October to 18 December 2011 and received at the NRC.

In the defined period, 337 cases were identified. We interviewed 90 cases (or the parents for the children) by telephone with a standardised semi-structured questionnaire. The interviews were conducted between 7 and 21 December 2011. Date of onset of these cases ranged from 25 September (week 38) to 8 December (week 49). The first 62 cases were interviewed with a trawling questionnaire covering travel history, contact with other diarrhoea cases and food consumption during the seven days prior to symptoms onset. From 14 December onwards, interviews of the 28 most recent cases were undertaken with a lighter version of the questionnaire focusing on consumption and place of purchase of pork delicatessen.

During the interviews of the first 62 cases, 53 cases (84\%) reported eating cooked ham, 45 cases (73\%) Emmental cheese, 42 cases $(68 \%)$ dried pork sausages, 42 cases (68\%) chicken, 38 cases $(60 \%)$ minced beef and 38 cases $(60 \%)$ eggs. Dried pork sausages were the only food item that appeared to have been consumed more frequently than expected. We compared this proportion with the consumption of controls who were interviewed during a case control study on the risk factors for Campylobacter infection: $46 \%$ of the controls had consumed such products (week 44 to $51, \mathrm{n}=53, \mathrm{p}<10-3[8])$.

In total, 87 of 90 of the cases reported eating pork delicatessen and the most common items consumed were cooked ham ( 74 cases, $82 \%$ ) and dried pork sausage (58 cases, $65 \%)$. In addition, 42 interviewed cases (47\%) reported buying pork delicatessen at supermarket chain $\mathrm{A}$, and 18 cases $(22 \%), 16$ cases $(18 \%)$, and $14(16 \%)$ at supermarket chain $\mathrm{B}, \mathrm{C}$ and $\mathrm{D}$, respectively. These results are not exclusive as about $33 \%$ of the supermarket chain B's clients are also clients of supermarket chain A.

Health authorities of the European Union were first alerted on the 9 December and regularly updated through the Epidemic Intelligence Information System and the Early Warning Response System (EWRS) of the European Centre of Disease Prevention and Control (ECDC). As of 16 January 2012, no other European country has reported an excess of Salmonella enterica serotype 4,[5],12:i:- in November and December 2011.

\section{Microbiological investigation}

The NRC performed subtyping on a selection of 129 monophasic variants with serotype 4,[5],12:i:- isolated from cases between 2 November and 5 December 2011.

PulseNet-standardised XbaI pulsed-field gel electrophoresis (PFGE) [9] multilocus variable number of tandem repeats analysis (MLVA) subtyping [10] and molecular typing based on the CRISPR polymorphisms (Crispol subtyping) [11] revealed a major profile among the epidemic isolates. It was characterised by a XTYM-159 PFGE pattern (found on 12 of 13 tested strains), a 3-13-9-NA-211 MLVA profile (9 of 9 tested strains) and a Crispol type 1 ( 87 of 129 tested strains). The antibiotic resistance ASSulTe (resistance to ampicillin, streptomycin, sulphonamide and 
tetracycline) was found on all 33 tested strains. Those profiles are currently predominant in France, and it was therefore not possible to distinguish with certainty between epidemic and non-epidemic cases.

\section{FOOD INVESTIGATION AND TRACE-BACK}

\section{Loyalty cards}

Epidemiological investigations pointed to a dried pork sausage purchased principally at supermarket chain A and consumed after week 44 2011. Therefore purchases of pork delicatessen at supermarkets A and B up to four weeks prior to symptom onset were investigated by the DGAL using data recorded through supermarket loyalty cards.

Among the 90 interviewed cases, 39 provided the number of their loyalty card for supermarket chain A during the interview. For 17 cases no purchases of dried pork sausage could be found. Of the 22 cases with documented purchase of dried pork sausage, 15 had bought sausage from a French producer $\mathrm{X}$ and the remaining seven cases bought sausages of seven different brands and origins from other producers. Dried pork sausages from producer X represented less than 3\% of supermarket chain A's sales for this type of food item.

Eleven loyalty cards from supermarket chain B were collected. However, the supermarkets of chain B buy products individually rather than centrally for the whole chain, and the products are therefore not coded in the central database and cannot be traced through the loyalty card data.

\section{Investigation at producer $X$}

Forty-five lots of the pork sausage (one lot $=8,000$ sausages) had been produced between 1 September and 15 December 2011. Between 1 October and 15 December, 80 to $100 \%$ of the sausages were distributed to supermarket chain A. The remaining lots were distributed to other supermarket chains including chain B and others used by the cases.

As of 15 December, the producer's own checks on raw materials and final products as well as food inspection done during the outbreak investigation of 43 samples $(25 \mathrm{~g}$ per sausage per lot) of dried pork sausages produced between 24 August and 21 November resulted negative for Salmonella.

The sausages had been distributed nationwide in metropolitan France, the French department of La Reunion, the French overseas territories of Saint Pierre and Miquelon and French Polynesia, and also in Maurice Island. In addition, there was secondary distribution by supermarket chain A to Poland, Portugal and Slovenia.

\section{DisCUSSION}

We describe a nationwide outbreak of salmonellosis involving 337 identified cases of infection with the Salmonella enterica serotype 4,[5],12:i:- between 31 October and 18 December 2011. The investigation indicated dried pork sausage from producer $\mathrm{X}$ as being the most likely source of the outbreak. 
The incrimination of the dried sausage was supported by the following findings: Firstly, an unusually high proportion of the interviewed cases reported having eaten dried sausage. Secondly, the proportion of cases that had bought pork delicatessen in supermarket chain A was much higher than the market share of this supermarket chain among the different supermarket chains in France. Thirdly, according to loyalty card records from supermarket chain A, around $68 \%$ of the cases' purchases of sausages were sausages from producer X. However producer X's sausages represent less than $3 \%$ of the sausages market share at supermarket chain A. This discrepancy makes it likely that the vehicle of infection was dried pork sausage from producer X. Finally, the fact that more than half of the production of producer $\mathrm{X}$ is sold through supermarket chain A explains the high proportion of cases that purchased dried pork sausage at supermarket chain A.

Public health measures were implemented on 16 December 2011: The DGAL ordered a withdrawal and a recall with a press release and posters, which applied to all supermarkets distributing the incriminated sausage. As accurate identification of suspect lots was not possible, the withdrawal/recall applied to all lots put on the market between 1 October and 15 December, considering the three months of shelf life of the product. To be released on the market, newly produced lots had to pass a reinforced sampling plan and a clearance monitoring. Countries that received those sausages from producer $\mathrm{X}$ or via the supermarket chains were informed on 20 and 23 December through the Rapid Alert System for Food and Feed (RASFF).

The use of the loyalty card from supermarket chain A was important to identify the vehicle of infection and the local producer involved in this outbreak. These cards are used more and more and prove helpful in the investigation of food-related outbreaks. Nevertheless we should keep in mind that they do not necessarily reflect the consumption of cases perfectly. For instance, the card may not be used systematically, the household can purchase foods in additional shops and markets for which they have no loyalty cards, many food products are consumed outside the household and not recorded on the card, and the central database of the supermarket does not always contain data on all foods sold such as foods directly purchased by the retailers. For these reasons the data have to be interpreted together with the results from epidemiological and microbiological investigations.

That the producer and microbiological analysis did not find Salmonella does not exclude contamination. The limited number of samples and the processing of the food (especially salting and drying) reduce the likelihood of isolating the bacteria. Implementing checks earlier in the process (before salting and drying) and using additional methods of testing such as polymerase chain reaction (PCR) should be considered.

The outbreak strain was the most common genotype of Salmonella enterica serotype 4,[5],12:i:-. The low diversity of genotypes among this serotype did not allow a more specific case definition with the techniques used.

In this investigation we focused efforts on descriptive epidemiology and detailed trace-back data from loyalty cards. A case control study was not performed because such a study may have shown an association with sausage, but would not have contributed to the identification of the brand name necessary to take control measures. 


\section{Conclusion}

Considering the epidemiological investigation and trace back results suggesting a link between Salmonella enterica 4,[5],12:i:- infection and consumption of dried pork sausages from producer $\mathrm{X}$, and despite the absence of positive sampling results on the sausages, control measures including withdrawal/recall were implemented. The epidemic peak has passed and the number of cases has been at the usual level since week 522011.

Monophasic Salmonella enterica variants are becoming predominant in the European Union [2,4-7 and personal communication, European Centre for Disease prevention and Control, 17 Jan 2011] and are increasingly reported in humans, animals and food samples. This is the second described outbreak in France involving dried pork sausage, and indicates that this food item might be a likely vehicle of infection and further outbreaks in humans may be expected [12].

Given the limitations to detect Salmonella in dried sausages, the ability of the standard reference method to detect of monophasic variant strains in dried sausages is questionable. Additional methods should be explored in order to improve monitoring protocols. 


\section{REFERENCES}

1. EFSA Panel on Biological Hazards (BIOHAZ). Scientific Opinion on monitoring and assessment of the public health risk of "Salmonella Typhimuriumlike" strains. EFSA Journal. 2010;8:1826. doi:102903/jefsa20101826. Available from: http://www.efsa.europa.eu/en/efsajournal/pub/1826.htm

2. Hopkins KL, Kirchner M, Guerra B, Granier SA, Lucarelli C, Porrero MC, et al. Multiresistant Salmonella enterica serovar 4,[5],12:i:- in Europe: a new pandemic strain? Euro Surveill. 2010;15:pii=19580. Available from: http://www.eurosurveillance.org/ViewArticle.aspx?ArticleId=19580

3. Bugarel M, Granier SA, Bonin E, Vignaud ML, Roussel S, Fach P, et al. Genetic diversity in monophasic $(1,4,[5], 12: \mathrm{i}:-$ and 1,4,[5],12:-:1,2) and in non-motile $(1,4,[5], 12:-:-)$ variants of Salmonella enterica S. Typhimurium. Food Research International. 2011. doi:10.1016/j.foodres.2011.06.057

4. Dionisi AM, Graziani C, Lucarelli C, Filetici E, Villa L, Owczarek S, et al. Molecular characterization of multidrug-resistant strains of Salmonella enterica serotype Typhimurium and Monophasic variant (S. 4,[5],12:i:-) isolated from human infections in Italy. Foodborne Pathog Dis. 2009;6(6):711-7.

5. Echeita MA, Herrera S, Usera MA. Atypical, fljB-negative Salmonella enterica subsp. enterica strain of serovar 4,5,12:i:- appears to be a monophasic variant of serovar Typhimurium. J Clin Microbiol. 2001;39:2981-3.

6. Mossong J, Marques P, Ragimbeau C, Huberty-Krau P, Losch S, Meyer G, et al. Outbreaks of monophasic Salmonella enterica serovar 4,[5],12:i:- in Luxembourg, 2006. Euro Surveill. 2007;12(6):pii=719. Available from:

http://www.eurosurveillance.org/ViewArticle.aspx?ArticleId=719

7. Switt AI, Soyer Y, Warnick LD, Wiedmann M. Emergence, distribution, and molecular and phenotypic characteristics of Salmonella enterica serotype 4,5,12:i. Foodborne Pathog Dis. 2009;6:407-15.

8. Gallay A, Bousquet V, Siret V, Prouzet-Mauleon V, Valk H, Vaillant V, et al. Risk factors for acquiring sporadic Campylobacter infection in France: results from a national case-control study. J Infect Dis. 2008;197:1477-84.

9. Hunter SB, Vauterin P, Lambert-Fair MA, Van Duyne MS, Kubota K, Graves L, et al. Establishment of a universal size standard strain for use with the PulseNet standardized pulsed-field gel electrophoresis protocols: converting the national databases to the new size standard. J Clin Microbiol. 2005;43:1045-50.

10. Larsson JT, Torpdahl M, Petersen RF, Sorensen G, Lindstedt BA, Nielsen EM. Development of a new nomenclature for Salmonella typhimurium multilocus variable number of tandem repeats analysis (MLVA). Euro Surveill. 2009;14:pii=19174. Available from:

http://www.eurosurveillance.org/ViewArticle.aspx?ArticleId=19174

11. Wattiau P, Boland C, Bertrand S. Methodologies for Salmonella enterica subsp. enterica subtyping: gold standards and alternatives. Appl Environ Microbiol. 2011;77:7877-85.

12. Bone A, Noel H, Le Hello S, Pihier N, Danan C, Raguenaud ME, et al. Nationwide outbreak of Salmonella enterica serotype 4,12:i:- infections in France, linked to dried pork sausage, March-May 2010. Euro Surveill. 
2010;15(24):pii=19592. Available

from: http://www.eurosurveillance.org/ViewArticle.aspx?ArticleId=19592 


\section{Chapter 6}

MULTI-COUNTRY OUTBREAKS OF Hepatitis A VIRUS INFECTION IN THE EUROPEAN UNION, 2013 


\title{
THREE SIMULTANEOUS, FOOD-BORNE, MULTI-COUNTRY OUTBREAKS OF HEPATITIS A VIRUS INFECTION REPORTED IN EPIS-FWD IN 2013: WHAT DOES IT MEAN FOR THE EUROPEAN UNION?
}

\author{
Euro Surveill. 2014;19(43):pii=20941. Available online: \\ http://www.eurosurveillance.org/ViewArticle.aspx?ArticleId=20941
}

Céline M. Gossner, Ettore Severi

Between March and May 2013, three multi-country outbreaks of hepatitis A virus (HAV) infection were reported through the Epidemic Intelligence Information System for Food- and Water-borne diseases (EPIS-FWD) of the European Centre for Disease Prevention and Control (ECDC). The aim of this work is to put these outbreaks into a European Union (EU) and European Economic Area (EEA) perspective and highlight opportunities for improving detection and investigation of such outbreaks. Although HAV outbreaks are not unusual in the EU/EEA, having three large food-borne multicountry outbreaks declared within three months is an unexpected event, particularly when at least two of these outbreaks are associated with frozen berries. Factors influencing the occurrence of these events include the increased number of susceptible Europeans, the limited coverage of HAV vaccination, the global trade of potentially contaminated products introduced in the EU/EEA, and the 'awareness chain effect' leading to a wave of notifications. Further studies should be conducted to understand the risk posed by frozen berries. Laboratory capacity and surveillance of viral infections in the EU/EEA, as well as HAV vaccination recommendations to travellers to endemic countries should be strengthened. Finally, timely reporting foodborne events through EPIS-FWD, to ensure timely response. 


\section{SURVEILLANCE AND EARLY WARNING FOR HEPATITIS A VIRUS INFECTION IN THE EUROPEAN UNION AND COUNTRIES OF THE European Economic Area}

Hepatitis A is a self-limiting viral disease caused by hepatitis A virus (HAV). HAV has low to very low endemicity in northern and western Europe and intermediate to low endemicity in eastern and southern Europe [1]. Infection takes place mainly via the faecal-oral route through person-to-person contact but food- and waterborne transmission is also common. Groups at increased risk for HAV infection include travellers to endemic areas, men who have sex with men, people who inject drugs, recipients of blood and blood product and close contacts of infected individuals [1].

Hepatitis A is a notifiable disease at the European Union (EU)/European Economic Area (EEA) level. In 2011, the overall annual disease incidence in EU/EEA was 3 per 100,000 inhabitants; of 28 countries for which incidence is available, 19 reported HAV incidence below one per 100,000 inhabitants and three reported more than ten per 100,000 inhabitants, the highest incidence being 74 per 100,000 inhabitants in Bulgaria [2]. Cases are usually confirmed through serological analysis. Only a few EU countries perform routine molecular characterisation of the viral isolates of the cases. Timely collection and analysis of surveillance information is essential to monitor hepatitis A trends over time and early detect increases in disease incidence. Molecular characterisation of the collected HAV isolates is then helpful to understand whether reported cases are linked. While EU/EEA countries report individual cases of HAV infection on an annual basis to The European Surveillance System (TESSy) of the European Centre for Disease Prevention and Control (ECDC), outbreaks with a potential international dimension are reported in real time through ECDC Epidemic Intelligence Information System for Food- and Water-borne Diseases [3]. EPIS-FWD was established in March 2010 and is a communication platform for early detection and assessment of food- and waterborne threats with potential international dimension. The system gathers epidemiologists and microbiologists from all EU/EEA countries, plus Australia, Canada, Japan, New Zealand, South Africa, Switzerland, Turkey and the United States. In 2010 and 2011, three outbreaks of HAV infections were reported via EPIS-FWD. Two of these outbreaks, involving Australia, France, the Netherlands and the United Kingdom, were due to the consumption of semi-dried tomatoes [4-6]; the source of infection of the third outbreak in Estonia was not identified, but a food-borne origin was suspected. No HAV outbreak was reported in EPIS-FWD in 2012.

Between March and May 2013, three multi-country outbreaks of hepatitis A virus infection were reported through EPIS-FWD. Prompt analysis of surveillance information and timely reports triggered rapid and coordinated response among affected countries and ECDC.

The aim of this work is to put these recent outbreaks into a EU perspective and highlight opportunities for improving detection and investigation of future multinational HAV outbreaks. 
Table. Description of the food-borne multi-country hepatitis A outbreaks in the European Union/European Economic Area in 2013

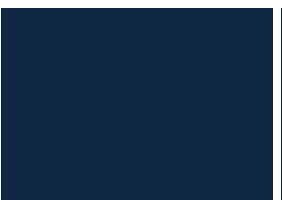

1 March 2013

Denmark reports a

national outbreak in

EPIS-FWD

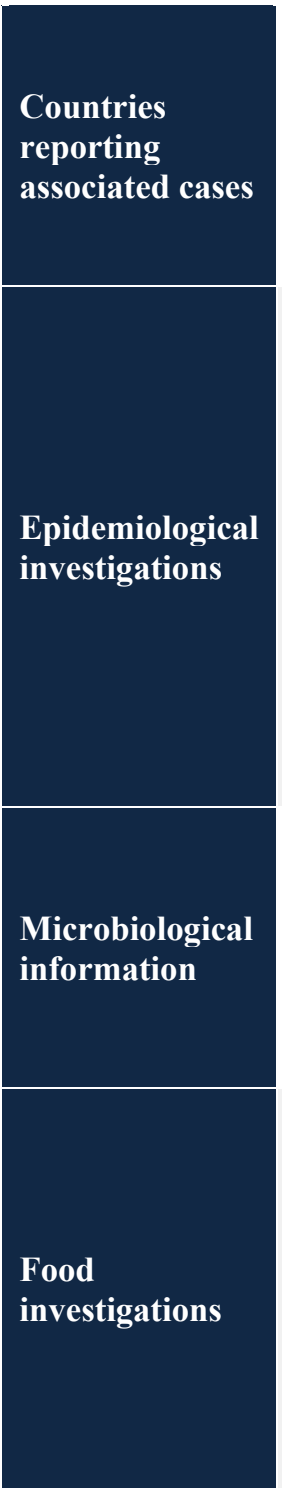

As of 6 August 2013, there were 106 cases reported since 1

October 2012.

$61 \%$ female, median age 23 years old.

Trawling

questionnaires and

case control studies in

affected countries

pointed towards

frozen strawberries as

vehicle of infection.

Subgenotype 1B.

Two RNA sequences

(sequence 1 and sequence 2) which differed by $1.7 \%$ over 847 bp.

Trace-back analysis pointing to strawberries from Egypt and Morocco. No food sample was positive.

One RASFF

notification issued.

\section{April 2013}

Norway reports an

outbreak in travellers

returning from Egypt in

EPIS-FWD

Denmark, Estonia,

Finland, France, Germany,

Ireland, Latvia, Lithuania,

Norway, Slovakia,

Sweden, Switzerland, the

Netherlands and the United

Kingdom

As of 20 August 2013, there were 107 cases reported since 1 November 2012.

$50 \%$ female, median age 36 years old.

Trawling questionnaire and case control study in affected countries pointed to foodborne transmission. Strawberries were suspected among other fruits.

Subgenotype 1B.

One RNA sequence which differed by $1.22 \%$ over 1,233 bp and by $1.26 \%$ over $397 \mathrm{bp}$ from sequence 1 and 2 of the Nordic countries outbreak.

No information available about possible food investigations in Egypt.

\section{May 2013}

Germany reports an outbreak in travellers returning from Italy in EPIS-FWD

Italy, Ireland, Germany, the Netherlands and Poland

As of 27 July, there were more than 200 reported cases in 2013, the majority in Italy.

Trawling questionnaire and case-control study in the affected countries pointed towards frozen mixed berries.

Subgenotype 1A.

One RNA sequence.
HAV isolated in frozen mix berries of various origins, mostly from Eastern European countries. One isolate from the food samples had an identical sequence to the outbreak strain.

Eleven RASFF

notifications issues.

EPIS-FWD: Epidemic Intelligence Information System for Food-and Water-borne diseases; RASFF: Rapid Alert System for Food and Feed

The three outbreaks of HAV infection reported on EPIS-FWD between March and May 2013 involved over 400 cases from 15 EU/EEA countries and Switzerland. The first outbreak was initially reported by Denmark on 1 March, with cases subsequently reported by Finland, Norway and Sweden. As of 6 August, 106 cases had been reported by the four Nordic countries of Denmark, Sweden, Norway and Finland [7]. Two closely related strains with subgenotype IB were associated to this outbreak [8]. Epidemiological investigations, including case interviews and case control study, and 
purchase history investigations pointed towards frozen strawberries from Egypt and Morocco as the most likely source of infection [9,10]. Although strawberries are not botanical berries, they are treated as berries in this article. Despite extensive food sampling and testing of frozen strawberries, no HAV could be isolated.

The second outbreak was initially notified by Norway on 17 April and subsequently an additional 13 countries reported associated cases (see Table). As of 20 August, 107 travellers returning from different locations in the Red Sea region, Egypt, were reported infected. The outbreak strain was subgenotype IB as well, but with a different sequence from the Nordic countries outbreak mentioned above. Multicountry epidemiological investigations, including case interviews and case control study, suggested that the implicated vehicle of infection was a food item distributed to different hotels in Egypt, with strawberries suspected among other fruits [11,12].

The third outbreak, reported on 8 May on EPIS-FWD, was thought to have affected about 200 Italian residents as of August 2013, although it was initially reported by Germany following identification of nine HAV infections in travellers returning from northern Italy [13]. A Dutch traveller and five Polish travellers to Italy were also part of this outbreak [14]. In addition, 21 people living in Ireland with no travel history to Italy were infected with an HAV strain with identical sequence [15]. The outbreak strain was subgenotype IA. Case interviews and a case control study in Italy, including the Dutch and Polish cases, identified imported frozen mixed berries as the vehicle of infection $[14,16]$. Subsequently, a case-control study in Ireland led to the same conclusion [15]. Isolation of HAV in frozen mixed berries in Italy led to eleven notifications through the Rapid Alert System for Food and Feed (RASFF), which is the EU notification system to exchange information on measures taken on risks related to food and feed. Berries forming the mix mentioned in the RASFF notifications originated mostly from east European countries [17]. Several isolates from the food samples had a sequence identical to the outbreak strain $[16,18]$.

\section{IS THERE A LINK BETWEEN THESE OUTBREAKS?}

The epidemiological and microbiological information available suggests no direct link between these simultaneous HAV outbreaks. All outbreaks were caused by a different persistent source of exposure: two were confirmed to be associated with the consumption of berries, while strawberries were one of the suspected vehicles of infection in the third outbreak. In the Nordic countries outbreak, having two closely related sequences co-circulating may suggest an environmental contamination of the berries, most likely through sewage water [19,20], or that the berries have geographically close origins.

Three of the outbreaks strains belong to subgenotype IB (two from the Nordic countries outbreak, one from cases with travel history to Egypt). The fourth outbreak strain, associated with berries in Italy, belongs to subgenotype IA, which excludes any link between the Italian outbreak and the other two outbreaks. Based on overlapping RNA fragments in the VP1 2A region, it was established that the three subgenotype IB sequences differed from each other by less than $2 \%$ [8]. Considering that the rate of mutation of the HAV RNA sequence is low [21], a 2\% difference between sequences is a marker of a relatively long phylogenetic evolution. This suggests that it is unlikely that it would be one strain that would have rapidly mutated and spread but 
rather that the strains involved in the two IB subgenotype outbreaks would have a common geographical origin.

\section{IS THIS SITUATION UNUSUAL OR UNEXPECTED?}

Having three multi-country outbreaks declared within three months is an unexpected situation. Several HAV outbreaks in European travellers returning from HAV endemic countries such as Egypt were described in the past decade [22,23]. Foodborne HAV outbreaks due to the consumption of fruit including berries have previously been reported. Such outbreaks have involved vehicles like raspberries [24], strawberries [25], blueberries [26] and semi-dried tomatoes [4]. Also the simultaneous occurrence of HAV outbreaks in the EU has been previously observed, as in 2008 when three outbreaks in the Czech Republic, Latvia and Slovakia occurred. However, for these later outbreaks, transmission was mostly human-to-human [27].

Several factors have most likely drove toward this peculiar situation: first, the decreased incidence of HAV infections in the past decade, coupled with the fact that HAV was not included in the vaccination schedule of most of the countries of the EU/EEA, led to an increase in the number of susceptible European citizens, leaving the opportunity for large outbreaks to occur [1]; second, the limited coverage of HAV vaccination among European travellers to HAV endemic countries, particularly when staying in all-inclusive resorts [22,28], together with the increase in the number of travellers [29], explains the pool of cases among travellers to endemic areas; third, the large amount of fruit and vegetables and other food items imported into the EU and their extensive redistribution within the EU [30] may facilitate the introduction of HAV-contaminated products, leading to multi-country outbreaks. Contamination of the berries early in the food production chain seems most likely for the outbreaks in the Nordic countries and in Italy, allowing wide distribution of the contaminated fruit. Several pathways of contamination of berries can be suggested: irrigation with faecally-contaminated water prior to harvesting, infected field workers during the harvest or processing at the factory, and spraying with contaminated water before distribution [31].

Since the first RASFF notification in 1979, and as of 15 September 2013, over 37,100 notifications have been issued, and in the past five years, there has been an average of 3,400 notifications per year. So far, 35 notifications related to food-borne viruses and berries have been issued, which represents 7.4\% (35/474) of the notifications related to pathogenic microorganisms in fruits and vegetables. Both notifications related to berries contaminated with food-borne viruses and notifications of food-borne virus outbreaks implicating berries have increased in recent years. Thirty-nine notifications related to berries, of which $30(77 \%)$ were reported since 2009 and twelve (31\%) between 1 January and 15 September 2013. The most frequently reported pathogenic microorganism in berries was norovirus (23 notifications, 59\%) and HAV (nine notifications, 23\%). All nine HAV notifications in berries are since November 2012, which suggests that more berries have been found to be contaminated recently than in previous years. In addition, there were 30 notifications about food items contaminated with HAV, of which 16 (53\%) were made between 1 January 2012 and 15 September 2013. While notifications before 2012 on HAV findings in food and HAV outbreaks were mostly related to crustaceans and bivalve molluscs (10/14), since January 2012, the majority of HAV notifications have been related to fruit and vegetables (12/16), among which $9 / 12$ are berries. This may indicate that fruit and vegetables, particularly 
berries, have become more frequently contaminated in the recent years. It should be emphasised that these could also be an effect of increased frequency of samplings and improvement of the sensitivity of analytical methods.

Finally, the first outbreak in the Nordic countries, initially reported by Denmark, may have indirectly facilitated the reporting of the following two outbreaks. In fact, the investigation of the Nordic countries outbreak may have encouraged Norway to increase the sequencing of HAV isolates from reported cases and therefore to detect and report the second outbreak through EPIS-FWD. In the same way, these first two outbreaks may have facilitated the detection of the cases related to travel to Italy and prompted Germany to report the outbreak through EPIS-FWD. Finally, the Italian public health authorities were alerted to the travel-related cases and immediately acknowledged the occurrence of a local outbreak. In the absence of a direct link between the outbreaks, the hypothesis of an 'awareness chain effect' might explain the quasi-simultaneous notifications of these outbreaks.

\section{AVENUES TO PREVENT RECURRENCE OF SIMILAR HAV OUTBREAKS}

The outbreaks described have shown that frozen berries are efficient vehicles of HAV infection; to this extent, the risk posed by berries should be studied further. Such study could include the analysis of the pathways of berry contamination and the likelihood of being exposed to HAV-contaminated berries in the EU considering the intensive intra- and extra-EU trade of berries.

EPIS-FWD allowed the early detection of the multinational dimension of these outbreaks. The system supported the rapid exchange of information among the network's experts and easy access to up-to-date epidemiological and microbiological results. EPIS-FWD was also used as a document repository for the line listings, questionnaires and protocols, and rapid risk assessments prepared by ECDC. Although the system currently extends beyond EU/EEA borders, it is limited to very few non-EU/EEA countries. To fill the gap, the new version of EPIS-FWD, launched in July 2013, allows inviting non-network countries to participate in a discussion if the need arises, aiming to facilitate the exchange of information.

The development of molecular characterisation, and particularly RNA sequencing, has allowed the three simultaneous outbreaks to be identified and defined, and has allowed dispersed cases to be either linked or individuated within the outbreaks. ECDC and the European Commission should play a role in ensuring that adequate capacity to isolate and sequence HAV in food and human samples is available at the EU level, through promoting common protocols and sharing expertise.

The ECDC food- and waterborne toolbox for outbreak investigation [32] could be further developed beyond the standard trawling questionnaires already present to include the necessary protocols for HAV detection and sequencing.

Timely coordination of the control actions by the European Commission, including coordination of the trace-back and trace-forward activities at the EU/EEA level, is crucial during multi-country investigations. To minimise the risk of contamination of berries at farm and processing plant level, and therefore to minimise the risk of importing contaminated berries into the EU, food safety agencies and private food industries in the importing and exporting countries should work closely together, 
ensuring that best practices are applied. Good intersectoral cooperation is paramount during outbreak investigation to timely receive information about distribution of the product and eventual breaches in production practices.

These outbreaks have shown the complexity of viral epidemiology and microbiology. ECDC has initiated in 2013 the nomination of food-borne viral infections experts (microbiologists and epidemiologists) from the EU/EEA countries to contribute in providing data and expertise through TESSy and EPIS-FWD. Strong collaboration with existing international networks such as the International HAV laboratory network, HAVNET (www.havnet.nl), managed by the Dutch National Institute for Public Health and the Environment (RIVM) should be ensured.

The outbreak in travellers to Egypt also highlights the importance of vaccination in travellers to endemic areas in a time of increasing tourism to endemic destinations.

More HAV outbreaks are expected to occur in the EU. The 2013 experience demonstrates the absolute necessity for extensive collaboration between countries and between the public health and food sectors to identify as quickly as possible the vehicle of infection and, ideally, to control the outbreak in an timely fashion. 


\section{REFERENCES}

1. World Health Organization (WHO), Strategic Advisory Group of Experts (SAGE) Hepatitis A Working Group. Evidence based recommendations for use of hepatitis A vaccines in immunization services: Background paper for SAGE discussions. Geneva: WHO; 2011. Available from:

http://www.who.int/immunization/sage/1_HepABackground_170ct final2_nov11.pd $\underline{f}$

2. European Centre for Disease Prevention and Control (ECDC). Annual epidemiological report: Reporting on 2011 surveillance data and 2012 epidemic intelligence data. Stockholm: ECDC; 2013. Available from:

http://www.ecdc.europa.eu/en/publications/Publications/Annual-EpidemiologicalReport-2013.pdf

3. Gossner C. ECDC launches the second version of the EPIS-FWD platform. Euro Surveill. 2013;18(27):pii=20517.

4. Donnan EJ, Fielding JE, Gregory JE, Lalor K, Rowe S, Goldsmith P, et al. A multistate outbreak of hepatitis A associated with semidried tomatoes in Australia, 2009. Clin Infect Dis. 2012;54(6):775-81. http://dx.doi.org/10.1093/cid/cir949

5. Fournet N, Baas D, van Pelt W, Swaan C, Ober H, Isken L, et al. Another possible food-borne outbreak of hepatitis $\mathrm{A}$ in the Netherlands indicated by two closely related molecular sequences, July to October 2011. Euro Surveill. 2012;17(6). pii: 20079.

6. Gallot C, Grout L, Roque-Afonso AM, Couturier E, Carrillo-Santisteve P, Pouey J, et al. Hepatitis A associated with semidried tomatoes, France, 2010 Emerg. Infect Dis. 2011;17:566-7. http://dx.doi.org/10.3201/eid1703.101479

7. European Centre for Disease Prevention and Control (ECDC).

Epidemiological update: outbreak of hepatitis A virus infection in four Nordic countries. 6 August 2013. [Accessed 16 September 2013]. Available from:

http://www.ecdc.europa.eu/en/press/news/_layouts/forms/News_DispForm.aspx?List $=8 \mathrm{db} 7286 \mathrm{c}-\mathrm{fe} 2 \mathrm{~d}-476 \mathrm{c}-9133-$

$18 \mathrm{ff} 4 \mathrm{cb} 1 \mathrm{~b} 568 \& \mathrm{ID}=841 \&$ RootFolder $=\% 2 \mathrm{Fen} \% 2 \mathrm{Fpress} \% 2 \mathrm{Fnews} \% 2 \mathrm{FLists} \% 2 \mathrm{FNews}$ \&Source $=$ http $\% 3 \mathrm{~A} \% 2 \mathrm{~F} \% 2 \mathrm{Fwww} \% 2 \mathrm{Eecdc} \% 2$ Eeuropa $\% 2 \mathrm{Eeu} \% 2 \mathrm{Fen} \% 2 \mathrm{Fhealthtopics}$ \%2Fhepatitis_A\%2FPages\%2Findex\%2Easpx\&Web=86661a14-fb61-43e0-9663$\underline{0 \mathrm{~d} 514841605 \mathrm{~d}}$

8. Nordic outbreak investigation team. Joint analysis by the Nordic countries of a hepatitis A outbreak, October 2012 to June 2013: frozen strawberries suspected. Euro Surveill 2013;18(27):pii=20520.

9. Danish Food Agency. Jordbær fra Egypten og Marokko sandsynlig kilde til Hepatitis A. [Strawberries from Egypt and Morocco likely source of Hepatitis A]. Glostrup: Danish Food Agency; 2013. Danish. Available from: http://www.foedevarestyrelsen.dk/Nyheder/Nyheder/Arkiv 2013/Sider/Jordbær-fraEgypten-og-Marokko-sandsynlig-kilde-til-Hepatitis-A.aspx

10. Norwegian Food Safety Authority. Importerte fryste jordbær er trolig kilden til utbruddet med hepatitt A i Norden. [Imported frozen strawberries are probably the source of the outbreak of hepatitis A in the Nordic countries]. Brumunddal:

Norwegian Food Safety Authority; 2013. Norwegian. Available from: 
http://www.matportalen.no/matsmitte_og hygiene/tema/smittestoffer/importerte fryst e jordbaer_er_trolig kilden til_utbruddet_med_hepatitt_a i norden

11. Sane J, MacDonald E, Vold L, Gossner C, Severi E, on behalf of the International Outbreak Investigation Team. Multistate foodborne hepatitis A outbreak among tourists returning from Egypt- need for reinforced vaccination recommendations. Euro Surveill. Forthcoming.

12. Macdonald E, Steens A, Stene-Johansen K, Gillesberg Lassen S, Midgley S, Lawrence J, et al. Increase in hepatitis A in tourists from Denmark, England, Germany, the Netherlands, Norway and Sweden returning from Egypt, November 2012 to March 2013. Euro Surveill. 2013;18(17):20468.

13. European Centre for Disease Prevention and Control (ECDC). Weekly Communicable Threat Report (CDTR), week 30, 21-27 Jul 2013. Stockholm: ECDC; 2013. Available from:http://ecdc.europa.eu/en/publications/Publications/Communicable-diseasethreats-report-25-jul-2013.pdf

14. Rizzo C, Alfonsi V, Bruni R, Busani L, Ciccaglione AR, De Medici D, et al. Ongoing outbreak of hepatitis A in Italy: preliminary report as of 31 May 2013. Euro Surveill 2013;18(27):pii $=20518$

15. Fitzgerald M, Thornton L, O'Gorman J, O'Connor L, Garvey P, Boland M, et al. Outbreak of hepatitis A infection associated with the consumption of frozen berries, Ireland, 2013 - linked to an international outbreak. Euro Surveill. Forthcoming.

16. European Centre for Disease Prevention and Control (ECDC), European Food Safety Authority (EFSA). Rapid outbreak assessment. Update: Outbreak of hepatitis A virus infection in Italy and Ireland. 9 July2013. Available from:

http://ecdc.europa.eu/en/publications/Publications/ROA-update HAV Italy Irelandfinal.pdf

17. European Food Safety Authority, 2014. Tracing of food items in connection to the multinational hepatitis A virus outbreak in Europe. EFSA Journal 2014;12:3821. [186 pp.]

18. Montano-Remacha C1, Ricotta L, Alfonsi V, Bella A, Tosti M, Ciccaglione A, et al. Hepatitis A outbreak in Italy, 2013: a matched case-control study. Euro Surveill. 2014 Sep 18;19(37):pii=20906.

19. Gallimore CI, Pipkin C, Shrimpton H, Green AD, Pickford Y, McCartney C, et al. Detection of multiple enteric virus strains within a foodborne outbreak of gastroenteritis: an indication of the source of contamination. Epidemiol Infect. 2005 Feb;133(1):41-7. http://dx.doi.org/10.1017/S0950268804003218

20. Sanchez G, Pinto RM, Vanaclocha H, Bosch A. Molecular characterization of hepatitis a virus isolates from a transcontinental shellfish-borne outbreak. J Clin Microbiol. 2002;40(Memish ZA. 2013. MERS-CoV—eastern Mediterranean (85): animal reservoir, \#5727):4148-55.

21. Cristina J, Costa-Mattioli M. Genetic variability and molecular evolution of hepatitis A virus. Virus Res. 2007;127:151-7.

http://dx.doi.org/10.1016/j.virusres.2007.01.005 
22. Couturier E, Roque-Afonso AM, Letort MJ, Dussaix E, Vaillant V, de Valk H. Cluster of cases of hepatitis A with a travel historyto Egypt, September-November 2008, France. Euro Surveill. 2009;14:pii=19094.

23. Frank C, Walter J, Muehlen M, Jansen A, van Treeck U, Hauri AM, et al. Major outbreak of hepatitis A associated with orange juice among tourists, Egypt, 2004. Emerg Infect Dis. 2007;13(1):156-8. http://dx.doi.org/10.3201/eid1301.060487

24. Ramsay CN, Upton PA. Hepatitis A and frozen raspberries. Lancet. 1989;1(8628):43-4. http://dx.doi.org/10.1016/S0140-6736(89)91698-X

25. Hutin YJ, Pool V, Cramer EH, Nainan OV, Weth J, Williams IT, et al. A multistate, foodborne outbreak of hepatitis A. National Hepatitis A Investigation Team. N Engl J Med. 1999;340:595-602. http://dx.doi.org/10.1056/NEJM199902253400802

26. Calder L, Simmons G, Thornley C, Taylor P, Pritchard K, Greening G, et al. An outbreak of hepatitis A associated with consumption of raw blueberries.

Epidemiol Infect. 2003;131(1):745-51. http://dx.doi.org/10.1017/S0950268803008586

27. Payne L, Coulombier D. Hepatitis A in the European Union: responding to challenges related to new epidemiological patterns. Euro Surveill. 2009;14:pii=19101.

28. Leder K, Torresi J, Libman MD, Cramer JP, Castelli F, Schlagenhauf P, et al. GeoSentinel surveillance of illness in returned travelers, 2007-2011. Ann Intern Med. 2013;158(6):456-68. http://dx.doi.org/10.7326/0003-4819-158-6-201303190-00005

29. IPK International. ITB world travel trends report, December 2012/2013. Berlin: Messe Berlin GmbH; 2012. Available from: http://www.itbberlin.de/media/itbk/itbk media/itbk pdf/WTTR Report 2013 web.pdf

30. Eurostat Statistical books. External and intra-EU trade, A statistical yearbook, Data 1958 - 2010. Luxembourg: Publications Office of the European Union, 2011. Available from: http://epp.eurostat.ec.europa.eu/cache/ITY OFFPUB/KS-GI-11001/EN/KS-GI-11-001-EN.PDF

31. Bosch A, Bidawid S, Le Guyader S, Lees D, Jaykus LA. Norovirus and Hepatitis A virus in shellfish, soft fruits and water. In: Hoorfar J, editor. Rapid Detection, Identification, and Quantification of Foodborne Pathogens. Washington DC: ASM Press; 2011. Available from: http://archimer.ifremer.fr/doc/00066/17769/15285.pdf

32. European Centre for Disease Prevention and Control (ECDC). Toolkit for investigation and response to Food- and Water-borne Disease Outbreaks with an EU dimension. Stockholm: ECDC. [Accessed 13 September 2013]. Available from: http://ecdc.europa.eu/en/healthtopics/food_and_waterborne_disease/toolkit/Pages/ind $\underline{\text { ex.aspx }}$ 



\section{Chapter 7}

USING SURVEILLANCE DATA TO RESPOND TO MULTICOUNTRY OUTBREAKS OF HEPATITIS A VIRUS INFECTION IN THE EUROPEAN UNION 


\section{Changing hepatitis A epidemiology in the European UNION: NEW CHALLENGES AND OPPORTUNITIES}

Euro Surveill. 2015;20:pii=21101. Available online: http://www.eurosurveillance.org/ViewArticle.aspx?ArticleId=21101

Céline M. Gossner, Ettore Severi, Niklas Danielson, Yvan Hutin, Denis Coulombier

This perspective on hepatitis A in the European Union and European Economic Area (EU/EEA) presents epidemiological data on new cases and outbreaks and vaccination policies. Hepatitis A endemicity in the EU/EEA ranges from very low to intermediate with a decline in notification rates in recent decades. Vaccination uptake has been insufficient to compensate for the increasing number of susceptible individuals. Large outbreaks occur. Travel increases the probability of introducing the virus into susceptible populations and secondary transmission. Travel medicine services and healthcare providers should be more effective in educating travellers and travel agents regarding the risk of travel-associated hepatitis A. The European Centre for Disease Prevention and Control (ECDC) endorses the World Health Organization's recommendations on vaccination of high-risk groups in countries with low and very low endemicity and on universal vaccination in countries with intermediate endemicity. Those recommendations do not cover the use of hepatitis A vaccine to control outbreaks. ECDC together with EU/EEA countries should produce evidencebased recommendations on hepatitis A immunisation to control outbreaks. Data about risk behaviours, exposure and mortality are scarce at the EU/EEA level. EU/EEA countries should report to ECDC comprehensive epidemiological and microbiological data to identify opportunities for prevention. 


\section{Hepatitis A}

This paper is a perspective on hepatitis $\mathrm{A}$ in the European Union and European Economic Area (EU/EEA) taking account of epidemiological data on new cases and outbreaks, and on vaccination policies.

Hepatitis A is a common acute viral infection caused by hepatitis A virus (HAV) that affects 120 million people annually worldwide [1]. The virus spreads mostly through the faecal-oral route via person-to-person contact or ingestion of contaminated food or water; in rare cases, transmission can also occur via infected blood. HAV belongs to the family Picornaviridae; six genotypes have been identified, with subtypes A and B of genotypes I, II, and III infecting humans [2].

Young children often have asymptomatic HAV infection. The proportion of symptomatic infection and severe disease increases with age. The incubation period is 30 days ranging from 15 to 50 days. Symptoms include fever, diarrhoea, fatigue, anorexia, nausea, dark-coloured urine and jaundice. Hepatitis A illness ranges from mild to severe and lasts from two weeks to several months. $\mathrm{Bi}$ - or multiphasic relapsing hepatitis with a duration of up to 40 weeks may complicate the course in 6 to $10 \%$ of symptomatic HAV infections [3] but recovery is complete and no chronic infections have been reported. Immunity after infection is life-long. HAV infection rarely causes fulminant hepatitis and liver failure (overall case fatality ratio: 0.1 to $0.3 \%$ ). Patients with underlying chronic liver disease and people older than 50 years have higher case fatality ratios $(1.8 \%)$ [4].

HAV survives in the environment and resists many common food preservation methods including drying or freezing [5]. Hence, food can be a vehicle of HAV transmission. Contamination with HAV early in the production chain of commercial food products can result in large, prolonged and geographically dispersed outbreaks $[6,7]$.

\section{GeOGRAPHICAL DistribUTiON}

The annual risk of infection with HAV is associated with indicators of socioeconomic development, hygiene and access to safe water. Because few countries report notification rates, the World Health Organization (WHO) estimates the level of endemicity based on the age-specific seroprevalence estimates of HAV antibodies in the population. Seroprevalence varies widely among countries [1]. In areas with high endemicity (e.g. Sub-Saharan Africa and parts of South-East Asia) at least $90 \%$ of people have antibodies against HAV by age 10 years. Outbreaks are rarely reported from these areas because most children have asymptomatic infections and the majority of adults are immune. Areas of intermediate endemicity are defined as those with at least $50 \%$ seroprevalence by age 15 years, with less than $90 \%$ by age 10 years, and include southern and eastern parts of the European Union (EU), China, Latin America, northern Africa, the Middle East and Russia. In these areas, a larger proportion of the population reaches adulthood uninfected, leading to higher susceptibility in older age groups and recurrent outbreaks of symptomatic disease. Finally, in areas with low endemicity (seroprevalence of at least $50 \%$ by age 30 years and less than $50 \%$ by age 15 ) and very low endemicity (less than $50 \%$ seroprevalence by age 30 years) such as western and northern parts of the EU and European Economic Area (EEA), Australia, Canada, Japan, and the United States (US), virus 
circulation is limited and the proportion of susceptible individuals is large in all age groups.

\section{EPidemiology of hepatitis A In THE EU/EEA}

The notification rate in the EU/EEA has fallen between 1997 and 2011, from 10.0 to 2.5 per 100,000 population [8,9]. In 2011, of the 28 EU/EEA countries reporting to The European Surveillance System (TESSy), 21 reported notification rates of up to one per 100,000 population while four central and eastern EU Member States reported notification rates above three per 100,000 population (Figure 1). Male cases accounted for $56 \%$. Children aged five to 14 years were most affected and there was a peak in reported cases in September and October as people returned from holidays and family visits in endemic countries [9-11]. Most countries that report cases to TESSy do not include information about risk behaviour and exposure, preventing analysis on risk factors. From 2005 to 2012, the reported proportion of cases infected abroad ranged from 49 to $80 \%$ in Sweden (average: 65\%) [12] and was estimated at $37 \%$ in Germany and 36\% in France in the same time period [13,14]. In France, 50\% of hepatitis A cases resulted from secondary transmission from a primary case: $80 \%$ of these occurred through a household contact [14]. Case reports to TESSy do not consistently include outcome information which makes it impossible to monitor case fatality ratios or the proportion of cases with complications.

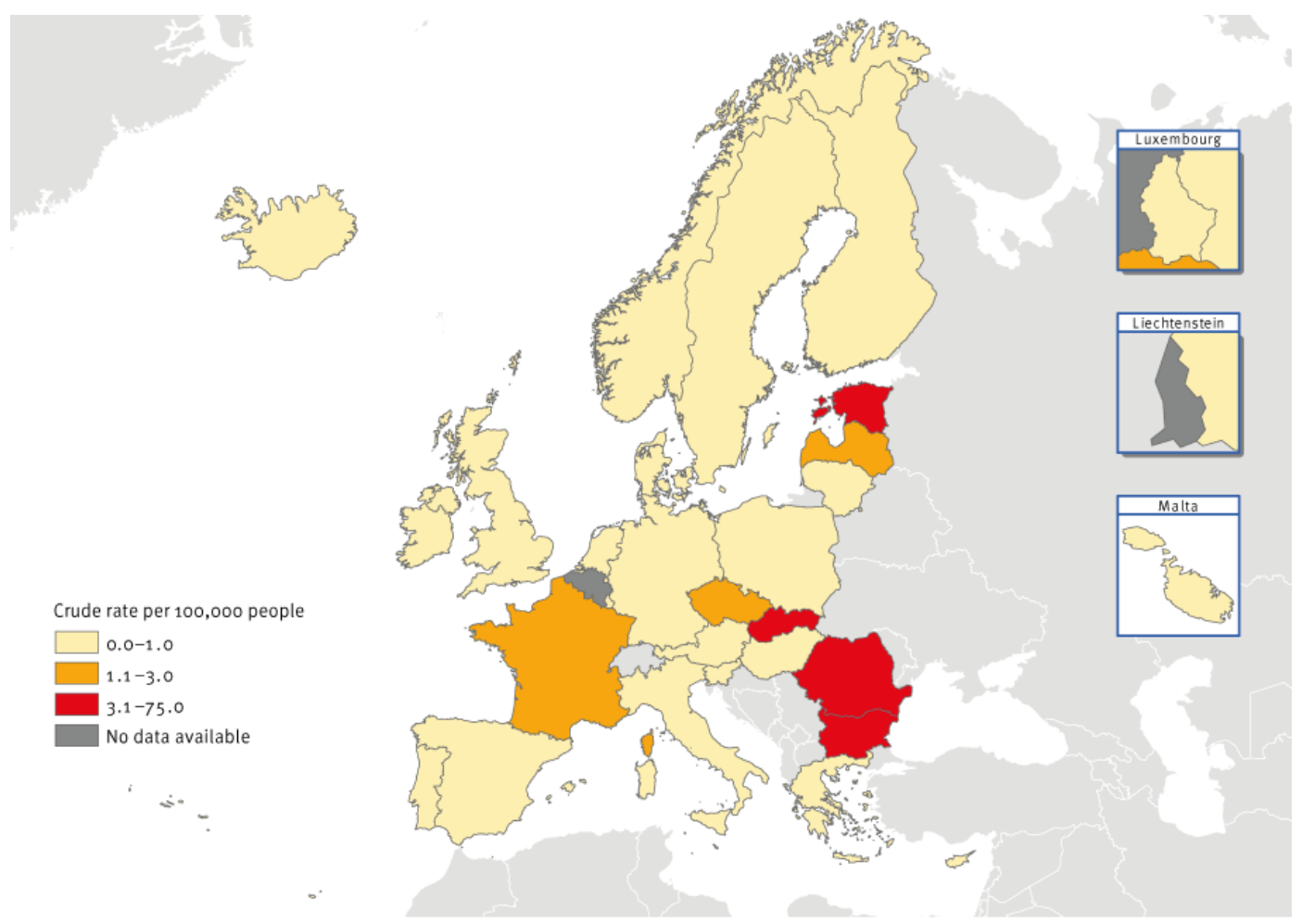

Figure 1. Distribution of hepatitis A crude notification rates in the EU/EEA countries, 2011

EEA: European Economic Area; EU: European Union. 


\section{RISK GROUPS AND VACCINATION IN THE EU/EEA}

Susceptible individuals from the EU/EEA countries at higher risk of exposure to HAV include travellers to areas of high endemicity, people visiting friends and family in high endemicity areas, expatriates living in these areas, marginalised groups living under poor sanitary conditions, people who inject drugs, men who have sex with men [1] and, very rarely, recipients of blood and blood products [15]. The number of travellers from the EU/EEA to destinations with high hepatitis A endemicity is increasing. As a result, those destinations may appear less exotic and individuals may be less prone to consult travel medicine clinics before departure.

Inactivated hepatitis A vaccines are safe and effective for both pre- and post-exposure prophylaxis [16]. The WHO recommends routine childhood vaccination in countries with intermediate endemicity, including southern and eastern EU countries, but not in high endemicity countries. In western and northern EU/EEA countries, where endemicity ranges from low to very low, the WHO recommendation is to vaccinate only high-risk groups [1]. Some EU countries with intermediate endemicity recommend universal vaccination at the national level (e.g. Greece since 2008 [17]) or at the regional level (e.g. Catalonia, Spain [18] or Apulia, Italy [19] since 1998). Most EU/EEA countries have issued recommendations at least for some risk groups (Figure 2) but those are not necessarily associated with programmes, budgeted resources and coverage monitoring [20,21]. An economic evaluation conducted in the US estimated that the universal hepatitis A vaccination for children implemented in 2006 in the US led to herd immunity and has been a cost saving intervention for the first three years after introduction and cost-neutral over the first 10 years of the programme [22]. Information campaigns and increased access through removal of financial barriers can increase uptake in the EU/EEA countries. For example, Denmark and Norway provide hepatitis A vaccine free of charge to people with chronic liver diseases and people who inject drugs [17]. The WHO does not provide recommendations on the use of hepatitis A vaccination for outbreak control: although immunisation has been reported to be effective in controlling outbreaks in small communities, there is still lack of evidence on the wide-spread use of vaccination to control large outbreaks [1]. 


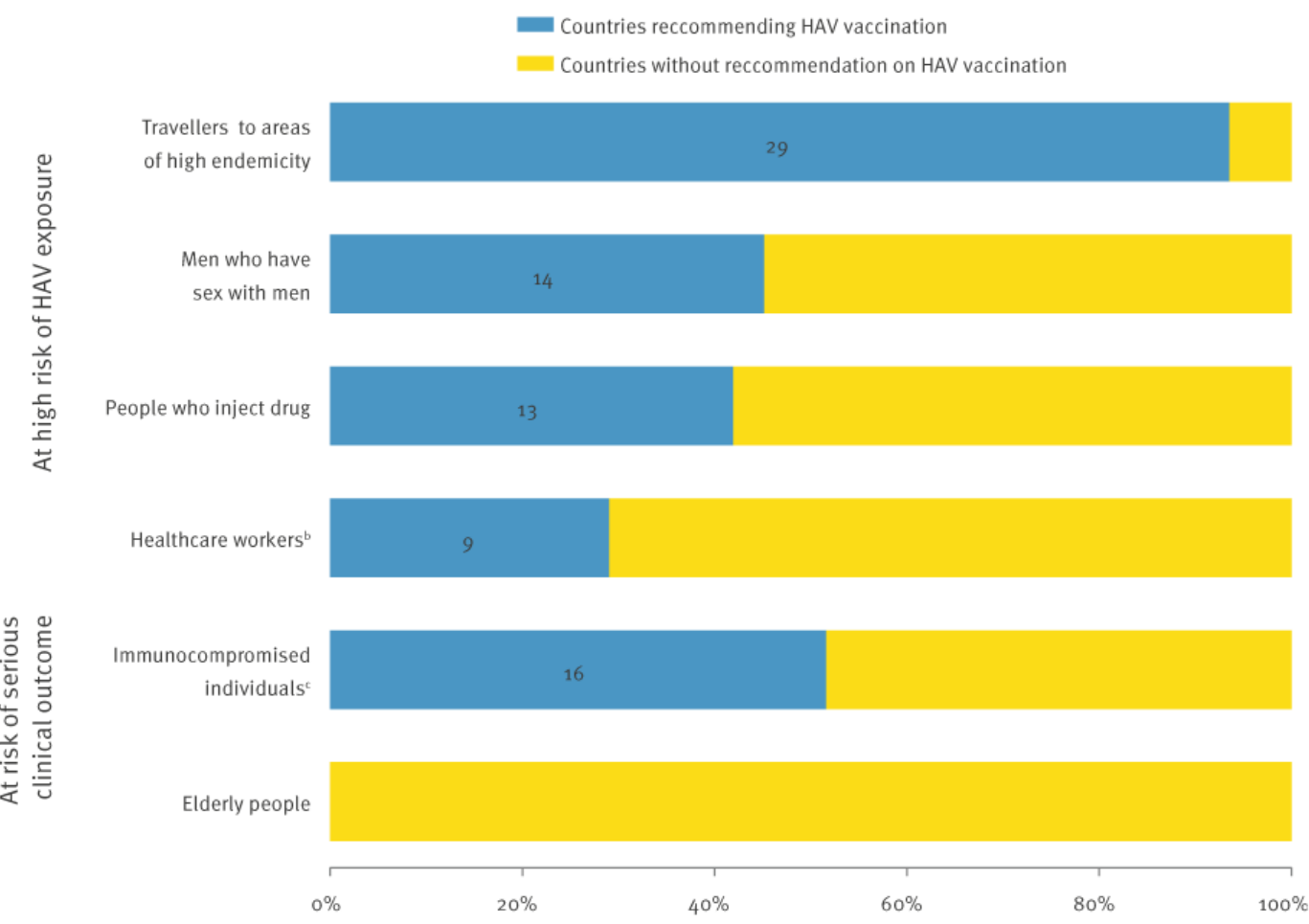

Figure 2. EU/EEA countries recommending hepatitis A virus vaccination to groups defined by the WHO as at high risk for exposure or at risk of serious clinical outcome, $2013\left(n=30^{a}\right)$

EEA: European Economic Area; EU: European Union; HAV: hepatitis A virus; HIV: human immunodeficiency virus; WHO: World Health

Organization.

${ }^{a}$ Data from Cyprus were not available.

${ }^{b}$ Some countries recommend $H A V$ vaccination only for specific groups of healthcare workers (e.g. laboratory staff).

${ }^{c}$ Countries recommending HAV vaccination to HIV patients and/or chronic liver disease patients have been included in this category.

Source: Epidemic Intelligence Information System for Vaccine Preventable Diseases, websites of National Public Health Institutes and Ministries of Health in the European Union and European Economic Area.

\section{OUTBREAKS IN THE EU/EEA IN THE PAST DECADE}

Several hepatitis A outbreaks have been reported in the EU/EEA in the past decade. Some have affected high risk groups while others have spread in the general population. We divided the outbreaks in three groups, depending on the mode and setting of infection.

Travel-related outbreaks were defined as those affecting EU/EEA residents while abroad, regardless of the mode of transmission. From November 2012 to June 2013, over 100 travellers to Egypt from 14 EU/EFTA countries were infected with HAV of 
sub-genotype IB [23,24]. Similar outbreaks among European travellers to Egypt were reported in 2004 [25] and 2008 [21]. For all these outbreaks, a food- and/or waterborne transmission was plausible.

Community-wide outbreaks were defined as those for which the primary mode of transmission was person-to-person contact, including among people who use drugs. These outbreaks often start within high-risk groups and later spread to the general community (e.g. in Latvia in 2008 [26]). Also religious groups, migrants and ethnic minorities have been affected (e.g. the Orthodox Jewish community in London 2011 [27]).

Food-borne outbreaks were defined as those for which consumption of contaminated food in the EU/EEA was the primary vehicle of infection. From 2009 to 2011, three clusters of HAV infection with sub-genotype IB in France, the Netherlands and the United Kingdom were associated with consumption of semi-dried tomatoes from Turkey $[6,7,28]$. In the first half of 2013, two different outbreaks of hepatitis A associated with consumption of frozen berries were reported, one in Denmark, Finland, Norway and Sweden (sub-genotype IB) [29] and the other in Italy and Ireland (sub-genotype IA) [30]. In several outbreaks associated with fresh food products, investigations pointed to food handlers involved in harvesting or preparation of the products as the source of contamination, for example in 2004 in Belgium [31].

\section{WHY DO WE SEE OUTBREAKS IN THE EU AND WHAT TO EXPECT IN THE FUTURE?}

The susceptible proportion of the EU/EEA population is growing fast as a result of declining HAV incidence. HAV vaccine uptake has not been high enough to compensate for the fall in natural immunity. On the one hand, as disease severity increases with the patient's age, increasing numbers of susceptible adults could potentially result in more severe disease, and eventually in higher case fatality ratios. On the other hand, the lower rates could also compensate for the higher case fatality ratios and the overall mortality might not increase or decrease.

'Seeding events', when HAV is introduced to a population with low immunity via a food- or travel-associated primary case, may lead to community transmission. However, person-to-person transmission is uncommon. In the outbreak in Denmark, Finland, Norway and Sweden in 2013, associated with consumption of frozen berries, only $10 \%$ of cases were secondary cases [29].

Self-controls by the industries and official controls by the food safety authorities are unlikely to completely prevent the importation of HAV-contaminated foods from highly endemic countries into the EU/EEA. The infective dose is presumably low [32] and it is technically challenging to detect HAV contamination in food products [33]. Because the virus is resistant to many preservation methods, contaminated preserved products (e.g. frozen fruits and dried vegetables) may remain on the market over long periods of time and result in slowly propagating multinational outbreaks in which the cases are widely dispersed in time and space.

Investigations of food-borne hepatitis A outbreaks are challenging. Cases may have difficulties remembering what they ate four weeks before onset of symptoms, and the opportunities to sample implicated food for testing are often limited. If the suspected 
vehicle is a mixed food item (e.g. mixed berries), it may be impossible to identify the contaminated ingredient.

Unvaccinated EU/EEA travellers visiting endemic countries are at risk of infection. If infected abroad, they expose their close contacts to secondary transmission after returning home. Healthcare providers and travellers underestimate the risk of hepatitis A in tourist destinations. Twenty per cent of returning travellers with hepatitis A had not been vaccinated against hepatitis A despite receiving pre-travel medical advice [34].

Better surveillance and increased international collaboration within the EU/EEA region may partially explain the increased number of multinational outbreaks reported since 2012. Increasing availability and affordability of molecular characterisation techniques has made it possible to link apparently sporadic cases and to associate them with slowly evolving multinational outbreaks. Through the pooling of epidemiological and microbiological information at the EU/EEA level, the Epidemic Intelligence Information System for Food and Waterborne Disease and for Vaccine Preventable Diseases of the European Centre for Disease Prevention and Control (ECDC) facilitate communication among disease experts in the EU/EEA countries and allow rapid identification of the multi-country dimension of reported outbreaks [35]. In linking geographically and temporarily dispersed cases, RNA sequencing techniques for HAV isolates have facilitated investigations of multicountry outbreaks. Improved surveillance in the EU/EEA may lead to the identification of more outbreaks at an earlier stage in the future.

\section{CONCLUSIONS AND RECOMMENDATIONS}

Hepatitis A notification rates have declined in the past two decades in the EU/EEA and this has resulted in a growing proportion of adults who are susceptible to HAV infection. Higher mean age at the time of infection could result in more symptomatic infection and more severe disease. Unfortunately, HAV data reports to TESSy do not include information that would allow assessing the impact of this epidemiological shift on disease severity and case fatality ratio [1]. There are gaps in the vaccination uptake among high-risk groups in low and very low endemicity countries [20,24], and among populations living in intermediate endemicity areas. In addition, international recommendations on vaccination strategies for outbreak control are lacking. Travel continues to cause imported cases and secondary transmission. Outbreaks provide valuable information on missed opportunities for prevention.

On the basis of these conclusions, we recommend improving our knowledge on the epidemiology of hepatitis A as well as prevention efforts: Firstly, ECDC should work closely with the EU Member States to ensure better reporting of cases through TESSy, including information on mode of transmission, risk behaviours and deaths. Secondly, EU/EEA countries should follow WHO recommendations and consider (i) including hepatitis A vaccination in routine childhood vaccination schedules in regions with intermediate endemicity and (ii) vaccinating individuals at high risk of infection in countries with low and very low endemicity. Thirdly, ECDC together with the EU/EEA countries should also consider examining the evidence of the effectiveness of hepatitis A vaccine use in controlling outbreaks in the EU/EEA. Fourthly, travel medicine services and healthcare providers must educate travellers and travel agents regarding the risks of travel-associated hepatitis A, emphasising that 
staying in all-inclusive luxury resorts does not protect travellers from infection because food and water might be contaminated [21-25]. Finally, Member States and ECDC should gather information from outbreaks to identify missed opportunities for prevention. Useful actions are (i) timely reporting of signals of multinational outbreaks though EPIS, (ii) prompt sharing of epidemiological and microbiological data on human and food safety, and (iii) sharing of testing protocols and interpretation frameworks for sequencing results. 


\section{REFERENCES}

1. WHO position paper on hepatitis A vaccines - June 2012. Wkly Epidemiol Rec. 2012;87:261-76. PMID:22905367

2. Desbois D, Couturier E, Mackiewicz V, Graube A, Letort MJ, Dussaix E, et al. Epidemiology and genetic characterization of hepatitis A virus genotype IIA. J Clin Microbiol. 2010;48:3306-15. http://dx.doi.org/10.1128/JCM.00667-10 PMID:20592136

3. Schiff ER. Atypical clinical manifestations of hepatitis A. Vaccine. 1992;10:S18-20. http://dx.doi.org/10.1016/0264-410X90534-Q PMID:1475999

4. Heymann DL, editor. Control of communicable diseases manual. 19th ed. Washington: American Public Health Association; 2008.

5. Baert L, Debevere J, Uyttendaele M. The efficacy of preservation methods to inactivate foodborne viruses. Int J Food Microbiol. 2009;131(2-3):83-94. http://dx.doi.org/10.1016/j.ijfoodmicro.2009.03.007 PMID:19349089

6. Fournet N, Baas D, van Pelt W, Swaan C, Ober H, Isken L, et al. Another possible food-borne outbreak of hepatitis $\mathrm{A}$ in the Netherlands indicated by two closely related molecular sequences, July to October 2011. Euro Surveill. 2012;17(6):20079. PMID:22340976

7. Petrignani M, Harms M, Verhoef L, van Hunen R, Swaan C, van Steenbergen J, et al. Update: a food-borne outbreak of hepatitis A in the Netherlands related to semi-dried tomatoes in oil, January-February 2010. Euro Surveill.

2010;15(20):19572. PMID:20504389

8. European Centre for Disease Prevention and Control (ECDC). Annual epidemiological report on communicable diseases in Europe. Report on the status of communicable diseases in the EU and EEA/EFTA countries. Stockholm: ECDC; 2007.Available from:

http://ecdc.europa.eu/en/publications/Publications/0706_SUR_Annual_Epidemiologic al_Report_2007.pdf

9. European Centre for Disease Prevention and Control (ECDC). Annual epidemiological report 2013. Reporting on 2011 surveillance data and 2012 epidemic intelligence data. Stockholm: ECDC; 2013. Available from:

http://www.ecdc.europa.eu/en/publications/Publications/Annual-EpidemiologicalReport-2013.pdf

10. Sane J, de Sousa R, van Pelt W, Petrignani M, Verhoef L, Koopmans M. Risk of hepatitis A decreased among Dutch travelers to endemic regions in 2003 to 2011. J Travel Med. 2014. [Epub ahead of print].

11. Tjon G, Xiridou M, Coutinho R, Bruisten S. Different transmission patterns of hepatitis A virus for two main risk groups as evidenced by molecular cluster analysis. J Med Virol. 2007;79(5):488-94. http://dx.doi.org/10.1002/jmv.20821 PMID:17385681

12. Public Health Agency of Sweden. Hepatit A. [Hepatitis A]. Solna: Folkhälsomyndigheten. [Accessed: 25 Mar 2013]. Swedish. Available from: http://www.folkhalsomyndigheten.se/amnesomraden/statistik-ochundersokningar/sjukdomsstatistik/hepatit-a/ 
13. Robert Koch Institute (RKI). Infektionsepidemiologisches Jahrbuch für 2007 [Annual epidemiological report on notifiable infectious diseases for 2007]. Berlin: RKI; 2008. German. Available from:

http://www.rki.de/DE/Content/Infekt/Jahrbuch/Jahrbuch_2007.pdf? blob=publicatio $\underline{\text { nFile }}$

14. Institut de Veille Sanitaire (InVS). Hépatite A. Données épidemiologiques 2006-2012. [Hepatitis A. Epidemiological data 2006-2012]. [Accessed: 13 Dec 2013]. French. Available from: http://www.invs.sante.fr/Dossiers-thematiques/Maladiesinfectieuses/Maladies-a-declaration-obligatoire/Hepatite-A/Donneesepidemiologiques

15. Perevoscikovs J, Lenglet A, Lucenko I, Steinerte A, Payne Hallström L, Coulombier D. Assessing the risk of a community outbreak of hepatitis A on blood safety in Latvia, 2008. Euro Surveill. 2010;15(33):19640. PMID:20739001

16. Werzberger A, Mensch B, Kuter B, Brown L, Lewis J, Sitrin R, et al. A controlled trial of a formalin-inactivated hepatitis A vaccine in healthy children. $\mathrm{N}$ Eng1 J Med. 1992;327:453-7. http://dx.doi.org/10.1056/NEJM199208133270702 PMID: 1320740

17.European Centre for Disease Prevention and Control (ECDC). Epidemic Intelligence Information System for Vaccine Preventable Diseases. Stockholm: ECDC. [Accessed: 13 Dec 2013].

18. Martínez A, Broner S, Torner N, Godoy P, Batalla J, Alvarez J, et al. Hepatitis A outbreaks in the vaccination era in Catalonia, Spain. Hum Vaccin. 2011;7(sup1) Suppl;205-10.

19. Chironna M, Prato R, Sallustio A, Martinelli D, Tafuri S, Quarto M, et al. Hepatitis A in Puglia (South Italy) after 10 years of universal vaccination: need for strict monitoring and catch-up vaccination. BMC Infect Dis. 2012;12(1):271. http://dx.doi.org/10.1186/1471-2334-12-271 PMID:23098290

20. Faber MS, Stark K, Behnke SC, Schreier E, Frank C. Epidemiology of hepatitis A virus infections, Germany, 2007-2008. Emerg Infect Dis. 2009;15:1760-8. http://dx.doi.org/10.3201/eid1511.090214 PMID:19891863

21. Couturier E, Roque-Afonso AM, Letort MJ, Dussaix E, Vaillant V, de Valk H. Cluster of cases of hepatitis A with a travel history to Egypt, September-November 2008, France. Euro Surveill. 2009;14:14. PMID:19161726

22. Armstrong GL, Billah K, Rein DB, Hicks KA, Wirth KE, Bell BP. The economics of routine childhood hepatitis A immunization in the United States: the impact of herd immunity. Pediatrics. 2007;119(1):e22-9. http://dx.doi.org/10.1542/peds.2006-1572 PMID:17200247

23. European Centre for Disease Prevention and Control (ECDC). Outbreak of hepatitis A virus infection in travellers returning from Egypt. Rapid risk assessment. Stockholm: ECDC; April 2013. Available from: http://www.ecdc.europa.eu/en/publications/Publications/RRA-Outbreak-hepatitis-Avirus-infection-travellers-returning-from-Egypt.pdf

24. Sane J, MacDonald E, Vold L, Gossner C, Severi E, Outbreak Investigation Team. Multistate foodborne hepatitis A outbreak among European tourists returning from Egypt--need for reinforced vaccination recommendations, November 2012 to 
April 2013. Euro Surveill. 2015;20:21018. http://dx.doi.org/10.2807/15607917.ES2015.20.4.21018 PMID:25655054

25. Frank C, Walter J, Muehlen M, Jansen A, van Treeck U, Hauri AM, et al. Major outbreak of hepatitis A associated with orange juice among tourists, Egypt, 2004. Emerg Infect Dis. 2007;13(1):156-8. http://dx.doi.org/10.3201/eid1301.060487 PMID: 17370535

26. Perevoscikovs J, Lucenko I, Magone S, Brila A, Curikova J, Vennema H. Community-wide outbreak of hepatitis A in Latvia in 2008 - an update. Euro Surveill. 2009; 14:19092. PMID:19161728

27. Edelstein M, Turbitt D, Balogun K, Figueroa J, Nixon G. Hepatitis A outbreak in an Orthodox Jewish community in London, July 2010. Euro Surveill. 2010;15(37):19662. PMID:20929646

28. Gallot C, Grout L, Roque-Afonso AM, Couturier E, Carrillo-Santisteve P, Pouey J, et al. Hepatitis A associated with semidried tomatoes, France, 2010. Emerg Infect Dis. 2011;17:566-7. http://dx.doi.org/10.3201/eid1703.101479 PMID:21392466

29. Nordic Outbreak Investigation Team C. Joint analysis by the Nordic countries of a hepatitis A outbreak, October 2012 to June 2013: frozen strawberries suspected. Euro Surveill. 2013;18(27):20520. http://dx.doi.org/10.2807/15607917.ES2013.18.27.20520 PMID:23870076

30. European Centre for Disease Prevention and Control (ECDC). European Food Safety Authority. Update: outbreak of hepatitis A virus infection in Italy and Ireland. Rapid outbreak assessment. Stockholm: ECDC; July 2013. Available from: http://ecdc.europa.eu/en/publications/Publications/ROA-update HAV_Italy_Irelandfinal.pdf

31. Robesyn E, De Schrijver K, Wollants E, Top G, Verbeeck J, Van Ranst M. An outbreak of hepatitis A associated with the consumption of raw beef. J Clin Virol. 2009;44:207-10. http://dx.doi.org/10.1016/j.jcv.2008.12.012 PMID:19179106

32. US Food and Drug Administration. (US FDA). Bad Bug Book: Foodborne Pathogenic Microorganisms and Natural Toxins Handbook, Hepatitis A Virus. Silver Spring: US FDA; 2014. Available from:

http://www.fda.gov/Food/FoodborneIllnessContaminants/CausesOfIllnessBadBugBo ok/ucm071294.htm

33. US Food and Drug Administration. (US FDA). BAM 26B: Detection of Hepatitis A Virus in Foods. Silver Spring: US FDA; 2015. Available from: http://www.fda.gov/Food/FoodScienceResearch/LaboratoryMethods/ucm374006.htm

34. Leder K, Torresi J, Libman MD, Cramer JP, Castelli F, Schlagenhauf P, et al.GeoSentinel Surveillance Network. GeoSentinel surveillance of illness in returned travelers, 2007-2011. Ann Intern Med. 2013;158(6):456-68.

http://dx.doi.org/10.7326/0003-4819-158-6-201303190-00005 PMID:23552375

35. Gossner CM, de Jong B, Hoebe CJPA, Coulombier D, and European Food and Waterborne Diseases Study Group. Event-based surveillance of food- and waterborne diseases in Europe: A six-year review of urgent inquiries, 2008-2013. Euro Surveill. 2015. Forthcoming. 


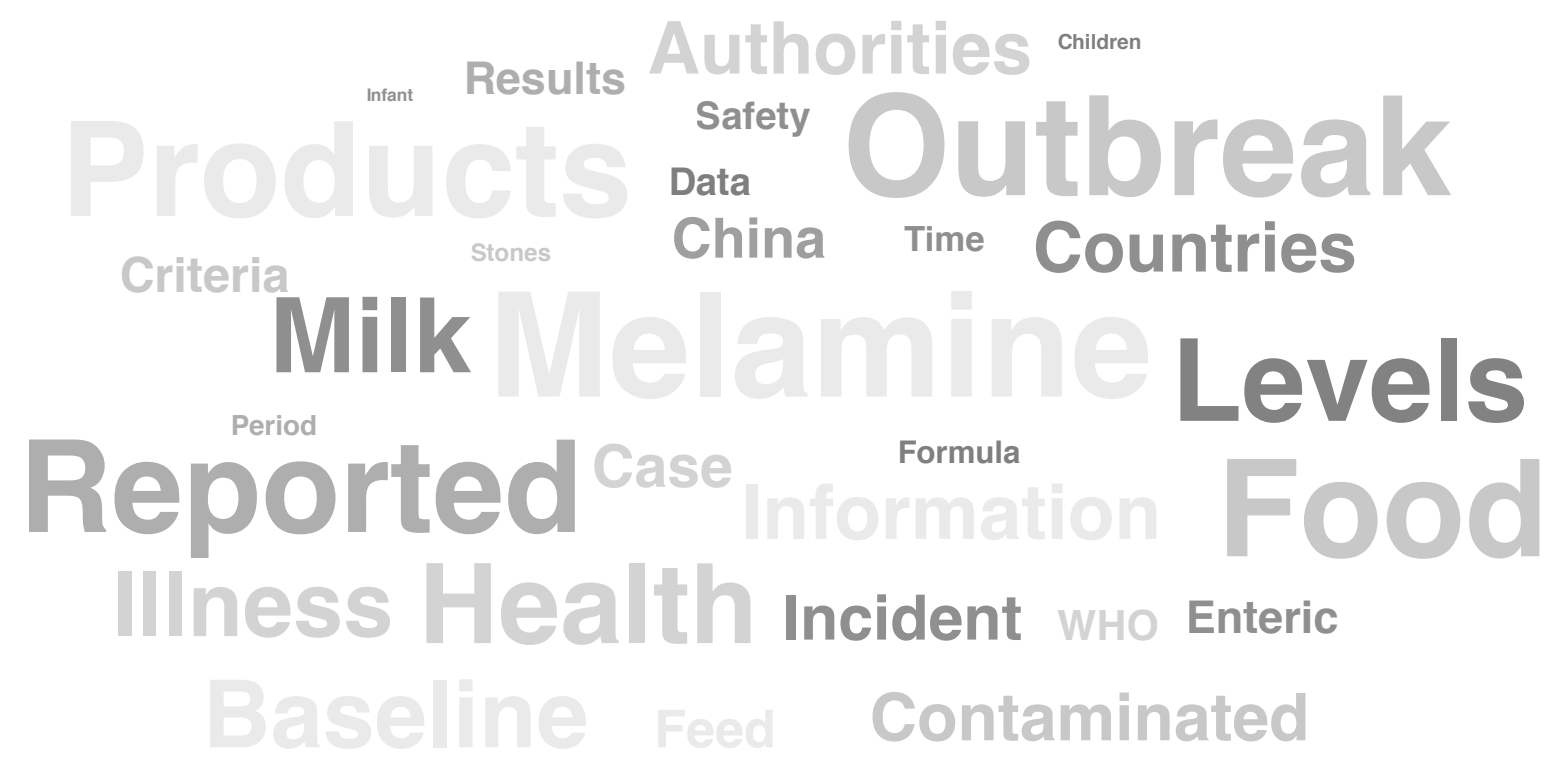

SECTION IV

DETECTION AND RESPONSE + TO FOOD- AND WATER-BORNE DISEASE OUTBREAKS BEYOND THE EUROPEAN UNION LEVEL AND CLOSURE OF QUTBREAKS 
Section IV extends the scope of outbreak detection and response beyond the EU level and provides guidance on closure of FWD outbreaks.

Using one of the largest deliberate food contamination incidents ever described, chapter 8 illustrates the complexity of international trade of food products and ingredients and how the response to such global food safety incident is coordinated by the World Health Organization.

Declaring the end of a FWD multi-country outbreak is a key step of an outbreak investigation that is unfortunately often neglected. Chapter 9 provides criteria to guide the decision to declare FWD multi-country outbreaks over. 


\section{Chapter 8}

\section{DETECTION AND RESPONSE TO FOOD- AND WATER-BORNE DISEASE OUTBREAKS WITH A WORLDWIDE SCOPE}




\section{THE MELAMINE INCIDENT: IMPLICATIONS FOR INTERNATIONAL FOOD AND FEED SAFETY}

Environ Health Perspect. 2009 Dec;117(12):1803-8. Available online: http://ehp.niehs.nih.gov/wp-content/uploads/117/12/ehp.0900949.pdf

Céline M. Gossner, Jørgen Schlundt, Peter Ben Embarek, Susan Hird, Danilo Lo-FoWong, Jose Javier Ocampo Beltran, Keng Ngee Teoh, and Angelika Tritscher

Background: A major food safety incident in China was made public in September 2008. Kidney and urinary tract effects, including kidney stones, affected about 300,000 Chinese infants and young children, with six reported deaths. Melamine had been deliberately added at milk-collecting stations to diluted raw milk ostensibly to boost its protein content. Subsequently, melamine has been detected in many milk and milk-containing products, as well as other food and feed products, which were also exported to many countries worldwide.

Objectives: The melamine event represents one of the largest deliberate food contamination incidents. We provide a description and analysis of this event to determine the global implications on food and feed safety.

Discussions: A series of factors, including the intentional character of the milk contamination, the young age of the population affected, the large number of potentially contaminated products, the global distribution of these products, and the delay in reporting led this event to take on unexpected proportions. This incident illustrated the complexity of international trade of food products and food ingredients that required immediate actions at international level.

Conclusion: Managing food safety events should be done internationally and early on as soon as multinational consequences are expected. Collaboration between food safety authorities worldwide is needed to efficiently exchange information and to enable tracking and recalling of affected products to ensure food safety and to protect public health. 
An increased incidence of kidney stones and renal failure among infants has been publicly reported in China from early September 2008 onward. The source of the illness was traced to the contamination of infant formula with melamine. Investigations showed that melamine had been deliberately added to diluted raw milk to boost its apparent protein content. Previous outbreaks of renal failure related to melamine, a molecule high in nitrogen content, have been reported in pets in 2004 in the Republic of Korea and in 2007 in the United States when the substance was added deliberately to a pet food ingredient [1]. Commonly used methods for protein analysis do not distinguish between nitrogen from protein and from nonprotein sources. Thus, the addition of melamine can lead to an incorrectly high protein reading. Because melamine is cheap and easily accessible, there is an economic incentive for its (illegal) addition.

Melamine is listed by the Organisation for Economic Co-operation and Development [2] as a high production volume chemical. The main use of melamine is in the synthesis of melamine formaldehyde resins for manufacture of laminates, plastics, coatings, commercial filters, glues and adhesives, and some dishes and kitchenware.

After acknowledging this food-contamination incident, direct communication between the Chinese Ministry of Health and the World Health Organization (WHO) led to information sharing through the WHO/Food and Agricultural Organization International Food Safety Authorities Network (INFOSAN) to countries worldwide.

\section{UNFOLding OF THE GLOBAL EVENT}

On 9 September 2008, the Shanghai Daily reported that 14 infants from Gansu Province were suffering from kidney stones after drinking a particular brand of powdered infant milk formula [3]. Although the exact onset date of illness resulting from contaminated infant formula and the beginning of the contamination itself remain unknown, it appears that companies received customer complaints about sick babies with discolored urine as early as December 2007 and that the first child died 1 May 2008 [4]. Up until 12 September 2008, the State Council of China reported 432 cases and 1 death. All the infants identified with kidney stones had consumed infant formula produced by the Sanlu Group.

Subsequently, Chinese authorities announced the seizure of $>2,000$ tons of milk powder from a Sanlu warehouse and the recall of about 9,000 tons of milk powder. A wide investigation into the extent of melamine contamination of dairy products revealed that 22 manufacturers of powdered infant formula were selling melamine-contaminated products. In the Sanlu products, melamine levels were reported to be as high as $2,563 \mathrm{mg} / \mathrm{kg}$ [5]. Two other producers of powdered infant formula reported exports to Bangladesh, Burundi, Gabon, Myanmar, and Yemen. The Agri-Food and Veterinary Authority of Singapore [6] reported the first melamine findings outside of China in Chinese milk and milk products on 17 September 2008; on 20 September, the government of Hong Kong Special Administrative Region announced that a 3year-old girl developed kidney stones after consuming contaminated milk [7].

Soon after, melamine was found in liquid milk and yogurts, frozen deserts, powdered milk and cereal products, confectionaries, cakes and biscuits, protein powders, and some processed foodstuffs. Subsequently, a variety of nondairy products originating from China were found to be contaminated with melamine. These products included 
ammonium bicarbonate [8], animal feed and animal feed ingredients [8, 9], dried whole egg, fresh hen eggs [10], and nondairy creamer [11].

\section{Levels of Contamination and Types of Products}

\section{AfFeCTED}

Over the course of the incident, different national authorities conducted laboratory tests for melamine. WHO collated analytical results obtained either from data published on official government web sites or through direct contact with national authorities via the INFOSAN network. It should be noted that not all national authorities that tested for melamine published their results or reported them to WHO; some authorities did not report positive results if the levels of contamination were below the regulatory or action limits for melamine in the country, which is most commonly $1.0 \mathrm{mg} / \mathrm{kg}$ for infant foods and $2.5 \mathrm{mg} / \mathrm{kg}$ for other food products. Hence, the data on product contamination presented here are not fully representative of the total number of products that might have been tested. It should also be noted that the results reported by the various laboratories were obtained using different analytical methods with varying limits of detection and quantification. Keeping these limitations in mind, we present the most complete collection of global data from the 2 October 2008 event to 31 January 2009 in Tables 1 and 2. Table 1 summarizes 326 individual analytical results for melamine in a variety of food products: an analysis of dairy products conducted by China's General Administration of Quality Supervision, Inspection and Quarantine as of 2 October $2008(\mathrm{n}=77)$, and the results reported by other national food-safety authorities $(n=249)$, as published on official web sites or reported directly to WHO via INFOSAN (up to 31 January 2009). Table 2 shows the total number of positive results, reported as individual results as summarized in Table 1, plus 74 results reported as ranges rather than as individual results. Overall, these results illustrate the broad range of melamine levels found in the different product categories. 
Table 1. Products positive for melamine.

\begin{tabular}{|c|c|c|c|c|c|c|c|}
\hline \multirow[b]{2}{*}{$\begin{array}{l}\text { Product } \\
\text { category }\end{array}$} & \multirow{2}{*}{$\begin{array}{l}\text { No. of } \\
\text { positive } \\
\text { products }\end{array}$} & \multicolumn{6}{|c|}{ No. of samples with different levels of melamine $(\mathrm{mg} / \mathrm{kg})$} \\
\hline & & $<1$ & $\begin{array}{c}1 \text { to } \leq \\
2.5\end{array}$ & $\begin{array}{c}2.5 \text { to } \leq \\
10\end{array}$ & $\begin{array}{c}10 \text { to } \leq \\
100\end{array}$ & $\begin{array}{c}100 \text { to } \leq \\
1,000\end{array}$ & $>1,000$ \\
\hline \multicolumn{8}{|c|}{ Reported by Chinese authorities } \\
\hline $\begin{array}{l}\text { Powdered } \\
\text { infant } \\
\text { formula }\end{array}$ & 22 & 2 & 1 & 2 & 13 & 3 & 1 \\
\hline $\begin{array}{l}\text { Liquid milk } \\
\text { and yogurt }\end{array}$ & 24 & 4 & 5 & 15 & 0 & 0 & 0 \\
\hline $\begin{array}{l}\text { Powdered } \\
\text { milk products }\end{array}$ & 31 & 0 & 1 & 2 & 7 & 10 & 11 \\
\hline Total & 77 & 6 & 7 & 19 & 20 & 13 & 12 \\
\hline \multicolumn{8}{|c|}{ Reported by other national authorities ${ }^{\mathrm{a}}$} \\
\hline $\begin{array}{l}\text { Liquid milk } \\
\text { and yogurt }\end{array}$ & 17 & 0 & 4 & 7 & 5 & 1 & 0 \\
\hline $\begin{array}{l}\text { Powdered } \\
\text { milk products }\end{array}$ & 23 & 14 & 3 & 2 & 3 & 1 & 0 \\
\hline $\begin{array}{l}\text { Frozen dairy } \\
\text { products }\end{array}$ & 5 & 0 & 0 & 2 & 3 & 0 & 0 \\
\hline $\begin{array}{l}\text { Confectionary } \\
\text { products }\end{array}$ & 158 & 0 & 4 & 92 & 53 & 9 & 0 \\
\hline Snack foods ${ }^{\mathrm{c}}$ & 13 & 1 & 1 & 5 & 6 & 0 & 0 \\
\hline $\begin{array}{l}\text { Frozen } \\
\text { processed } \\
\text { foods }\end{array}$ & 15 & 5 & 3 & 2 & 5 & 0 & 0 \\
\hline $\begin{array}{l}\text { Ammonium } \\
\text { bicarbonate }\end{array}$ & 2 & 0 & 0 & 0 & 0 & 2 & 0 \\
\hline $\begin{array}{l}\text { Nondairy } \\
\text { creamer }\end{array}$ & 1 & 0 & 1 & 0 & 0 & 0 & 0 \\
\hline $\begin{array}{l}\text { Protein } \\
\text { powder }\end{array}$ & 2 & 0 & 0 & 2 & 0 & 0 & 0 \\
\hline $\begin{array}{l}\text { Dried egg } \\
\text { powder and } \\
\text { liquid eggs }\end{array}$ & 5 & 3 & 1 & 1 & 0 & 0 & 0 \\
\hline Whole eggs & 4 & 0 & 0 & 4 & 0 & 0 & 0 \\
\hline Animal feed & 4 & 0 & 0 & 2 & 1 & 0 & 1 \\
\hline Total & 249 & 23 & 17 & 119 & 76 & 13 & 1 \\
\hline
\end{tabular}

${ }^{a}$ Does not include results that were reported as a range rather than as a single data point, because the number of samples taken for these results was not apparent. ${ }^{b}$ Includes products where the use of milk as an ingredient was apparent, such as in chocolate or biscuits with cream filling. ${ }^{c}$ Includes products where the use of milk as an ingredient was not obvious, such as in potato crackers or rice crisps. ${ }^{d}$ Includes products such as frozen pizza dough or frozen fried chicken. 
Table 2. Range of melamine levels detected in various food products.

\begin{tabular}{|l|}
\hline Product category \\
\hline Powdered infant formula \\
\hline Liquid milk and yogurt \\
\hline Powdered milk products \\
\hline Frozen dairy products \\
\hline Confectionary products \\
\hline Snack foods \\
\hline Frozen processed foods \\
\hline Ammonium bicarbonate \\
\hline Nondairy creamer \\
\hline Protein powder \\
\hline Dried egg powders and liquid eggs \\
\hline Whole eggs \\
\hline Animal feed \\
\hline
\end{tabular}

\section{Contamination range $(\mathrm{mg} / \mathrm{kg})$}

$\begin{array}{cc}0.1-2,563 & 22 \\ 0.6-648 & 52 \\ <1-6,196 & 56 \\ 4.4-60.8 & 6 \\ 0.3-945.9 & 200 \\ 0.5-41 & 17 \\ 33.4-508 & 20 \\ 1.5-6,694 & 4 \\ 3.8-8.3 & 2 \\ 0.1-5 & 2 \\ 2.9-4,7 & 8 \\ 2.9-4.7 & 4 \\ 3.3-21,000 & 7\end{array}$

\section{HEALTH IMPACT}

As the incident developed, updates on affected infants and children were provided by the Chinese Ministry of Health. The most recent update confirmed a total of 6 deaths and 294,000 cases associated with the consumption of melamine-contaminated milk and milk products as of 1 December 2008 [12] (Table 3).

Table 3. Reported number of children affected by melamine in China (of 22.4 million patients screened) as of 1 December 2008 [12].

\begin{tabular}{|l|c|c|}
\hline Status & No. & $\begin{array}{c}\text { Percentage of } \\
\text { reported cases }\end{array}$ \\
\hline Cases reported & 294,000 & 100 \\
\hline Cases hospitalised & 51,900 & 17.6 \\
\hline Hospitalized cases already discharged & 51,039 & 17.4 \\
\hline Hospitalized cases still in serious condition & 154 & 0.05 \\
\hline Cases still in hospital & 861 & 0.3 \\
\hline Deaths & 6 & 0.002 \\
\hline
\end{tabular}

Two clinical case reports for a total of 74 children who were hospitalized with either acute renal failure or confirmed renal stones state the average duration of hospitalization was 13-16 days [13]. Of the 2,085 children screened, 17\% (348 children) had stones, but only $25 \%$ had symptoms. In another study involving 589 children, $8.5 \%$ had stones, $19 \%$ were suspected of having stones, and $72.5 \%$ had no stones; all children were equally likely to have symptoms [14]. This finding suggests that there may be many more children with urinary tract calculi or stones as a consequence of consuming melamine-contaminated products who remain asymptomatic and therefore undiagnosed. Urinary tract calculi or stones were found in kidney, ureter, or bladder. A study of children with and without urinary tract calculi in Hangzhou, China, found risk factors for calculi included long duration of formula feeding, high melamine content in infant formula, and minimal water intake [15]. The median duration of consumption of contaminated formula reported by one study of 25 
children diagnosed with calculi was 8 months (range, 15 days to 13 months). In another study, 40 Sanlu milk powders collected at random in children's homes were analyzed: $93 \%$ contained melamine and $73 \%$ also contained the melamine analog cyanuric acid. Melamine concentrations ranged from $150 \mathrm{mg} / \mathrm{kg}$ to $4,700 \mathrm{mg} / \mathrm{kg}$ (median, $1,900 \mathrm{mg} / \mathrm{kg}$ ), and cyanuric acid concentrations ranged from 0.4 to 6.3 $\mathrm{mg} / \mathrm{kg}$ (median, $1.2 \mathrm{mg} / \mathrm{kg}$ ) [13].

In a screening study conducted in Taiwan, China, Wang et al. [16] reported the mean duration of exposure as 7.19 months (range, 0.67-36 months) in the high-exposure group, versus 17.4 months (range, 3-48 months) in the low-exposure group (defined as children who had consumed brands of contaminated milk with lower measured melamine levels).

\section{Countries Affected And Regulatory Response}

In total, 47 countries (Figure 1) received melamine-contaminated products, as reported to INFOSAN or published on each country's official government web site, either through direct import or through third countries. Illegal distribution of contaminated product from China has also been demonstrated [17].

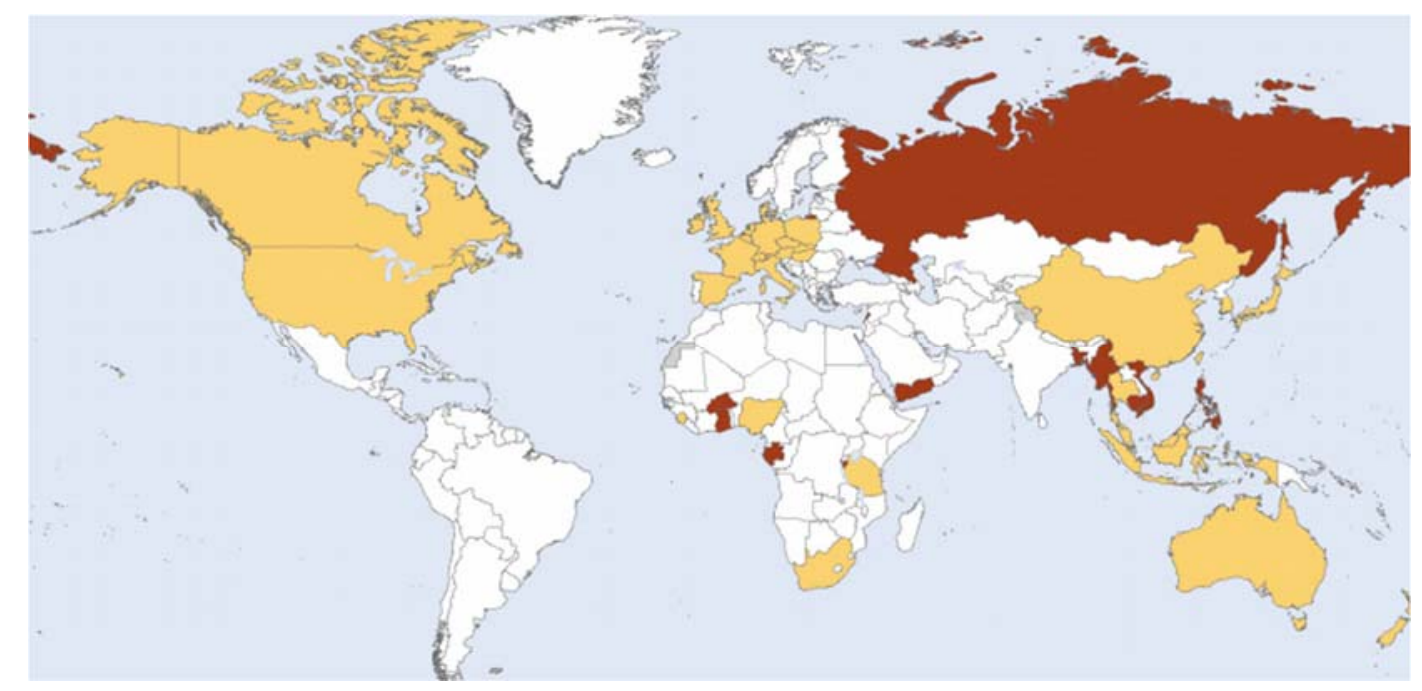

Figure 1. Global distribution of melamine-contaminated products as reported to INFOSAN and published on national official web sites.

Light shading indicates countries that reported melamine findings in products originating from China or in products containing ingredients from China. The positive results were transmitted to WHO directly by the country, or by another relevant authority, or via the country's official web site (Australia, Austria, Belgium, Canada, China, Hong Kong, Macao, Taiwan, Czech Republic, Denmark, France, Germany, Hungary, Indonesia, Ireland, Italy, Japan, Malaysia, Malta, Netherlands, New Zealand, Nigeria, Poland, Republic of Korea, Singapore, Slovakia, Slovenia, Solomon Islands, South Africa, Spain, Switzerland, Thailand, United Kingdom, Tanzania, and United States). Dark shading indicates countries to which import of contaminated products occurred, as declared by the exporting country, and countries that reported the import of contaminated products (Bangladesh, Brunei, Burkina Faso, Burundi, Cambodia, Gabon, Ghana, Lebanon, Myanmar, Palau, Philippines, Russian Federation, Seychelles, Viet Nam, Yemen). Data from WHO Map Production, 
by public health information and geographic health information systems, WHO toxicological and Health Aspects of Melamine and Cyanuric Acid [13]; all rights reserved. The boundaries and names shown and the designations used on this map do not imply the expression of any opinion whatsoever on the part of WHO concerning the legal status of any country, territory, city, or area or of its authorities, or concerning the delimitation of its frontiers or boundaries. Dotted lines on maps represent approximate border lines for which there may not yet be full agreement.

Countries responded through a wide range of actions - from no action at all to the ban of all imports of milk and milk products from China. A number of countries implemented testing of all imported Chinese products. Other countries focused testing on implicated products, and 68 countries banned or recalled foods suspected of containing melamine [18]. Several countries established (interim) limits for melamine in food and feed (e.g., Australia, Canada, China, European Union, Malaysia, New Zealand, United States). Other countries took the approach that melamine should be absent (i.e., a "zero-tolerance" approach). However, low levels (usually in the microgram per kilogram range) of melamine are found in some foods, not as a result of adulteration but through normal food production and processing (e.g., migration from food contact material, pesticides, or fertilizer use). Such levels are not a health concern. Moreover, "zero tolerance" in practice is dependant on the performance of the analytical method used, hence the actual acceptable level varies.

To respond to the request for information from countries around the word, INFOSAN elaborated and disseminated through its network lists of contaminated products, a list of laboratories that could analyze for melamine, a list of analytical methods for melamine and cyanuric acid in food and feed, and a list of limits set by national food safety authorities.

\section{Toxicology and Risk Assessment}

Several national and regional authorities around the world and the WHO have issued preliminary risk assessments and guidance on levels in food, mainly based on information from the 2007 pet-food incident, as a first pragmatic approach for public health protection [19]. Subsequently, a meeting of independent international scientific experts was organized by WHO and the following brief summary provides relevant aspects of the report [13].

Toxicology. Absorption, distribution, metabolism, and excretion. Melamine and its structural analog cyanuric acid are rapidly absorbed and rapidly excreted almost completely unmetabolized in the urine. The elimination half-lives for these two compounds are about $3 \mathrm{hr}[13,20]$. No information is available for other structural analogs, and no information is available on the absorption and excretion of the melamine-cyanurate complex.

Toxicity of melamine. Melamine is of low acute toxicity, with oral median lethal doses in mice and rats exceeding $3,000 \mathrm{mg} / \mathrm{kg}$ body weight. Several subchronic studies in rats and mice are reported [21,22] at doses up to $18,000 \mathrm{mg}$ melamine $/ \mathrm{kg}$ feed. The main observed toxicity was related to the excretory organs, kidney, and bladder. The most consistent and dose-related effects observed were bladder-stone 
formation and hyperplasia of the bladder epithelium. These effects were more pronounced in males than in females.

Melamine has been tested for carcinogenicity by oral administration in mice and rats [22]. The most significant and consistent finding from these studies was the production of urinary bladder carcinomas in male rats. In male mice, urinary bladder hyperplasia was detected. All tumor findings correlated strictly with calculus formation and exposure to high doses. In female rats, chronic inflammation of the kidney, distinct from chronic nephropathy in aging rats, was observed.

Melamine is not genotoxic, and it is not considered a reproductive and developmental toxicant.

Toxicity of cyanuric acid. The toxicologic profile of cyanuric acid is very similar to that of melamine. It is of low acute oral toxicity, and subchronic toxicity at concentrations up to $5,375 \mathrm{mg} / \mathrm{L}$ in drinking water resulted in a low incidence of bladder calculi at the highest dose. In a 2-year study of rats that were given sodium cyanurate in the drinking water at doses estimated up to $371 \mathrm{mg} / \mathrm{kg}$ body weight per day $(5,375 \mathrm{mg} / \mathrm{L})$, no substance-related increase in tumor incidence was observed [20].

Cyanuric acid is not considered to be genotoxic, and it is not teratogenic or a reproductive toxicant.

Combined toxicity. From previous incidents in pets and livestock, and after experimental studies to investigate the combined effects of melamine plus cyanuric acid in cats [23] and in fish and pigs [24], it is apparent that oral exposure to melamine given simultaneously with cyanuric acid caused much more severe renal damage than did oral exposure to melamine or cyanuric acid alone.

Risk assessment. The formation of bladder calculi was identified as the most relevant end point, and because the calculi formation is dose-dependent or local-concentration dependant, with no signs of significant accumulation, the subchronic studies in rats serve as the basis for the risk assessment.

By applying dose-response modeling to the combined data for male rats from the two subchronic feeding studies, a 95\% lower bound of the $10 \%$ benchmark dose (BMDL10) of $415 \mathrm{mg} / \mathrm{kg}$ diet was calculated. Dietary conversion and an additional feed-intake-reduction factor of $14 \%$ led to the BMDL10 of $35 \mathrm{mg} / \mathrm{kg}$ body weight per day. An uncertainty factor of 200 was applied, deriving a tolerable daily intake (TDI) of $0.2 \mathrm{mg} / \mathrm{kg}$ body weight (rounded to one significant figure). The uncertainty factor comprises the default 100-fold factor plus an extra 2-fold factor to account for sensitivity of infants and for data uncertainty in relation to possible underreporting of bladder calculi due to tissue preparation.

For adults, estimated exposure from "baseline" levels of melamine, defined as levels in food that do not result from adulteration or misuse from all sources, has been estimated to be up to $13 \mu \mathrm{g} / \mathrm{kg}$ body weight per day. Conservative exposure estimates from adulterated products from this incident were 0.8-3.5 times the TDI. For comparison, estimated exposure of infants in China to adulterated infant formula, at median levels of the most affected brand, ranged from 8.6 to $23.4 \mathrm{mg} / \mathrm{kg}$ body weight per day. These levels are about 40-120 times the TDI and explain the dramatic health outcome in Chinese infants. 


\section{Discussion}

Sources and levels of contamination. The sources of melamine contamination have been divided into "baseline" levels, which refer to levels in food that do not result from adulteration or misuse, and "adulteration" levels, which refer to levels in food that result from the intentional illegal addition of melamine to food or feed [13]. Such a distinction is useful for practical purposes, but it is evident that a clear distinction is not always possible. For example, low levels of melamine in food could result from carryover from adulterated animal feed.

Baseline concentrations of melamine are present in the environment and in the food chain as a result of the widespread use of materials that contain melamine. Generally, baseline levels are expected to be $<1 \mathrm{mg} / \mathrm{kg}$ [13], and these levels are not considered to be a health concern. Melamine concentrations in food and animal feed above baseline levels are considered to be the result of misuse or adulteration. The high levels of melamine detected in many products related to the 2008 incident are a clear indication of adulteration.

Data showing the presence of melamine in animal tissue (including fish), milk, and eggs demonstrate that carryover from feed to tissues, milk, and eggs does occur.

Figure 2 presents the four major possible paths for deliberate contamination: a) liquid milk in the milk-collecting stations that was then used in the production of powdered infant formula, liquid and powdered milk products, and processed milk-containing foods; b) animal feed that resulted in contamination of milk, eggs, and potentially meat; c) nondairy creamer and protein powder that lead to the contamination of instant nondairy beverage products; and d) ammonium bicarbonate that was used to produce several types of processed food.

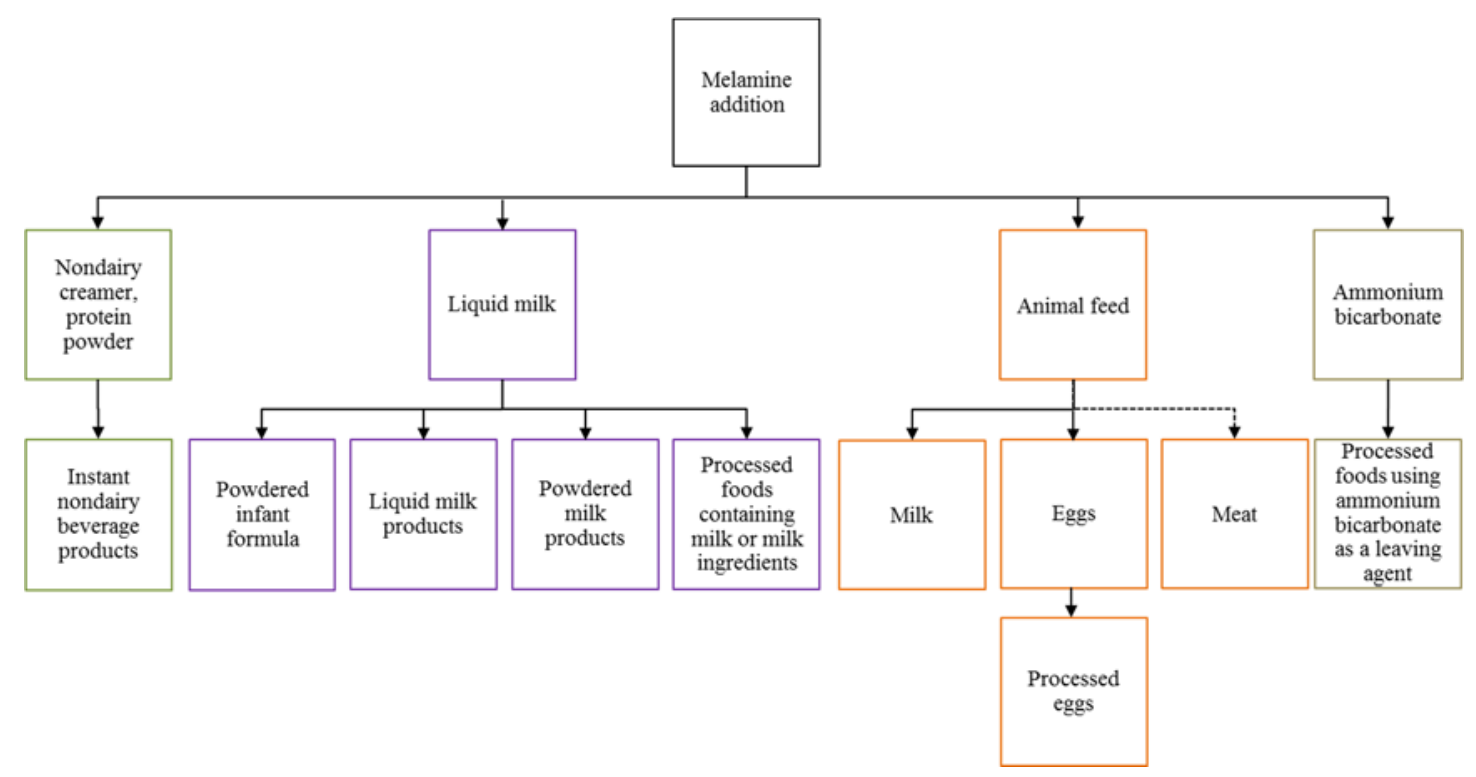

Figure 2. Flow chart of the melamine-contamination chain from adulteration. Solid lines indicate contaminated products as observed during the 2008 incident. Dashed lines indicate possible contamination but not reported during the 2008 incident.

From the wide-ranging levels of melamine found in the different product categories (Table 2), it cannot be immediately determined which of the positive results are due to 
baseline contamination and which are due to intentional misuse and adulteration of melamine in food and feed. It is currently still unclear how products such as ammonium bicarbonate, nondairy creamer, and protein powder have been contaminated with melamine. However, it is assumed that melamine, of high purity grade as white powder, was added directly to such products, as it would serve as an inexpensive substitute for other raw material or boost apparent protein content.

The detection of melamine in products such as dried egg powder and whole eggs indicates carryover of melamine from feed to food products. In one particular incident in South Africa, it was reported that locally produced powdered-milk products were contaminated with melamine due to the use of old stocks of contaminated feed, from the 2007 incident, for dairy cattle [25]. The discovery of very high levels of melamine $(21,000 \mathrm{mg} / \mathrm{kg})$ [8] in rice-protein concentrate from China, an animal feed ingredient, would also seem to serve as corroborating evidence that the risk of carryover from feed to food products is likely. Further studies on this subject are warranted.

Overall reports of $>400$ positive results in a broad variety of food products have been compiled by WHO up to 31 January 2009. It is assumed that more analytical results are available worldwide and that monitoring is ongoing. It is interesting to note that almost no positive results for melamine in infant formula have been reported by authorities outside of China. This result may be due to rapid actions such as import bans. However, many countries require premarket approval or notification for infant formula, and many countries may not allow Chinese infant formula in their market. In Canada, one study was performed by authorities to study baseline levels in local infant formula, where melamine was detected in 60 of the 80 local products sampled, at concentrations ranging from 4.31 to $346 \mu \mathrm{g} / \mathrm{kg}$ [26]. It served to identify baseline levels in infant formula.

Health impact. Because the epidemiologic studies showed that many children with identified calculi where asymptomatic, it is likely that there were many more cases that were not brought to the attention of medical authorities. Considering the global distribution of affected products, as well as informal distributions, it is also possible that there are unidentified and therefore unreported cases in countries other than China. Also, many children had small calculi or stones that were not detectable with standard methods, further leading to a possible underreporting of affected children.

There is a lack of information on the long-term effects of melamine in humans, which makes predicting the subchronic and chronic health problems that might follow from the 2008 incident difficult. The carcinogenic effects reported in animal studies subsequent to irritation caused by stones formed after high exposure [27] do raise health concerns. Thus, it is essential that treatment to eliminate calculi and stones be continued and that long-term studies into the human health effects of melamine be carried out. Information obtained from the current incident is critical to identify the long-term effects of high levels of melamine consumption in humans including conducting large-scale epidemiologic investigations such as longitudinal cohort studies, long-term follow-up of affected cohorts, and more extensive case findings to establish the total population affected.

Toxicology. The TDI is derived from short-term toxicology studies in animals. These studies were not designed to investigate bladder or kidney crystal and calculi formation. However, they form a strong basis for risk assessment, particularly considering that the effects seen in humans are similar to the effects seen in animals. Nevertheless, uncertainty remains, particularly in light of the new findings that 
melamine crystals dissolve rapidly in formalin, which is routinely used for tissue fixation. This may have led to an underestimation of the formation of bladder crystals, the critical effect used as a basis for derivation of the TDI.

It is important to note that the adverse effects seen in experimental animals, and probably in humans as well, are due to a local physical effect rather than a systemic effect. Melamine and its analogs are rapidly excreted, and crystal formation occurs only at high doses when a critical concentration is reached in the excretory organ. It appears that only when this threshold is exceeded do adverse effects occur. However, available data do not allow identification of this threshold concentration, for melamine alone or in combination with its analogs, and further investigations are needed.

Delay of reporting. As soon as WHO requested information, the Chinese authorities acknowledged the melamine event and cooperated with WHO. According to information provided to INFOSAN by Chinese authorities on 29 September 2008, parents of the infants who consumed Sanlu formula filed complaints to the company as early as December 2007, and the company had detected melamine in its products in June 2008. The company only reported its findings to the local government in August 2008 , followed by a further delay until 9 September when the incident was reported to the provincial government.

A timely response is important to assure appropriate actions to limit the spreading of contaminated product and to ensure that all contaminated product-domestic and exported - can be taken off the market. There is a clear responsibility for all parties involved in the food-production chain (producers and authorities), to release immediately any information related to any contamination with a possible human health impact. Withholding such information will negatively affect health outcome and the credibility of all involved.

International consequences and lessons learned. The managing of outbreaks depends strongly on a well-structured food-safety system; communication and access to information are key components that will determine a positive reaction to an incident. China, the country at the origin of this incident, shared information internationally through INFOSAN. Data from outside China were collated and also communicated to national authorities through the INFOSAN network. This incident, and the rapid spread of the affected products worldwide, has evidenced the need for a mechanism for coordination and information exchange linking food-safety authorities and promoting the rapid exchange of information.

In any important food-safety event, there is an urgent need to provide the best available scientific knowledge in the area. Such knowledge can save lives and help to control an outbreak. Sharing information across borders is essential to obtain the best advice possible and to avoid confusion when tackling international events. This information should include international agreement about testing and reporting methodology; without these, coherent international analysis and action are not possible. In general, there is a need to achieve international scientific agreement relative to the risk of melamine in food and feed. A WHO expert meeting [13] provided the first international forum for exchange and joint analysis of data in this area. The Chinese authorities should be commended for the pertinent data provided at this meeting. 
During the 2008 incident, significant confusion existed regarding which level of melamine in food presents a human health risk. Communication relative to the levels protective of health was made additionally difficult by the fact that countries in some cases published different "action" levels; some countries even used any melamine concentration detected as a signal for action. It is important for authorities to present clear, understandable reasoning for any action or nonaction taken. There is a need for a common understanding of the underlying science that ideally leads to one harmonized international set of limits in food and feed, typically achieved through the Codex Alimentarius Commission.

Ensuring food safety to protect public health. Some 68 countries have taken different restrictive trade measures against a range of food products originating from China. These were introduced at the onset of the event in September 2008. Several months later, questions still remain as to when and how to consider this incident under control. For many trading partner countries, it is difficult to assess the safety of future supplies and to decide on what basis to lift the restrictive measures imposed. For the Chinese authorities, demonstrating that the measures they have put in place will ensure an appropriate level of confidence in the future safety of food products is also posing a challenge.

This incident has clearly demonstrated a need to develop, at the international level, risk-based import-inspection systems. In addition, guidance regarding the necessary measures to demonstrate, with a certain degree of confidence, the appropriate levels of safety when a major food-safety event has seriously shaken confidence in the capabilities of a system to ensure the safety of the food it produces.

This incident has also clearly demonstrated that food safety can only be ensured if all the stakeholders along the food chain are sharing information and data in a timely manner. 


\section{REFERENCES}

1. Brown CA, Jeong KS, Poppenga RH, Puschner B, Miller DM, Ellis AE, et al. Outbreaks of renal failure associated with melamine and cyanuric acid in dogs and cats in 2004 and 2007. J Vet Diagn Invest. 2007 Sep;19(5):525-31.

2. Organisation for Economic Co-operation and Development. 2009. The 2007 OECD List of High Production Volume Chemicals. Series on Testing and Assessment No. 112. Available: http://www.oecd.org/dataoecd/32/9/43947965.pdf [accessed 3 November 2009].

3. ProMED-mail. 2008a. Infant Kidney Stones - China: Gansu, Milk Powder Suspected. Request for Information. 10 Sept: 20080910.2828. Available: http://www.promedmail.org/pls/otn/f?p=2400:1001:283306898322970::NO:: F2400 P1001 BACK PAGE,F2400 P1001 PUB MAIL ID:1010,73896 [accessed 19 October 2009].

4. Melamine and food safety in China. Lancet. 2009 Jan 31;373(9661):353.

5. ProMED-mail. 2008b. Infant Kidney Stones - China (03): Melamine. 17 Sept: 20080917.2915. Available:

http://www.promedmail.org/pls/otn/f?p=2400:1001:59091680167141:..::F2400_P100 1 BACK PAGE,F2400 P1001 ARCHIVE NUMBER,F2400 P1001 USE ARCHI VE:1001,20080917.2915,Y [accessed 19 October 2009].

6. Agri-Food and Veterinary Authority of Singapore. 2008. Consumer AdvisoryRecall of Yili Natural Choice Yogurt Flavoured Ice Bar with Real Fruit. Available: http://www.ava.gov.sg/NR/rdonlyres/C9BF6E49-C88E-4703-98739EC7FF9EBAC6/21933/MicrosoftWordPressReleaseonrecallofYiliYogurtbar_1.pdf [Accessed 21 October 2009].

7. Centre for Health Protection. 2008. Case of Renal Disease Associated with Contaminated Milk Product Detected. Available:

http://www.chp.gov.hk/content.asp?lang=en\&id=116\&info $\mathrm{id}=13952 \& \mathrm{pid}=14$ [accessed 21 October 2009].

8. Rapid Alert System for Food and Feed (RASFF). 2008c. Overview Notification Reports. Week 2008/50. Available:

http://ec.europa.eu/food/food/rapidalert/archive_2008_en.htm [accessed 21 October 2009].

9. Rapid Alert System for Food and Feed (RASFF). 2008b. Overview Notification Reports. Week 2008/44. Available:

http://ec.europa.eu/food/food/rapidalert/archive 2008 en.htm [accessed 21 October 2009].

10. Centre for Food Safety. 2008. Latest Test Results for Melamine. Available: http://www.cfs.gov.hk/english/press/2008_10_28_1_e.html [accessed 21 October 2009].

11. Korean Food and Drug Administration. 2008. List of Melamine Contaminated Products. Available:

http://www.foodnara.go.kr/kfda/melamineunfit/main/melamine 06.html [accessed 21 October 2009].

12. Chinese Ministry of Health. 2008. Report from the Ministry of Health of the People's Republic of China on Sanlu Infant Milk Powder Incident and Medical 
Treatment Situation [in Chinese]. Available:

http://www.moh.gov.cn/sofpro/cms/previewjspfile/mohbgt/cms 00000000000000001 44 tpl.jsp?requestCode $=38386 \&$ CategoryID $=4800$ [accessed 21 October 2009].

13. World Health Organization (WHO). 2009. Toxicological and Health Aspects of Melamine and Cyanuric Acid. Available:

http://www.who.int/foodsafety/fs_management/infosan_events/en/index.html [accessed 21 October 2009].

14. Guan N, Fan Q, Ding J, Zhao Y, Lu J, Ai Y, et al. Melamine-contaminated powdered formula and urolithiasis in young children. N Engl J Med. 2009 Mar 12;360(11):1067-74.

15. Zhang L, Wu LL, Wang YP, Liu AM, Zou CC, Zhao ZY. Melaminecontaminated milk products induced urinary tract calculi in children. World J Pediatr. 2009 Feb;5(1):31-5.

16. Wang IJ, Chen PC, Hwang KC. Melamine and nephrolithiasis in children in Taiwan. N Engl J Med. 2009 Mar 12;360(11):1157-8.

17. Rapid Alert System for Food and Feed (RASFF). 2008a. Overview Notification Reports. Week 2008/42 Available:

http://ec.europa.eu/food/food/rapidalert/archive_2008_en.htm [accessed 21 October 2009].

18. Bhalla V, Grimm PC, Chertow GM, Pao AC. Melamine nephrotoxicity: an emerging epidemic in an era of globalization. Kidney Int. 2009 Apr;75(8):774-9.

19. World Health Organization (WHO). 2008. Melamine and Cyanuric Acid: Toxicity, Preliminary Risk Assessment and Guidance on Levels in Food. Available: http://www.who.int/entity/foodsafety/fs_management/Melamine.pdf [accessed 21 October 2009].

20. World Health Organization (WHO). 2004. Sodium dichloroisocyanurate. In: Safety Evaluation of Certain Food Additives and Contaminants. WHO Food Additives Series No. 52. Geneva:World Health Organization.

21. Heck HD, Tyl RW. The induction of bladder stones by terephthalic acid, dimethyl terephthalate, and melamine (2,4,6-triamino-s-triazine) and its relevance to risk assessment. Regul Toxicol Pharmacol. 1985 Sep;5(3):294-313.

22. National Toxicology Program. 1983. Carcinogenesis Bioassay of Melamine (CAS No. 108-78-1) in F344/N Rats and B6C3F1 Mice (Feed Study). TR 245.

Research Triangle Park, NC:National Toxicology Program. Available: http://ntp.niehs.nih.gov/ntp/htdocs/LT_rpts/tr245.pdf [accessed 21 October 2009].

23. Puschner B, Poppenga RH, Lowenstine LJ, Filigenzi MS, Pesavento PA. Assessment of melamine and cyanuric acid toxicity in cats. J Vet Diagn Invest. 2007 Nov;19(6):616-24.

24. Reimschuessel R, Gieseker CM, Miller RA, Ward J, Boehmer J, Rummel N, et al. Evaluation of the renal effects of experimental feeding of melamine and cyanuric acid to fish and pigs. Am J Vet Res. 2008 Sep;69(9):1217-28.

25. Animal Feed Manufacturers Association. 2008. Animal Feed Manufacturers Investigate Contaminated Raw Materials with Melamine [press release]. Centurion, South Africa: AFMA, Safe Feed for Safe Food. 
26. Health Canada. 2008. Survey and Health Risk Assessment of Background Levels of Melamine in Infant Formula Allowed for Sale in Canada. Available: http://www.hc-sc.gc.ca/fn-an/alt formats/hpfb-dgpsa/pdf/pubs/melamine_surveyenquete hra-ers-eng.pdf [accessed 21 October 2009].

27. International Agency for Research on Cancer. 1999. Melamine. IARC Monogr Eval Carcinog Risk Hum 73:329-338. 


\section{Chapter 9}

Closure of food- And WATER-BORNE DISEASE OUTBREAKS 


\section{Criteria to CONSIDER When DECLARING THE END OF AN}

Submitted

Kristyn Franklin, Céline M. Gossner, Christine Gardhouse, Thai-An Nguyen, Birgitta de Jong, Matthew E. Wise, Jennifer Cutler, Joanne Tataryn, James Flint, and Andrea

Currie

Objective: The purpose of this report is to evaluate criteria for declaring the end of enteric illness outbreaks in community settings where disease transmission is predominately foodborne, waterborne or zoonotic.

Methods: Enteric illness investigators from Canada, the European Union and the United States developed this guidance document through iterative consultations and a review of publically available outbreak investigation protocols, outbreak reports and publications. The document was refined after being applied to several enteric illness outbreak investigations that occurred within these jurisdictions.

Results: Three criteria were developed to guide the decision to declare the end of an enteric illness. This involves determining that illnesses have returned to baseline levels (criterion 1), identifying the last time that individuals may have been exposed to the outbreak source (criterion 2) and allowing enough time to pass to allow these individuals to become ill and be reported to public health (criterion 3).

Conclusion: Having been validated against several foodborne disease outbreaks in Canada, the United States and Europe, these criteria provide an objective and scientifically based approach to determining when an enteric illness outbreak is over. 


\section{INTRODUCTION}

Declaring the end of an enteric illness outbreak is a key step in the investigation process. It is an important component of assessing and communicating risk to the public and informs decisions to demobilize outbreak resources and remove temporary restrictions that may have been instituted to mitigate risk. Since enteric illness outbreaks are complex and every outbreak is different, a consistent, transparent and objective approach to declaring the end of an outbreak is required.

Existing guidance suggests that outbreaks be declared over when the number of cases being reported returns to baseline levels or when two or more incubation periods have passed with no new primary cases reported (1-4). A return to baseline is logical but investigators need to decide how long baseline levels of reporting must be sustained before declaring the outbreak over. Two incubation periods in which no new cases are reported does not account for situations when the endemic rate of case reporting is non-zero. The time lapse of two incubation periods is likely derived from guidance for outbreaks that spread from person-to-person in institutions which are declared over if no new cases are identified following one incubation period and one period of communicability. However, the underlying rationale does not extend to community enteric illness outbreaks where transmission is predominantly through food, water or animal exposure.

We describe criteria for investigators at all levels of government to facilitate a science-based approach to declaring the end of enteric (bacterial, viral and parasitic) illness outbreaks in community settings where disease transmission is predominately foodborne, waterborne or zoonotic.

\section{METHODS}

Enteric illness investigators from Canada, the European Union (EU) and the United States developed these criteria through iterative consultations and a review of publically available outbreak investigation protocols, reports and publications. The document was refined after being applied prospectively and retrospectively to several enteric illness outbreak investigations that occurred within these jurisdictions during and prior to the development of these criteria.

\section{RESULTS}

Three criteria for declaring the end of an enteric illness outbreak were developed. For each of the criteria, a number of considerations were proposed to help assess whether or not the criteria have been met (Table 1). This approach involves determining that illnesses have returned to baseline levels (criterion 1), identifying the last time that individuals may have been exposed to the outbreak source (criterion 2) and allowing enough time to pass to allow these individuals to become ill and be reported to public health (criterion 3). The criteria are designed to be applied iteratively in the later stages of an outbreak investigation, and re-evaluated as new information becomes available. 


\section{Table 1: Criteria to consider when declaring the end of an enteric illness outbreak*}

Criterion 1: The number of outbreak cases being reported to public health authorities has returned to baseline levels.

Considerations:

What is the expected number of cases based on surveillance data prior to the outbreak and as defined by the outbreak case definition?

What is the specificity and sensitivity of surveillance?

What are the limitations of surveillance?

Was surveillance established or enhanced as part of the outbreak investigation?

If the rate of case reporting does not return to baseline, are there possible explanations for this unrelated to the outbreak?

Criterion 2: The last time that individuals may have been exposed to the implicated source has been identified or estimated.

Considerations:

To what extent has the vehicle of infection been identified?

- Has the source (food/water/animal) been identified?

- Has the point of contamination been identified?

- Has the root cause been identified?

To what extent has the hazard been eliminated?

- Was there an intervention to prevent further exposure to the vehicle of infection and how effective was it (e.g. food recall, restaurant closure)?

- Were control measures implemented at the point of contamination to eliminate the hazard (e.g. corrective actions at plant, distributor or farm level)?

If the hazard was not identified and eliminated:

- When did outbreak case reporting return to baseline?

- What is the most recent illness onset in an outbreak case?

- What is the likely period of exposure for this case?

Criterion 3: Sufficient time has lapsed for potentially exposed individuals to become ill and be reported to investigating public health authorities.

Considerations:

- What is the maximum incubation period of the outbreak pathogen based on the literature and/or evidence from the outbreak?

- How long does it take for individuals who become ill to be reported to public health based on the current and/or previous outbreaks due to the same pathogen?

* Apply iteratively, reassessing as new information becomes available.

\section{Criterion 1}

The first criterion requires that the rate of case reporting, as defined by the outbreak case definition, has returned to baseline. Baseline is the expected or endemic rate of case reporting. It is estimated using historical surveillance data relevant to the time period, geography and/or defined community of the outbreak (5). The outbreak pathogen may be a rare strain as characterized by molecular subtyping and identifying a return to baseline near zero is straightforward. Alternatively, statistical methods that detect aberrations in case reporting relative to the baseline may be required $(6,7,8)$. 
It is important to understand the strengths, limitations and any recent changes to surveillance that may influence baseline estimations. These include changes to case finding methods or the sensitivity of laboratory tests. Established surveillance systems with high sensitivity and specificity, that capture trends over time allow for more accurate estimation of the baseline rate of case reporting and determination of a return to baseline. In the absence of historical surveillance data (e.g., outbreaks of new or emerging pathogens), determining the baseline incidence may be informed by other data sources including surveys, surveillance from other geographic areas, expert consultations, or analysis of data generated by surveillance established for the outbreak investigation $(11,12)$. In some instances, case reporting may not return to baseline and further investigation will be required to determine if this is related or unrelated to the outbreak (e.g., change in epidemiology of pathogen resulting in sustained increase) before declaring the outbreak over (13).

\section{Criterion 2}

The second criterion requires identifying the last time that individuals may have been exposed to the implicated source. If there is a high degree of confidence that the source of the outbreak was identified and effective action taken, the last time individuals may have been exposed is equivalent to the date that the hazard was eliminated (Figure 1). For example, this would be appropriate for outbreaks associated with contamination at a restaurant which has been closed or foodborne outbreaks in which complete recall of the implicated food is verified through $100 \%$ effectiveness checks.

These situations are rare. In many outbreaks, even when the source of the outbreak is identified there is uncertainty regarding the extent of hazard removal. For example in outbreaks where a food ingredient is the source, it is difficult to identify all products containing the implicated ingredient and it is difficult to monitor the recall effectiveness of widely distributed food items. Similar difficulties apply to outbreaks of contaminated frozen fruits and vegetables, when the products are contaminated early in the supply chain and subsequently dispersed and distributed under different names and mixed with similar products from different origins. In these instances the last time individuals may have been exposed is estimated by the exposure period of the most recent case. For simplicity, the most recent illness onset date can be used as a proxy unless the time period between onset of illness and the minimum incubation period is significant (e.g., Hepatitis A). In the event that the source is not identified and the baseline rate of reporting is greater than zero, the date that the rate of case reporting returned to baseline can be used as a proxy (Figure 2, 3).

\section{Criterion 3}

The third criterion requires that enough time pass to allow individuals who may have been exposed to develop illness and be reported to public health. This time period is equal to the maximum incubation period of the pathogen (as reported in the literature) plus the reporting lag between illness onset and the case being reported to the lead investigating authority (as observed in the current outbreak). If unusual incubation periods are observed for cases in the outbreak, the incubation period for outbreak cases may be used (17). If the outbreak involves few cases, the reporting lag may be based on previous outbreaks due to the same pathogen. In order to balance the need to ensure all cases are reported against unnecessarily extending the duration of an outbreak due to unusually long reporting delays (e.g., cases reported slower prior to outbreak detection), the $75^{\text {th }}$ percentile reporting lag is generally accepted. 
The incubation period plus reporting lag can be viewed as a 'lag window' or shaded box on the outbreak epidemic curve. Depending on the assessment of Criterion 2, it may be projected forward from either 1) the date on which the source of the outbreak was eliminated; 2) the most recent illness onset date or; 3) the date that case reporting returned to baseline to determine the earliest date that the outbreak may be declared over. Alternatively, for outbreaks where the source was not eliminated, it may be applied from today's date backwards and the outbreak may be declared over once only baseline levels are observed in the 'lag window'.

It is important to assess new information as it becomes available during this time period. In particular, newly reported cases may or may not be indicative of an ongoing outbreak. For example, cases that are clearly attributable to a source that has since been eliminated, laboratory-acquired cases or cases captured due to mandatory testing during public health follow-up would not change the date the outbreak is declared over.

\section{DisCUSSION}

This guidance document outlines three science-based criteria to support decision making around declaring the end of an enteric illness outbreak. The criteria provide a transparent and consistent approach to decision-making while remaining flexible to adapt to the unique characteristics of each outbreak. This guidance is intended for declaring the end of an outbreak which is independent of the completion of investigative activities. In many situations the investigation will not be complete until after the outbreak is over, and it is also possible for the investigation to conclude before the outbreak is over.

The Public Health Agency of Canada has used these criteria informally since October 2012 and will continue to use them as standard practice in multi-jurisdictional enteric illness outbreak investigations. The criteria have proven useful both in deciding when to declare the outbreak over and in communicating the rationale for this decision to public health stakeholders. The lag window is typically applied prospectively projecting the earliest time at which the outbreak can be declared over.

The United States Centers for Disease Control and Prevention (CDC) also use these criteria for bacterial enteric illness outbreaks. As in Canada, outbreaks investigated at the federal level in the United States typically require molecular subtyping of clinical isolates by pulsed-field gel electrophoresis (PFGE) to confirm an outbreak case and the majority are caused by widely distributed vehicles wherein complete elimination of the hazard cannot typically be guaranteed. Thus, the CDC uses a statistical measure to identify increases above baseline levels of reporting for the outbreak PFGE pattern as defined by a five-year seasonally-adjusted estimate. They overlay the lag window based on the $75^{\text {th }}$ or $90^{\text {th }}$ percentile reporting delay (excluding the incubation period) on the epidemic curve counting backwards from the current date and will declare the outbreak over once case reporting for the outbreak PFGE pattern no longer exceeds the statistical threshold for the duration of the lag window (i.e., only baseline levels of reporting are observed within the lag window).

The European Centre for Disease Prevention and Control (ECDC) does not currently systematically declare the end of enteric illness outbreaks, however it is moving to implement these guidelines in the near future. The ECDC has only recently implemented molecular surveillance at the EU level and therefore continues to rely on 
member state national surveillance systems to detect outbreaks and identify potential multi-country outbreaks through reporting to the ECDC Epidemic Intelligence Information System for Food- and Waterborne Diseases and Zoonoses (EPIS-FWD). In some instances, this guidance may be applied independently by affected countries and at the EU level resulting in the outbreak being declared over earlier in one country.

Each enteric illness outbreak is unique and therefore there are limitations to the criteria described above. For example, the criteria may not apply to slow moving outbreaks or intermittent source outbreaks, where a return to baseline for a period longer than the incubation period plus the reporting lag may occur between cases or clusters, respectively. These situations highlight the need to critically assess and adapt the criteria in the context of each outbreak.

These criteria will continue to be validated over time and the guidance document will be refined prospectively as it is applied to enteric illness outbreak investigations. 


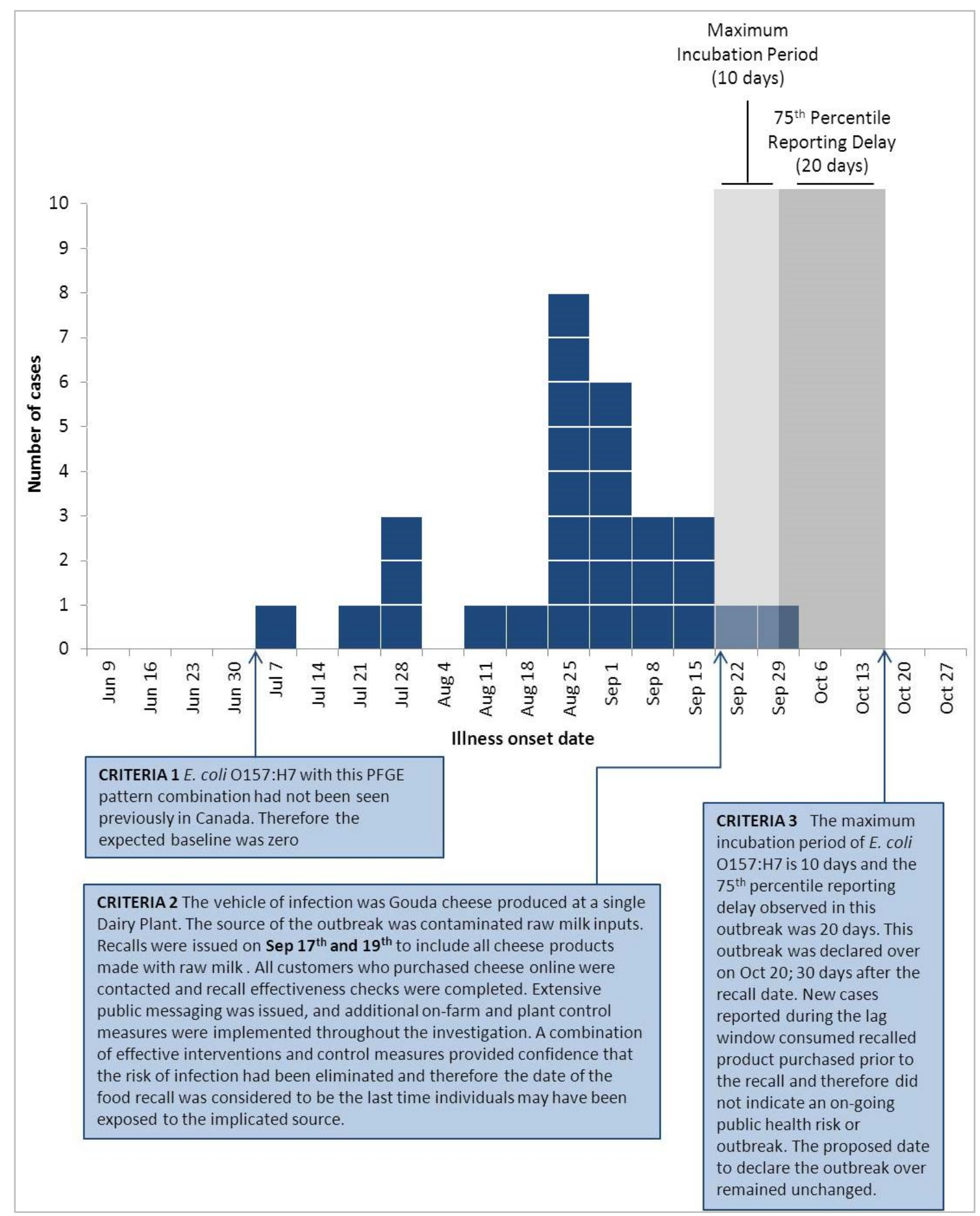

Figure 1: Criteria applied to an outbreak of $E$. coli $0157: H 7$ linked to Gouda cheese products made with raw milk produced at a single dairy plant, Canada $2013(n=29)$ 


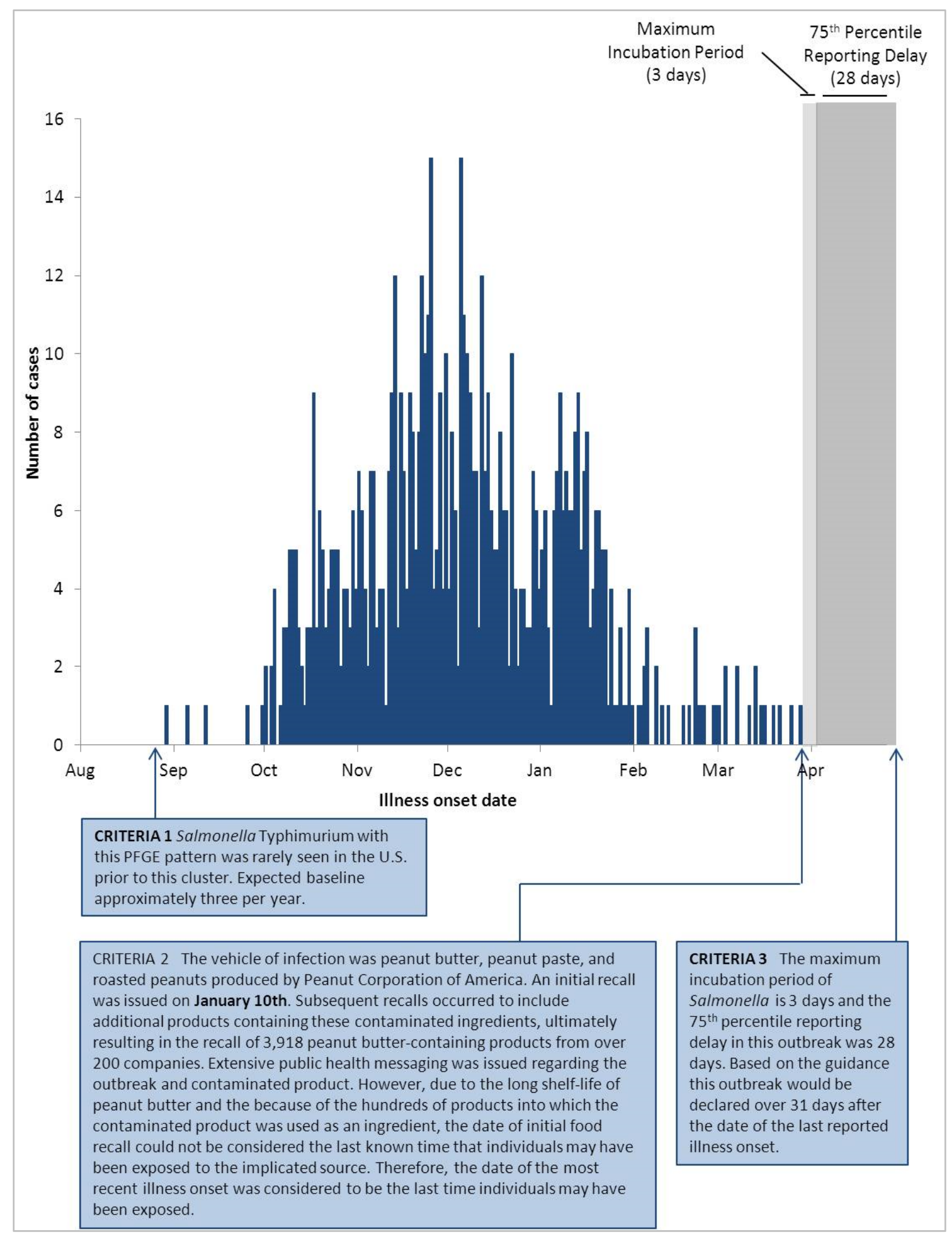

Figure 2: Criteria applied to an outbreak of Salmonella Typhimurium linked to peanut butter, peanut paste, and roasted peanuts produced by a single company in the United States, 2008-2009 $(n=714)$ 


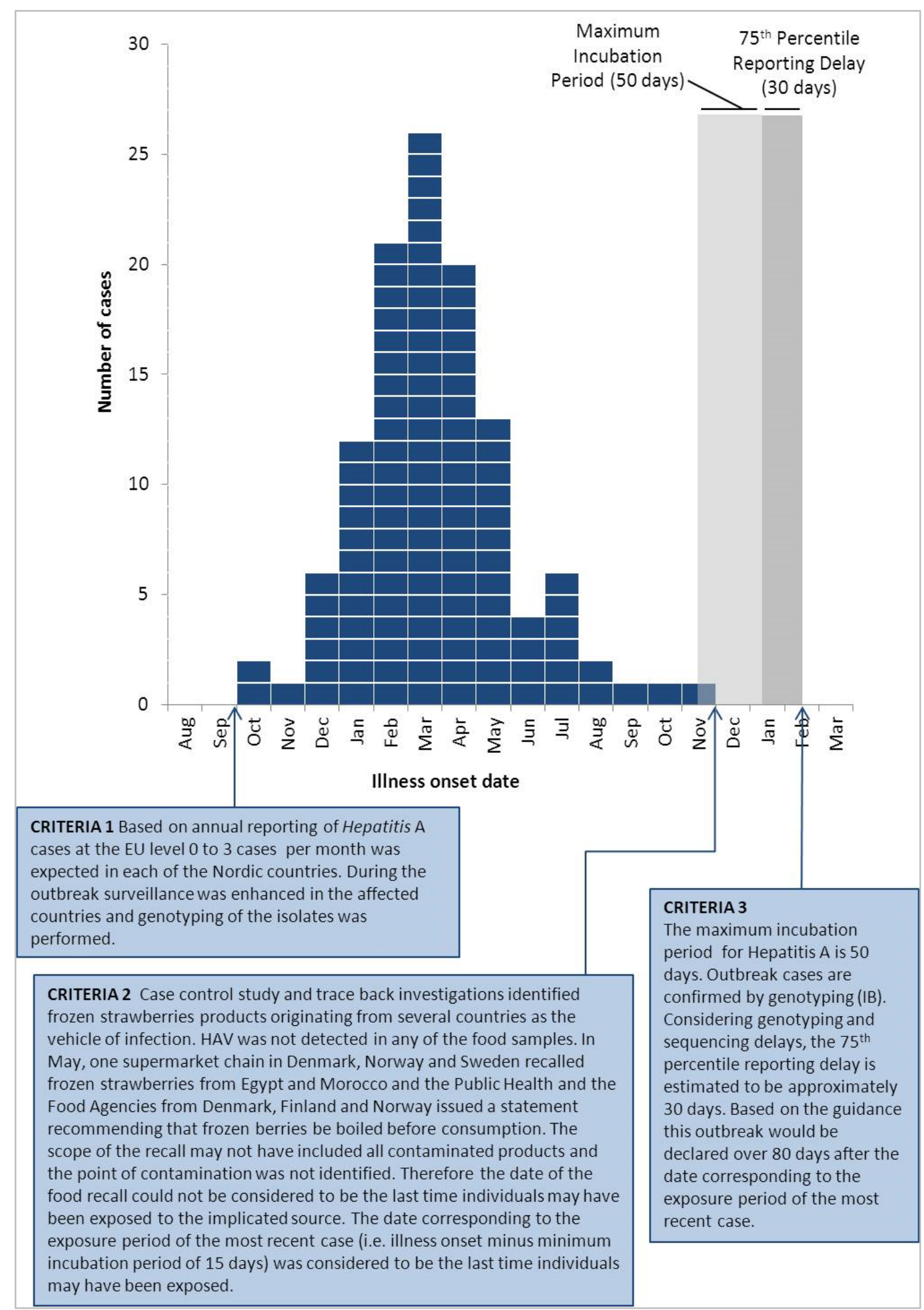

Figure 3: Criteria applied to an outbreak of $\boldsymbol{H e p a t i t i s} \boldsymbol{A}$ linked to frozen berries European Nordic countries (Denmark, Finland, Norway and Sweden), 2013 $(\mathbf{n}=117)$. 


\section{REFERENCES}

1. World Health Organization (WHO). Foodborne disease outbreaks: Guidelines for investigation and Control. 2008;

http://whqlibdoc.who.int/publications/2008/9789241547222 eng.pdf

2. Council to Improve Foodborne Outbreak Response (CIFOR). Guidelines for Foodborne Disease Outbreak Response. Atlanta: Council of State and Territorial Epidemiologists; 2009;

http://www.cifor.us/documents/CIFORGuidelinesforFoodborneDiseaseOutbreakResp onse.pdf

3. Queensland Health Foodborne Illness Outbreak Management Guidelines 2006; http://www.health.qld.gov.au/ph/documents/cdb/31572.pdf

4. The UK Outbreak Control Team. Foodborne outbreak of Salmonella Bareilly in the UK, 2010. September 2011;

http://www.hpa.org.uk/webc/HPAwebFile/HPAweb_C/1315372088636

5. Gregg MB. Field epidemiology. 3rd ed. Oxford: Oxford University Press; 2008.

6. Government of Canada. National Enteric Surveillance Program Annual Summary 2012: Public Health Agency of Canada. 2014.

7. Hulth A, Andrews N, Ethelberg S, Dreesman J, Faensen D, van Pelt W, Schnitzler J. Practical usage of computer-supported outbreak detection in five European countries. Euro Surveill. 2010;15. pii: 19658. Available from: http://www.eurosurveillance.org/ViewArticle.aspx?ArticleId=19658

8. Unkel S., Farrington CP, Garthwaite PH, Robertson C, Andrews N. Statistical methods for the prospective detection of infectious disease outbreaks: a review. Technical Report. Milton Keynes: Open University; 2010 Oct. Available from: http://statswww.open.ac.uk/TechnicalReports/OutbreakReviewPaper.pdf

9. Centers for Disease Control and Prevention. Updated guidelines for evaluating public health surveillance systems: recommendations from the guidelines working group. MMWR 2001;50 (No. RR-13): 1-51.

10. Stroup DF, Wharton M, Kafadar K, Dean AG. Evaluation of a method for detecting aberrations in public health surveillance data. Am J Epidemiol. 1993; $137: 373-80$

11. Chen X, Stanton B, Pach A, Nyamete A, Ochiai RL, Kaljee L, et al. Adults' perceived prevalence of enteric fever predicts laboratory-validated incidence of typhoid fever in children. J Health Popul Nutr. 2007;25:469-78.

12. Wadl M, Rieck T, Nachtnebel M, Greutelaers B, an der Heiden M, Altmann $\mathrm{D}$, et al. Enhanced surveillance during a large outbreak of bloody diarrhoea and haemolytic uraemic syndrome caused by Shiga toxin/verotoxin-producing Escherichia coli in Germany, May to June 2011 .Euro Surveill. 2011;16(24). pii : 19893.

Available from: http://www.eurosurveillance.org/ViewArticle.aspx?ArticleId=19893

13. Kinross P, van Alphen L, Martinez Urtaza J, Struelens M, Takkinen J, Coulombier D, et al. Multidisciplinary investigation of a multicountry outbreak of Salmonella Stanley infections associated with turkey meat in the European Union, 
August 2011 to January 2013. Euro Surveill. 2014;19. pii: 20801. Available from: http://www.eurosurveillance.org/ViewArticle.aspx?ArticleId=20801

14. Currie A. et al. Multi-provincial outbreak of E. coli O157:H7 infections in Canada sourced to aged, unpasteurized Gouda cheese. J. Food Prot. Submitted.

15. Centers for Disease Control and Prevention. Multistate outbreak of Salmonella infections associated with peanut butter and peanut butter-containing products United States, 2008-2009. MMWR 2009;58:85-90.

16. Nordic outbreak investigation team. Joint analysis by the Nordic countries of a hepatitis A outbreak, October 2012 to June 2013: frozen strawberries suspected. Euro Surveill 2013;18(27). pii: 20520. Available from:

http://www.eurosurveillance.org/ViewArticle.aspx?ArticleId=20520

17. Brooks JT, Matyas BT, Fontana J, DeGroot MA, Beuchat LR, Hoekstra M, et al. An outbreak of Salmonella serotype Typhimuirum infections with unusually long incubation period. Foodborne Pathog Dis. 2012 Mar;9:245-8.

18. Hutwagner et al. Using Laboratory-Based Surveillance Data for Prevention: An Algorithm for Detecting Salmonella Outbreaks. EID. Vol 3, No 3. July-Sept. 1997.

19. Gossner, C. ECDC launches the second version of the EPIS-FWD platform. Euro Surveillance 2013; 18(27). pii:20517. Available from :

http://www.eurosurveillance.org/ViewArticle.aspx?ArticleId=20517 


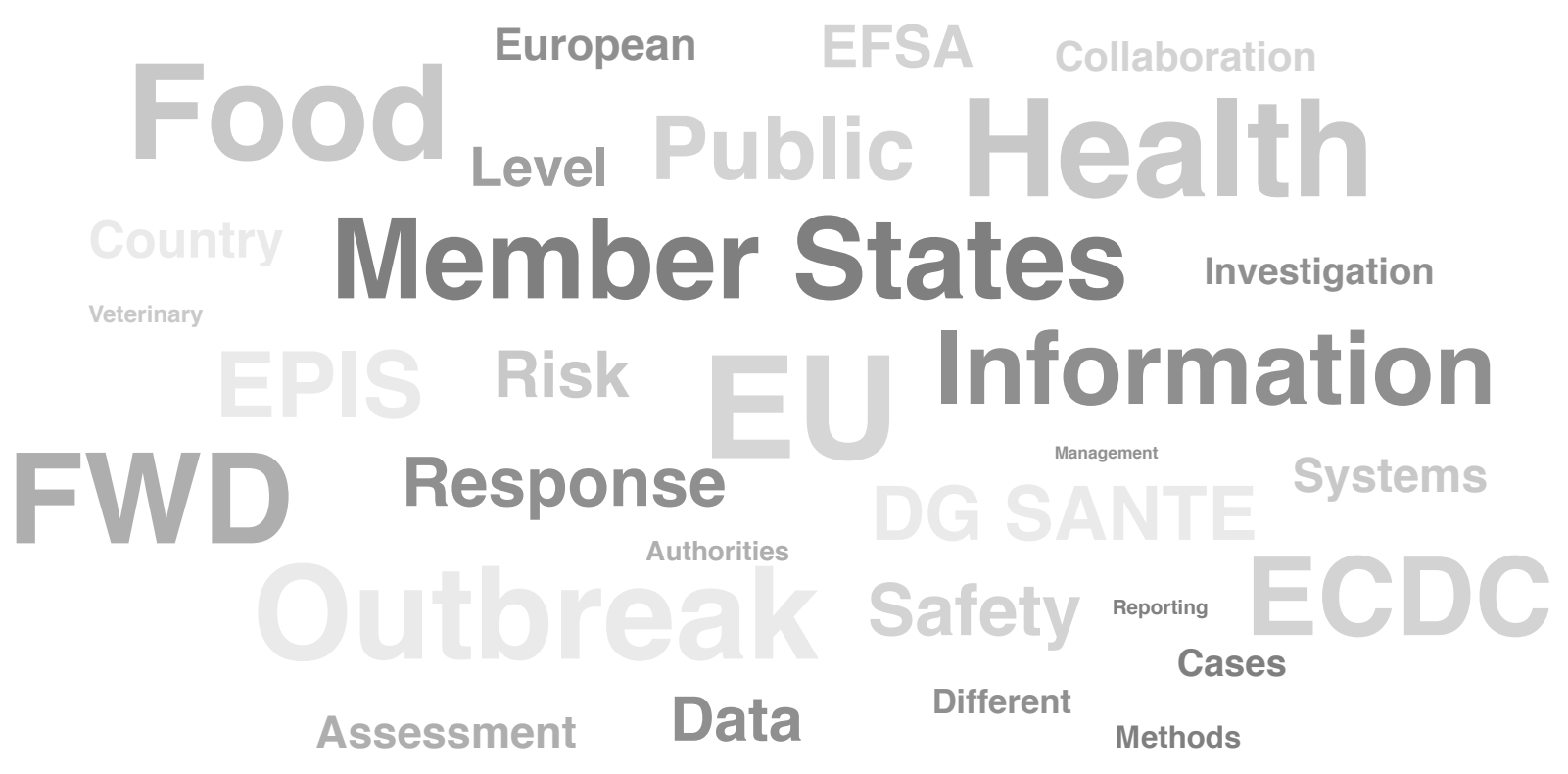

SECTION V

GENERAL DISCUSSION 
Section $\mathbf{V}$ is a general discussion to this thesis. Chapter $\mathbf{1 0}$ discusses the main findings presented earlier in this thesis, highlights some of the challenges of the FWD surveillance and response mechanisms, and provides some avenues for strengthening such mechanisms. 


\section{Chapter 10}

\section{DISCUSSION AND KEY RECOMMENDATIONS}


This chapter addresses four key topics of discussion that rose from the articles presented earlier in this thesis:

(i) people working on surveillance and outbreak response, with a focus on the collaboration among public health experts as well as between experts from different sectors at the national and the European Union (EU) level, highlighting the challenges;

(ii) systems for surveillance and outbreak response in place to support the activities, describing the multiple systems in place at the EU level and investigating possibilities to expand their scope and better connect them together;

(iii) epidemiological methods for detection, reporting and investigation of outbreaks, highlighting challenges and describing new tools that could be developed;

(iv) laboratory methods for detection and investigation of outbreaks, with their limitations and new technologies that may radically change the current surveillance processes.

This chapter concludes with ten key recommendations to strengthen event-based surveillance and response to Food- and Water-borne Diseases (FWD) outbreaks in the EU.

\section{(INTER-SECTORIAL) COLLABORATION}

\section{(Inter-sectorial) collaboration and its challenges: national perspective}

Because contaminated food can be broadly distributed within the EU and that point source outbreaks (e.g. restaurant outbreak) may occur in places visited by tourists, multi-country outbreaks are expected to occur in the EU. In order to early detect such outbreaks and reply appropriately, it is paramount that public health authorities in the 28 EU Member States have a coordinated surveillance and outbreak response strategy and that they actively collaborate among each other and with EU institutions. The EU is composed of very diverse Member States making this collaboration challenging. This diversity is expressed not only in terms of infectious disease dynamics, but also in terms of resource allocated to public health (i.e. financial, staff, equipment) and organisation of public health services.

Based on the participation of EU Member States to the EPidemic intelligence Information System for Food and Waterborne Diseases and zoonoses (EPIS-FWD) between 2008 and 2013, the overall collaboration to event-based surveillance in the EU can be considered good. All EU Member States have replied to at least one reported event (urgent inquiry). The difference in participation to EPIS-FWD is however noticeable and translates the diversity between Member States. A total of nine EU Member States did not launch any urgent inquiry between 2008 and 2013, while other countries such as the United Kingdom, France or Denmark posted 20 urgent inquiries or more during this period. In addition, the threshold for Member States to initiate urgent inquiries has been very different; Member States of northern and western Europe had the lowest threshold meaning that they were the most prone to launch urgent inquiries at an early stage and with the lowest number of cases [1].

While collaboration between countries is affected by the overall capacity (human and financial resources) of Member States, it is also affected by their capacity at a certain point in time. For instance, a Member State A may be experiencing several concurrent outbreaks and may decide not to give priority to a multi-country outbreak involving country $A, B, C$ and $D$, particularly if the number of cases that Member State A reports is very low. A priority for one country may not be a priority for another. In such circumstances, if long term collaboration 
with regular communication is established between Member States, it is more likely that they would be willing to support the investigation despite it is not their priority.

During a multi-country outbreak investigation, not only public health authorities in different Member States should collaborate among themselves but also they should collaborate with authorities from other sectors and particularly authorities from the food safety and veterinary health sector. Exchange of information between public health authorities and food safety and veterinary health authorities was proven essential during outbreak investigations, as showed in the investigation of the outbreak of monophasic $S$. Typhimurium in France in 2011 [2] and the multi-country HAV outbreak in the EU in 2013 [3]. Despite the good will of experts from all fields, coordination of multi-country investigations remains complex [4, 5]. Timely and transparent sharing of information is not systematically implemented for various reasons: simply not thinking about it, protectionisms, (perceived) lack of time or lack of procedure for sharing information. While collaboration between sectors is well established in some EU Member States, it is not yet routine procedure for other Member States [5]. The fact that public health as well as food safety and veterinary health experts are generally based in different institutions, with different missions may contribute to the challenge. While public health experts would aim at disclosing information as soon as possible about a suspected vehicle of infection, food safety authorities, and particularly risk managers, would generally be willing to wait until all the evidence possible is gathered and point without any doubt at one food item before communicating about the findings and implementing control measures such as a product recall. The recurrent question is "when is there enough evidence"? [4] Recalls or withdrawals of products have economical repercussion on the producer or the production sector at stake. Premature, erroneous announcement or withdrawal from the market can be disastrous for an industry $[6,7]$ and must be avoided. But how long can you wait until disclosing information about a potential vehicle of infection when, daily, new human cases are detected? To find the right balance it is crucial that all communications about a possible vehicle of infection is coordinated between all involved parties in order to avoid diffusing different messages and create confusion among consumers. Therefore timely sharing of evidence between experts and establishing a high level of trust is crucial to ensure that appropriate measures are timely implemented.

While the scientific independency of risk assessment agencies should be ensured (free from any political or commercial pressure), it is important to establish continuous exchange of information between risk assessors and risk managers, both at the national level and the EU level. In fact, all stakeholders gather information that may be relevant to the others. For instance, during the course of an outbreak investigation, the identification of a contaminated food item should trigger a notification through the Rapid Alert System for Food and Feed (RASFF). Such notification is part of food safety risk management procedures but it could be key information to the risk assessors both from the public health and from the food safety side. Likewise, risk managers should be informed as soon as possible about any potential threat detected through the surveillance systems in place in order to anticipate any potential need for mitigation measures. In addition, the contribution of risk assessors during trace-back and trace-forward activities, which is the responsibility of the risk managers, is crucial as risk assessors can support the interpretation of the results.

\section{(Inter-sectorial) collaboration and its challenges: $E U$ perspective}

At the EU level, a similar division between risk assessment and risk management for public health and food safety exist. 
The European Centre for Disease Prevention and Control (ECDC) is an independent EU agency mandated "to identify, assess and communicate current and emerging threats to human health from communicable diseases" [8].

The European Food Safety Authority (EFSA), also an independent EU agency, assesses and communicates about existing and emerging risks related to food and feed safety, nutrition, animal health and welfare, plant protection and plant health [9].

The European Commission is responsible for the management of the identified risks. The European Commission Directorate General for Health and Food Safety - Public health, country knowledge, crisis management directorate (DG SANTE C) is in charge of risk management activities regarding public health matters. The European Commission Directorate General for Health and Food Safety - Crisis management in food, animals and plants directorate (DG SANTE G) is in charge of risk management activities regarding food safety and veterinary health matters (Table 1).

Table 1. Division of responsibilities for food- and water-borne diseases event-based surveillance and outbreak response at the $E U$ level and geographical base of the stakeholders

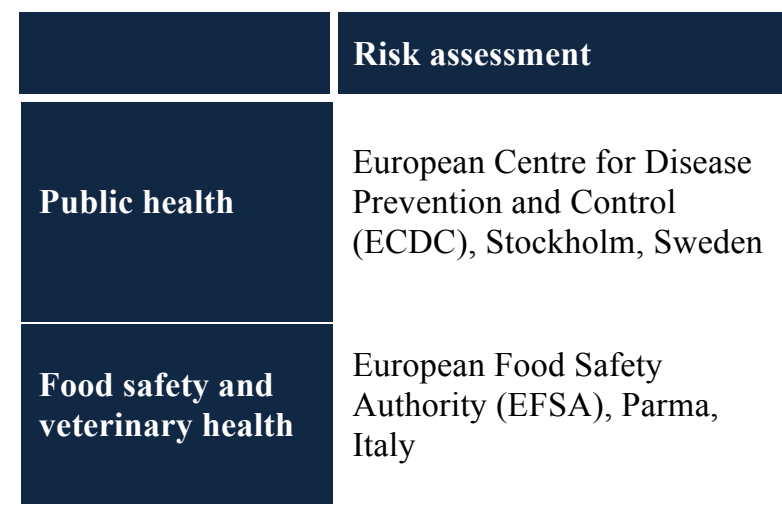

\section{Risk management}

European Commission Directorate General for Health and Food Safety - Public health, country knowledge, crisis management directorate (DG SANTE C), Luxembourg City, Luxembourg

European Commission Directorate General for Health and Food Safety - Crisis management in food, animals and plants directorate (DG SANTE G), Brussels, Belgium

The Treaties of the European Union are a set of international legal documents agreed among the EU Member States, which constitute EU constitutional basis. The Treaty on European Union (TEU) and the Treaty on the functioning of the European Union (TFEU) are the two core functional treaties of the EU, where TEU sets up general principles on EU law while TFEU defines the framework of EU's authority to legislate. According to the principle of conferral, the EU can only act within the limits of its competences. Competences that are not conferred to the EU remain by default with the Member States. As defined in Articles 2 to 6 of TFEU, there are three categories of competences: First, exclusive competence of the EU. Unless agreed beforehand with Member States, the EU is the only one to be able to legislate and adopt legally binding acts in the defined area. Second, shared competences between the EU and Member States. Both the EU and the Member States may legislate and adopt legally binding acts in the defined area. Third, the EU has the competence to carry out actions to support, coordinate or supplement the actions of Member States [10].

Agriculture, which includes food safety and veterinary health, is an area of shared competences. Protection and improvement of human health, which includes public health, is however an area where the EU should support, coordinate or supplement the actions of Member States [10].

This difference in EU competence between the area of agriculture and the area of protection and improvement of human health has a direct impact on how ECDC, EFSA, DG SANTE C 
and DG SANTE $G$ operate. Given the fact that agriculture is a shared competence, agricultural affairs are very much regulated at the EU level. As a consequence, EFSA's mandate is relatively constraining, leaving very little margin for the agency to act on its own initiative. In terms of public health threats, the EU legislation is restricted to Directive $1082 / 2013 / \mathrm{EU}$ on serious cross-border threats to health [10] and ECDC's mandate is therefore more loosely defined, offering "freedom" to the agency to act on its own initiative.

Because there is no perfect symmetry in terms of roles and responsibilities between ECDC and DG SANTE $\mathrm{C}$ on one side and EFSA and DG SANTE $\mathrm{G}$ on the other side, the collaboration among EU actors can be challenging, particularly during multi-country outbreak investigations as leadership can become a discussion point [11].

While ECDC routinely prepares rapid risk assessments within a couple of days that are mostly based on observational data and experts knowledge [11, 12], EFSA relies on expert panels who produce scientific opinions generally within few weeks/months and following the Codex Alimentarius guidance [13]. Therefore the working processes of assessing the risks are different making the production of joint assessments challenging. To standardise the production of joint assessments, ECDC and EFSA have been developing standard operating procedures that have been followed since 2013.

ECDC, EFSA, DG SANTE C and DG SANTE G have also been using different terminology. For instance, for using the word "risk" implies that the assessment follows Codex Alimentarius guidance, which does not hold true for ECDC. So joint assessment could not be called "joint rapid risk assessment" and have been renamed "joint rapid outbreak assessment". Another example is the term "outbreak investigation". While ECDC is considering outbreak investigation as gathering information to better assess the risk, DG SANTE G considers it is already part of the management of the risk.

Finally, not only the EU framework stakeholders are involved in surveillance and outbreak response, but also stakeholders from the United Nations (UN) framework. In fact, organisations such as the World Health Organization (WHO) and the Food and Agricultural Organization (FAO) have a global scope and therefore are also mandated to act within the EU. This adds a level of complexity in terms of coordination of actions within the EU but such collaboration between EU and UN organisations remains is extremely valuable, particularly when outbreaks are also affecting non-EU countries (e.g. melamine incident [14]).

The fact that all these stakeholders are based in different countries (Table 1) does not facilitate the collaboration. Despite exchange of information is eased by technology, face-toface interaction is always preferable to establish trust and build long-term work relationship.

\section{Avenues to strengthen (inter-sectorial) collaboration}

ECDC, EFSA, DG SANTE $C$ and DG SANTE $G$ should clarify their roles and responsibilities during outbreak investigation and further develop standard operating procedures to facilitate their collaboration. In addition, they should develop an information sheet, for national experts and the general public, summarising the EU response mechanisms to FWD outbreaks. Such information sheet could, eventually, serve as a lead example for national institutions within the EU. The complementary role of the WHO/FAO International Network of Food Safety Authorities (INFOSAN) should be included. This information sheet could include some case scenarios and success stories of outbreak investigations. 
Establishing direct contact and trust between experts from different institutions is key to ensure that experts would be willing to share information during an outbreak investigation. Such collaboration should be established during "peace time" and based preferably on routine work (e.g. the production of yearly reports).

On 14 and 15 May 2013, DG SANTE organised exercise Aristaeus [5] which was a large multidisciplinary simulation exercise aiming at reviewing processes of detection, assessment and management of multi-country food-borne outbreaks in order to strengthen preparedness. The exercise gathered public health experts, food safety experts and communication experts from all EU Member States, Switzerland, Norway, Iceland and Turkey, plus experts from ECDC, EFSA, DG SANTE C and DG SANTE G, and WHO. This type of multidisciplinary exercise proved to be very useful to highlight strengths and weaknesses of the surveillance and outbreak response activities at national and EU level. In addition, such large exercise is an excellent networking platform for experts and good training. Despite the high financial cost of such simulation exercise, it would be beneficial to organise them on a regular basis. In addition, multidisciplinary collaboration should be strengthened through joint public health and food safety and veterinary health trainings. ECDC, EFSA, DG SANTE C and DG SANTE G should jointly develop a training curriculum covering the different aspects of event-based surveillance and outbreak response that would be offered to EU Member States experts working in public health institutes, food safety and veterinary health institutes but also Ministries of health and Ministries of Agriculture. Such training could be based on existing training such as Better training for safer food [15] organised by DG SANTE G and short ECDC and EFSA training modules [16, 17]. Post outbreaks lessons learned workshop could also be organised in order to debrief on experiences and identify possible improvements.

\section{SYSTEMS FOR SURVEILLANCE AND OUTBREAK RESPONSE}

\section{Multiples independent systems in place at the EU level}

In this thesis, we used data collected through the main surveillance and outbreak responses systems for FWD in place at the EU level: EPidemic intelligence Information System for Food- and Water-borne Diseases and zoonoses (EPIS-FWD), The European Surveillance System (TESSY), the European Warning and Response System (EWRS), the Data Collection Framework (DCF) and the Rapid Alert System for Food and Feed (RASFF) (Table 2). In addition, we used data collected through the International Network of Food Safety Authorities (INFOSAN) of the United Nations (Table 2). 
Table 2. Description of the surveillance and outbreak responses systems for food- and water-borne diseases in place at the EU level

\begin{tabular}{|c|c|c|c|c|c|}
\hline $\begin{array}{l}\text { Name of the } \\
\text { surveillance and } \\
\text { response system }\end{array}$ & $\begin{array}{l}\text { Owner of the } \\
\text { system }\end{array}$ & Legal basis & $\begin{array}{l}\text { Type of } \\
\text { surveillance and } \\
\text { response systems }\end{array}$ & Participants & Objective(s) \\
\hline \multicolumn{6}{|c|}{ Public health risk assessment } \\
\hline $\begin{array}{l}\text { The EPidemic } \\
\text { intelligence } \\
\text { Information System } \\
\text { for Food- and Water- } \\
\text { borne Diseases and } \\
\text { zoonoses (EPIS- } \\
\text { FWD) }\end{array}$ & $\begin{array}{l}\text { European Centre } \\
\text { for Diseases } \\
\text { Prevention and } \\
\text { Control (ECDC) }\end{array}$ & $\begin{array}{l}\text { None, } \\
\text { voluntary } \\
\text { basis }\end{array}$ & $\begin{array}{l}\text { Event-based } \\
\text { surveillance and } \\
\text { response system }\end{array}$ & $\begin{array}{l}\text { Experts from the public health } \\
\text { institutes and ministries of health } \\
\text { from the } 28 \text { EU Member States, plus } \\
17 \text { non-EU countries [18] } \\
\text { Experts from DG SANTE C } \\
\text { On an ad-hoc basis, experts from } \\
\text { EFSA, DG SANTE G, WHO and } \\
\text { any other experts involved in an } \\
\text { investigation could be invited }\end{array}$ & $\begin{array}{l}\text { To ensure transparent and timely } \\
\text { information sharing in order to detect } \\
\text { public health threats at an early stage and } \\
\text { facilitate their reporting under Decision } \\
1082 / 2013 / \mathrm{EU}[10] \text { and the coordination } \\
\text { of response activities. }\end{array}$ \\
\hline $\begin{array}{l}\text { The European } \\
\text { Surveillance System } \\
\text { (TESSy) }\end{array}$ & ECDC & $\begin{array}{l}\text { Decision } \\
2000 / 96 / \mathrm{EC} \\
{[19] \text { and }} \\
2003 / 534 / \mathrm{EC} \\
{[20]}\end{array}$ & $\begin{array}{l}\text { Indicator-based } \\
\text { surveillance system }\end{array}$ & $\begin{array}{l}\text { Experts from the public health } \\
\text { institutes from the } 28 \text { EU Member } \\
\text { States plus Iceland and Norway } \\
\text { [21]. }\end{array}$ & $\begin{array}{l}\text { To collect in a structured way, } \\
\text { epidemiological and microbiological } \\
\text { human data for the detection of outbreak, } \\
\text { the assessment of the epidemiological } \\
\text { and microbiological situation and to } \\
\text { define trends. }\end{array}$ \\
\hline
\end{tabular}

Public health risk management

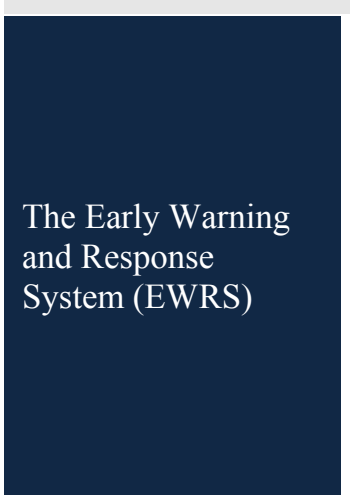

$\begin{array}{lll}\text { European } & & \\ \text { Commission } & & \\ \text { Directorate } & & \\ \text { General for } & & \\ \text { Health and Food } & \text { Decision } & \text { Event-based } \\ \text { Safety - Public } & 1082 / 2013 / \mathrm{E} & \begin{array}{l}\text { surveillance and } \\ \text { hesponse system }\end{array} \\ \text { knowledge, crisis } & \mathrm{U}[10] & \\ \text { management } & & \\ \text { directorate (DG } & & \\ \text { SANTE C) } & & \\ & & \end{array}$

Experts from ministries of health from the 28 EU Member States plus Iceland, Lichtenstein and Norway. Experts from ECDC, EFSA and the World Health Organization (WHO)

Other organisations non-relevant to FWD.
To ensure transparent and timely sharing of information about control measures for serious cross-border health threats. 
Food safety and veterinary health risk assessment response systems

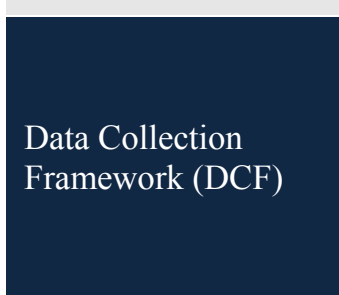

European Food Safety Authority

(EFSA)

Directive

2003/99/EC

[22]
Food safety and veterinary health risk management

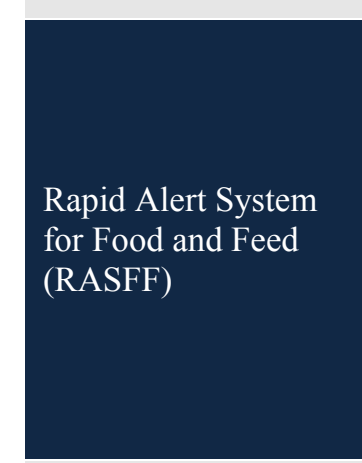

European

Commission

Directorate
General

for

Health and Food

Safety - Crisis

management in

food, animals

and plants

directorate (DG

SANTE G)
To collect in a structured way,

Experts from food and veterinary
Indicator-based surveillance system States plus Iceland, Norway and Switzerland [23]. epidemiological and microbiological data from food, feed, animal and environment and food-borne outbreaks for the

assessment of the epidemiological and microbiological situation and to define trends.
Public health and food safety and veterinary health risk assessment and management

International
Network of Food
Safety Authorities
(INFOSAN)

World Health

Organization

International

and Agriculture Regulation

Organization

(FAO)
Experts from the ministry of

agriculture from the 28 EU Member To rapidly share information about States plus Iceland, Liechtenstein,

Norway and Switzerland.

Experts from EFSA [25] and from risks detected in relation to food or feed. measures taken responding to serious

\section{ECDC}

National authorities from $28 \mathrm{EU}$ Member States plus 153 additional countries [27, 28].
Promoting the exchange of information among its members and strengthening capacity for outbreak management [29] surveillance and

response system
Experts from RASFF and ECDC 
Named systems have different focus and can be seen as complementary. They gather data that, combined, allows the observation of trends and supports the detection and assessment of multi-country outbreaks. In terms of systems' operability, their "interconnectivity" is limited and there is room for better integration of at least EPIS-FWD, EWRS and RASFF [1, 11]. To gather data during outbreak investigations, all EU surveillance and outbreak response systems (see table 2) are queried independently, results are compiled manually and shared afterwards with everybody involved in the investigation through EPIS-FWD, EWRS and potentially RASFF. These systems are working in silos and their respective roles are not clear to all users leading to a lack of consistency in notifying events through the appropriate system $[1,11]$.

In addition, both ECDC and EFSA are collecting data on human FWD outbreaks, through EPIS-FWD and DCF. The timeframe is different as EPIS-FWD aims at detecting outbreaks in "as much as possible" real-time while DCF aims at a collection of retrospective data. Nonetheless, considering that data on human outbreaks are gathered by public health institutes, ECDC may consider taking over the collection of retrospective data on food-borne outbreaks.

\section{Moving towards an integration of these systems and their expansion}

A first step to facilitate the reporting through the appropriate systems would be for ECDC and DG SANTE $C$ to develop guidelines for surveillance and outbreak response detailing how information should be reported through EPIS-FWD and EWRS [1]. In addition, ECDC and DG SANTE C should play a more active role in the monitoring of the notifications through EPIS-FWD and EWRS, and should provide guidance to the EU Member States when events or threats are not reported appropriately [1].

Ultimately, EU systems should be revised in order to streamline the flow of information. In 2013, ECDC launched an updated version of EPIS-FWD [30] with the aim to establish a connection between EPIS-FWD and TESSy and to promote a multidisciplinary approach to outbreak investigations. In the updated version of EPISFWD, cross-border microbiological signals that are detected using the molecular typing data on Salmonella, Listeria and STEC submitted through TESSy are registered as Molecular Typing Cluster Investigation (MTCI) in EPIS-FWD and affected Member States are automatically informed. The registration of such clusters is still performed manually, but ECDC is working towards an automation of the process.

In addition, the new version of EPIS-FWD allows the invitation of experts that are not regular users of the platform (e.g. food safety or environmental experts) to access the information shared regarding a specific event and to provide their expertise. Experts from WHO, EFSA and DG SANTE G can therefore also be invited when relevant. By bringing together experts from different fields, EPIS-FWD is playing a central role at the EU level in surveillance and outbreak response to FWD.

In 2015, ECDC, together with EFSA, initiated a revision of EPIS-FWD in order to foster inter-sectorial collaboration. By the end of 2016, EFSA and food safety and veterinary health experts nominated by EFSA should have a dedicated forum for the assessment of microbiological clusters from non-human (food, feed, animal and environmental) isolates. This mirrors the MTCI forum that ECDC and public health experts are using for the assessment of microbiological clusters from human isolates. 
Public health experts and food safety and veterinary health experts will be gathered for the assessment of microbiological clusters including human- and non-human isolates. Food safety and veterinary health experts and EFSA will then be invited in a more systematic way to contribute to the assessment of events (urgent inquiries) in EPIS-FWD. Through this integration, EPIS-FWD becomes a central assessment tool for multi-sectorial microbiological clusters and events in the EU.

Because contaminated products may be exported to or imported from non-EU countries and because EU citizens may be infected while abroad, EPIS-FWD is open to 17 non-EU countries [18]. In 2016, EPIS-FWD should go through a new enlargement with the entry of 15 additional countries from the Mediterranean region and Eastern Europe [31]. The challenge is to ensure that all new participating countries have the capacity to detect outbreak and contribute to the discussion. Opening the platform to new countries should be done following a step-wise approach in order to ensure that all new users are trained appropriately. The proven success of EPIS-FWD in detecting outbreaks at a very early stage relies on trust between the participating countries and, despite more countries will have access to the system, this trust should be maintained. To enforce confidentiality, all newly nominated experts accessing EPIS-FWD must sign a confidentiality agreement that, if not respected, would allow the exclusion of the user who did not respect the agreement. As EPISFWD gathers experts from non-EU countries, a close interaction between EPIS-FWD and INFOSAN is crucial. A matching of EPIS-FWD and INFOSAN users and potentially a link between systems could be foreseen.

A list of all RASFF notifications with limited epidemiological and microbiological information is made available daily on DG SANTE G website. This ensures that public health experts and any food safety experts who would not have access to RASFF are aware of all notifications. Further information can be requested through contacting relevant authorities.

EWRS contact points have access to EPIS-FWD, which provides a one-way continuum between risk assessment and risk management on the public health side. It is therefore important that ECDC ensures that EPIS-FWD is regularly updated with information from EWRS that is relevant to the assessment of the risk.

Finally, after ten years of operation ECDC initiated in 2015 a revision of its surveillance systems. The objective is to strengthen its data collection process and facilitate the joint analysis of the indicator- and event-based surveillance data. This revision includes both TESSy and EPIS-FWD, which will be assessed and potentially restructured from a business and IT perspective in the coming years. This could be the opportunity to confirm the central role of EPIS-FWD in strengthening its role in linking risk assessors and risk managers from the public health and the food safety and veterinary health sector. This could also be an opportunity to integrate the reporting of retrospective food-borne outbreaks currently ensured by EFSA to TESSy. Ideally, linkages between case-based data from TESSy, event-based data from EPISFWD and data on retrospective food-borne outbreaks should be implemented to allow cross-analysis. 


\section{DETECTION, REPORTING AND EPIDEMIOLOGICAL INVESTIGATIONS OF OUTBREAKS}

\section{Challenges of detection, reporting and epidemiological investigations}

Delay in detecting and reporting outbreaks

The delay in detecting and reporting outbreaks influences the chances to timely investigate outbreaks and implement efficient mitigation measures.

The length of the incubation period of pathogens not only affects the possibility to timely detect outbreaks, but also makes investigations more challenging. This is particularly true when the pathogen's genotype is prevalent. In fact, the longer the incubation period, the more difficult it is to link cases epidemiologically since the cases would be less likely to recall his/her food consumption. For instance, food consumption history is generally more difficult to collect when investigating listeriosis or HAV infection outbreaks compared to salmonellosis outbreaks. To overcome this recall bias, interview questionnaires of the cases focus on habits instead of actual consumption of specific products at the potential time of the infection.

Evidently, the lack of human and financial resources to collect and analyse the samples and the data is also a limitation to the detection of outbreaks.

In this thesis, we present two extreme examples of delays in reporting to the international level (EU or globally): Outbreak of monophasic Salmonella Typhimurium 4,[5],12:i:- infection associated with consumption of dried pork in France, 2011 [2] and the melamine incident from China, 2009 [14]. In the first example, France detected the salmonellosis outbreak and notified it through EPISFWD and EWRS within few days. Despite no food samples revealed to be positive, the food safety authorities initiated a product recall based on the epidemiological evidence. Within a few weeks, the outbreak ended. In the second example, the first children showed signs of renal failure more than six months before the Chinese national authorities officially acknowledged the event and reported it on the global level (through INFOSAN). Delay in reporting potential multi-country outbreaks through EPIS-FWD, may be due to the fact that the country did not detect the outbreak at the national level $[3,32]$ or that the country decided to not communicate the information [14]. Cultural differences between countries are clearly influencing the pro-activity of the countries to report potential multi-country events in EPISFWD. In fact, in some cultures transparency is very much valued and reporting outbreaks is seen as performance of the surveillance system. For other cultures, acknowledging the occurrence of an outbreak is seen as a failure in prevention; in addition, the fear of seeing trade and travel restrictions remains.

Reporting events and threats with a possible international public health impact is the responsibility of everyone involved in public health and food safety, including the private sector (i.e. food producers). Withholding the report of events or threats for political or economic reasons could only negatively affect the health outcome and the credibility of the authorities and the image of the entire production chain. To shorten reporting delays from EU Member States in EPIS-FWD, it is key that Member States understand the benefices of early reporting and that they trust that information provided will remain confidential. 


\section{Incompleteness of the data collected}

Another challenge for surveillance and outbreak response at the EU level is the incompleteness of some of the data collected through TESSy. When an outbreak is declared, it is expected that data about recent cases is incomplete and the assessment should take this into account and it should be updated as new information comes along. However, background information from previous years should be as complete as possible in order to compare the outbreak situation with previous years. While EU Member States must notify all cases of notifiable diseases through TESSy, only few descriptive variables are mandatory fields. The remaining of the epidemiological and microbiological variables is filled on a voluntary basis by Member States. The lack of completeness in the descriptive variables (i.e. severity, outcome, travel history) was particularly limiting while collecting background data for the assessment of the HAV situation in the EU in 2013 [33]. This incompleteness comes either from the fact that Member States are not capturing those variables at national level or that they are not submitting those to the EU level. A revision of the list of descriptive variables should be considered by ECDC to potentially have less variables but more complete data for the remaining variables.

\section{Multiple languages and diversity of food items}

During multi-country FWD outbreaks investigation, it is a challenge to develop questionnaires for trawling interviews and case control studies that could be used by several countries. First, the questionnaires are often developed in Microsoft Word format, which is not suitable for rapid analysis of the results, particularly when several countries are contributing with data. Second, a questionnaire developed by one country might not be automatically relevant to the other countries as food specialties and their name might be completely different from one country to the other. Third, the language barrier and the need to translate the questionnaire are issues that delay a lot the investigations.

On 23 and 24 February 2015, ECDC organised an expert meeting gathering experts from Denmark, France, Germany, Italy, Switzerland, the United States and EFSA in order to identify questionnaire tools existing in participating countries, define common needs and solutions to meet these needs, and to explore the possibilities to develop or adapt a tool that would allow easy and rapid creation of multi-language questionnaire for multi-country FWD outbreak investigations (descriptive and analytic studies) [34].

The main need identified by participants was to have a database of standard pretranslated questions with some sort of IT support to create a questionnaire when needed. This pool of questions would facilitate the development of trawling, case control and cohort study questionnaires. Standards questionnaires could be developed with the possibility to modify them as needed. The questions should be translated in several EU languages and possibly also in non-EU languages like Arabic or Turkish.

During multi-country investigations, using similar trawling questionnaires and casecontrol study questionnaires would make analysis much more powerful as the data could be easily compared. 


\section{New tools for outbreak investigation}

The living habits are constantly evolving and the tools used for epidemiological investigation of outbreaks need to be adapted. In article "Nationwide outbreak of Salmonella enterica serotype 4,[5],12:i:- infection associated with consumption of dried pork sausage, France, November to December 2011" [2], we described how the use of loyalty cards contributed to the outbreak investigation.

Credit/debit cards and loyalty cards are more and more used by consumers and were proven to be an asset during outbreak investigations. Credit/debit card receipts and loyalty cards can facilitate the identification of controls during case-control studies for point source outbreaks [35], allow the identification of food items purchased by cases or their relatives during a certain period [2, 36, 37] or support the tracing of food items purchased by cases during trace-forwards investigations [38].

These new tools have however some limitations. Credit/debit cards and loyalty cards receipts or records do not directly reflect the consumption of the cases as food items bought are not necessarily consumed by the cases and cases may have eaten food items not listed in the receipts/records [2]. In some countries the law prohibits or limits the use of such receipts and records due to data protection issues.

Despite the limitations, the new tools were proven to be useful, particularly in complement to traditional epidemiological investigations (e.g. interview of cases) and microbiological investigations.

\section{Outbreak closure}

Closing an outbreak is an integral part of an outbreak investigation. There is no internationally agreed guideline to define when a FWD outbreak should be closed [39] and it can be a complex exercise when the outbreak has a multi-country dimension [14]. Such official closure is however critical to communicate to all involved parties, including consumers, that the outbreak is over, and to re-allocate resources so far assigned to the investigation. It will also provide argument to remove trade barrier that have potentially been in place by other countries.

In the article "Criteria to consider when declaring the end of an enteric illness outbreaks" [39], we explore some criteria to be considered when closing a FWD outbreak. The three criteria suggested are (i) the number of outbreak cases being reported to public health authorities has returned to baseline levels, (ii) the last time that individuals may have been exposed to the implicated source has been identified or estimated, (iii) sufficient time has lapsed for potentially exposed individuals to become ill and be reported to investigating public health authorities. These criteria should support the outbreak investigation team in taking the decision to close the outbreak. Unfortunately, communication about closure of a FWD outbreak is a step that is often neglected by investigators who switch immediately to new or other ongoing investigations. 


\section{MOLECULAR CHARACTERISATION FOR SURVEILLANCE AND OUTBREAK RESPONSE}

\section{Overview of methods currently used and limitations}

As part of surveillance and outbreak investigation, molecular typing of FWD pathogens has become a key element. Through different laboratory methods, molecular typing allows detailed characterisation of organisms within the same species, based on their genomes or the phenotypic expression of it. Ideally, typing methods should be sensitive, rapid, inexpensive, robust, portable and easy to perform by any laboratory personnel [40].

The set of molecular typing methods applied is pathogen specific. For instance, for Salmonella enterica subsp. enterica, the gold standard typing methods are serotyping and Pulsed Field Gel Electrophoresis (PFGE) [40]. Used since the beginning of the 20th century, serotyping corresponds to the agglutination of the bacteria with specific sera and it serves as the basis of the White-Kauffmann-Le Minor scheme. It allows distinguishing more than 1500 serotypes of Salmonella enterica subsp. enterica [4143]. Serotyping is widely used despite it is a tedious, costly and relatively un-sensitive (low discriminatory power) method [44]. When the serotype is rare, serotyping can however be sufficient to detect an outbreak (e.g. Salmonella Strathcona outbreak in datterino tomatoes in Denmark, 2011 [45]). Introduced in the 1990s, PFGE is a DNA based subtyping method providing a higher resolution, despite its discriminatory power differs from serotype to serotype [46]. The method is time and labour intensive and requires a high level of standardization in order to obtain comparable results. However, it has been up to now a useful tool for the detection and investigation of Salmonella enterica subsp. enterica outbreaks.

In the past 20 years, new methods have been developed, most of them DNA based [40]. Among those new methods, one can cite Multiple Locus Variable-number tandem repeat Analysis (MLVA) [47] and Clustered Regularly Interspersed Short Palindromic Repeats (CRISPR) [40] that were both used to subtype monophasic Salmonella Typhimurium in one of the outbreak described earlier in this thesis [2].

MLVA is a simple and inexpensive method [40]. Given that it does not permit the assignment of serovars, it is mostly used to compare profiles within a same serotype. It is so far validated for only two serotypes: Salmonella Typhimurium and Enteritidis [48, 49]. CRISPR is a rapid technic that allows both typing and subtyping of Salmonella strains. The method is relatively new but seems to be a promising alternative to serotyping and PFGE [50].

One single serotype and six genotypes (genotypes I to VI) of hepatitis A virus (HAV) have been described [51, 52]. Only genotypes I, II and III, which are further divided into two subtypes A and B, are infecting human. The genotype is defined based on the analysis of the 900 nucleotides of the VP1 protein [52]. The first line characterisation of HAV for public health surveillance purposes is mostly based on genotyping and subtyping of the strains. However for the detection and delineation of multi-country HAV outbreaks, sequencing (RNA-sequencing) of additional regions of the HAV genome is necessary [3]. In the HAV outbreaks described in this thesis [3], an important laboratory limitation was the technical difficulty to isolate the virus in food products, which makes food attribution and source identification challenging.

For other pathogens like Campylobacter, outbreak detection is mostly limited by the lack of availability of typing methods that can be used routinely and that have a 
discriminatory power sufficient to delineate outbreaks. This explains the relatively low number of outbreak cases detected compared to the number of sporadic cases [1, 23, 53].

Molecular characterisation is a key element of surveillance and outbreak response to FWD. At the EU level, it is essential that all Member States have the capacity to routinely characterize common pathogens and that laboratory results can be shared and compared with other Member States. To achieve comparability of results, laboratories should use commonly agreed protocols. Systems like TESSy and EPISFWD allow the gathering and exchange of laboratory information at the EU level with support the detection and assessment of multi-country outbreaks.

\section{Whole genome sequencing and culture-independent diagnostic tests}

While some EU Member States have limited capacity to detect and investigate signals from the most common FWD pathogens [54], some other EU Member States are already moving towards next generation of advanced molecular detection such as Whole Genome Sequencing (WGS) (e.g. the United Kingdom [55]).

WGS potentially permits to find in one test, information about the species, serotype and subtype when three tests are otherwise required using traditional typing techniques. WGS is faster than PFGE typing and the process can be automated [56].

WGS is a precise forensic tool that is more and more used. It allows high level of delineation of an outbreak and strong association with potential causative agent of outbreaks when food and clinical isolates are available [55, 57-60] but results remain so far difficult to interpret. The main reasons for this have been the lack of standardisation of methods and analytical pathways and the computer power needed to process the large amounts of data generated using this methodology. By comparing WGS results with results obtained with commonly used methods, and combining the information with epidemiological data, microbiologists and epidemiologists are building experience and background knowledge that will allow better interpretation of the results.

EU surveillance and outbreak response systems will need to adapt to this shift in technology. The transition should be anticipated as much as possible by ECDC and EU national laboratories to ensure all Member States have the capacity to perform WGS and exchange information when the technology becomes widely used. To prepare for such transition, ECDC set up in 2014-2015 two experts groups: FWDNext and FWD-CRESP respectively for the introduction of next-generation typing methods for FWD [61] and for the development of operational procedures for FWD molecular surveillance and cluster response [62].

A current trend is that while new sequencing methods are being developed, clinicians and clinical laboratories are increasingly using culture-independent diagnostic tests (CIDTs), which allow rapid multi-pathogens testing [63]. As CIDTs do not provide an isolate and because clinicians and clinical laboratories are less likely to perform complementary isolation of pathogens, traditional (sub)-typing of pathogens and identification of resistance patterns will not be possible anymore. This would have direct consequences on the quality of patient therapies (i.e. targeted antibiotic therapy) but also on the entire surveillance strategy. In fact, without (sub)-typing, it will become impossible to link cases microbiologically and therefore impossible to timely detect and an investigate FWD outbreaks. This is why the United States Centres for 
Diseases Control and Prevention (US CDC) is encouraging laboratories to perform reflex culturing, meaning to isolate and culture pathogens with positive CIDT results [64]. US CDC is also working with industries to develop CIDTs that would allow further typing of pathogens and is already adapting its surveillance systems to meet this new public health challenge. At the EU level, ECDC has initiated the revision of the case definitions for FWD pathogens, as suggested by the working group FWDNext [61]. In addition, to ensure surveillance of FWD at national and EU levels, a minimum number of isolates should be sent to the national reference laboratories. Member States such as Austria and the United Kingdom have implemented legal requirement that guarantee the provision of a minimum number of isolate to the national reference laboratories. At the EU level, similar legal requirements will likely be needed [61]. 


\section{TEN KEY RECOMMENDATIONS}

Out of the discussion above, ten key recommendations are proposed aiming to strengthen event-based surveillance and response to FWD outbreaks in the EU.

\section{People working on surveillance and outbreak response}

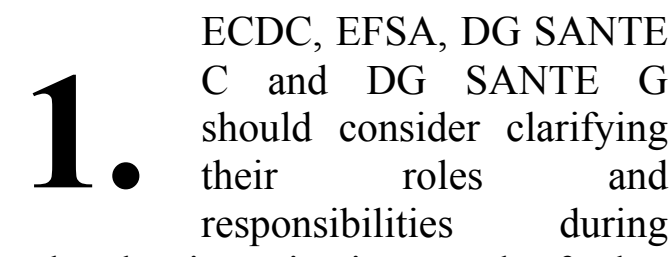

outbreak investigation and further develop standard operating procedures to facilitate their collaboration. In addition, they should consider developing an information sheet, for national experts and the general public, summarising the EU response mechanisms to FWD outbreaks. This information sheet should cover the complementary role of INFOSAN and could include some case scenarios and success stories of outbreak investigations.

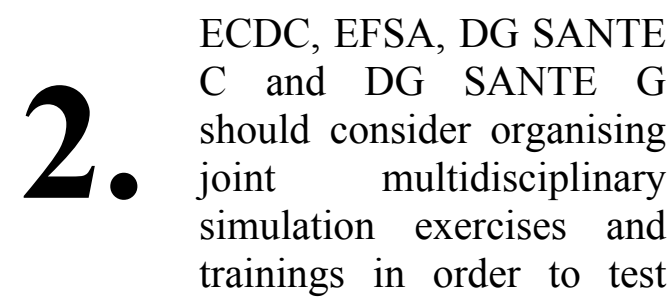

procedures and continuously train experts on different aspects of surveillance and outbreak response. Post outbreaks lessons learned workshop could also be organised in order to debrief on experiences and identify possible improvements. Reducing reporting delays and appropriately using EU surveillance and outbreak response systems should be topics of discussion during these exercises/trainings/workshops.
Systems in place to support surveillance and outbreak response

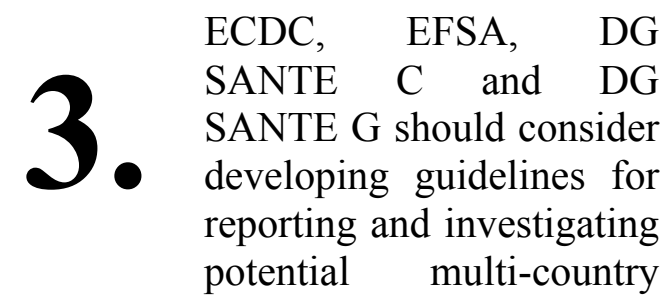

outbreaks to the EU level, including information sharing through EPISFWD and other EU surveillance systems. On the public health side, ECDC and DG SANTE C should play a more active role in monitoring notifications through EPIS-FWD and EWRS and provide guidance to Member States when events are not reported through the appropriate system.

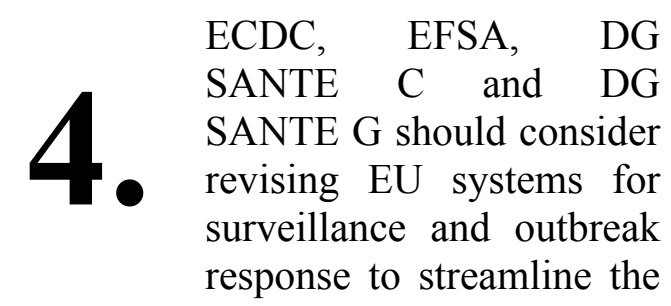
flow of information. The central role of EPIS-FWD in linking risk assessors and risk managers from the public health sector and the food safety and veterinary health sector should be confirmed. 


\section{Epidemiological methods}

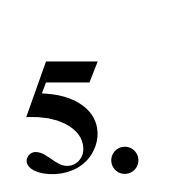

ECDC should consider revising the list of descriptive variables in TESSy in order to improve completeness of the data while still meeting the established surveillance objectives.

ECDC and Member States should consider preparing a "Best Practices" document on new epidemiological methods for outbreaks investigation (i.e. use of debit/credit cards and loyalty cards)

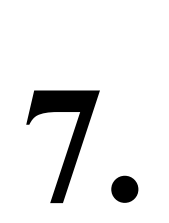

ECDC should consider developing a questionnaire tool for trawling and case control studies interviews during multi-country outbreaks. The tool would allow the rapid development of multilanguages questionnaires and take into consideration the food diversity in the EU.

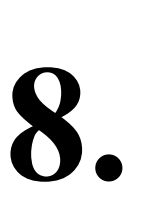

When multi-country outbreaks that have been investigated are considered over, ECDC, EFSA, DG SANTE C and DG SANTE $\mathrm{G}$ should systematically issue a joint closure statement following agreed criteria applied in a systematic way.

\section{Laboratory methods}

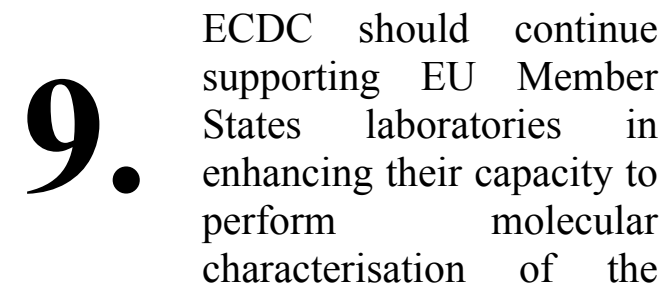

most common food-borne pathogens and promote the use of common protocols and expertise sharing among Member States laboratories.

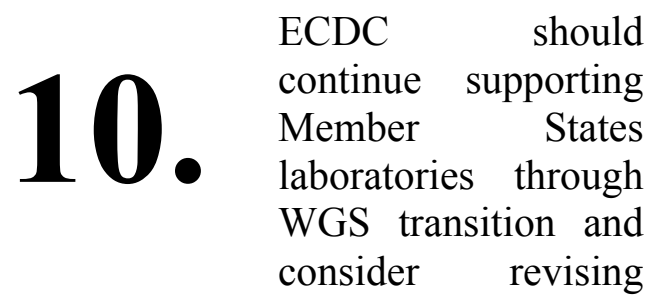
surveillance systems in the light of the generalisation of WGS and CIDTs. 


\section{REFERENCES}

1. Gossner CM, de Jong B, Hoebe CJ, Coulombier D, European F, Waterborne Diseases Study Group C. Event-based surveillance of food- and waterborne diseases in Europe: urgent inquiries (outbreak alerts) during 2008 to 2013. Euro Surveill. 2015;20(25).

2. Gossner CM, van Cauteren D, Le Hello S, Weill FX, Terrien E, Tessier S, et al. Nationwide outbreak of Salmonella enterica serotype 4,[5],12:i:- infection associated with consumption of dried pork sausage, France, November to December 2011. Euro Surveill. 2012;17(5).

3. Gossner C, Severi E. Three simultaneous, food-borne, multi-country outbreaks of hepatitis A virus infection reported in EPIS-FWD in 2013: what does it mean for the European Union? Euro Surveill. 2014;19(43).

4. Kinross P, van Alphen L, Martinez Urtaza J, Struelens M, Takkinen J, Coulombier D, et al. Multidisciplinary investigation of a multicountry outbreak of Salmonella Stanley infections associated with turkey meat in the European Union, August 2011 to January 2013. Euro Surveill. 2014;19(19).

5. Public Health England (PHE). Exercise Aristaeus report. foodborne outbreak, Luxembourg $14 \& 15$ May 2013. Final report 28 Jun 2013. London: PHE. [Accessed 28 July 2015]. Available from:

http://ec.europa.eu/health/preparedness response/docs/exercise aristaeus_report en.p df.

6. E. coli cucumber scare: Spain angry at German claims. BBC. 31 May 2011. Archived from the original on 1 June 2011. [Accessed 20 July 2015]. Available from: http://www.bbc.com/news/world-europe-13605910.

7. Commission staff working document. Lessons learned from the 2011 outbreak of Shiga toxin-producing Escherichia coli

(STEC) O104:H4 in sprouted seeds. SANCO/13004/2011. Available from: http://ec.europa.eu/food/food/biosafety/salmonella/docs/cswd lessons learned en.pdf

8. European Commission. Commission regulation No 851/2004 of 21 April 2004 of the European Parliament and of the Council, establishing the European centre for disease prevention and control. Official Journal of the European Union. Luxembourg: Publications Office of the European Union. 30.4.2004:L142/1. Available from: http://ecdc.europa.eu/en/aboutus/Key\%20Documents/0404_KD_Regulation_establish ing_ECDC.pdf. Official Journal of the European Union.

9. European Commission. Regulation (EC) No 178/2002 of the European Parliament and of the Council of 28 January 2002 laying down the general principles and requirements of food law, establishing the European Food Safety Authority and laying down procedures in matters of food safety. Official Journal of the European Union. Luxembourg: Publications Office of the European Union. 1.2.2002:L31. Available from: http://eurex.europa.eu/LexUriServ/LexUriServ.do?uri=OJ:L:2002:031:0001:0024:EN:PDF.

10. European Commission. Commission decision 1082/2013/EU of the European Parliament and of the Council of 22 October 2013 on serious cross-border threats to health and repealing Decision No 2119/98/EC. Official Journal of the European Union. Luxembourg: Publications Office of the European Union. 5.11.2013:L293/1. 
Available from:

http://ec.europa.eu/health/preparedness_response/docs/decision_serious_crossborder threats 22102013 en.pdf.

11. European Centre for Disease Prevention and Control. The second independent evaluation of the ECDC in accordance with its Founding Regulation (European Parliament and Council Regulation (EC) no 851/2004. Stockholm: ECDC; 2014.

12. European Centre for Disease Prevention and Control. Operational guidance on rapid risk assessment methodology. Stockholm: ECDC; 2011.

13. World Health Organization, Food and Agriculture Organization. Scientific basis for Codex work. [cited 201522 September]; Available from:

http://www.codexalimentarius.org/scientific-basis/en/.

14. Gossner CM, Schlundt J, Ben Embarek P, Hird S, Lo-Fo-Wong D, Beltran JJ, et al. The melamine incident: implications for international food and feed safety.

Environ Health Perspect. 2009 Dec;117(12):1803-8.

15. European Commission (EC). Better training for safer food. Brussels: EC [Accessed 26 November 2015]; Available from:

http://ec.europa.eu/food/training strategy/index en.htm.

16. European Centre for Disease Prevention and Control. Training. [13 Jan 2016]; Available from:

http://ecdc.europa.eu/en/activities/training_activities/Pages/index.aspx.

17. European Food Safety Authority. CT/EFSA/AFSCO/2012/01 - Specialised training courses on certain aspects of food safety risk assessment for EFSA

Panel/Scientific Committee members, open to EFSA scientific staff. [updated 27 Aug 201513 Jan 2016]; Available from:

http://www.efsa.europa.eu/fr/supporting/pub/866e.

18. European Centre for Disease Prevention and Control. Epidemic intelligence tools. [25 July 2015]; Available from:

http://ecdc.europa.eu/en/activities/epidemicintelligence/Pages/EpidemicIntelligence Tools.aspx.

19. European Commission. Commission decision 2000/96/EC of 22 December 1999 on the communicable diseases to be progressively covered by the Community network under Decision No 2119/98/EC of the European Parliament and of the Council. Official Journal of the European Union. Luxembourg: Publications Office of the European Union. 3.2.2000:L28/50. Available from: http://eur-lex.europa.eu/legalcontent/EN/TXT/PDF/?uri=CELEX:32000D0096\&from=EN.

20. European Commission. Commission decision 2003/534/EC of 17 July 2003 amending Decision No 2119/98/EC of the European Parliament and of the Council and Decision 2000/96/EC as regards communicable diseases listed in those decisions and amending Decision 2002/253/EC as regards the case definitions for communicable diseases. Official Journal of the European Union. Luxembourg: Publications Office of the European Union. 23.7.2003:L184/35. Available from: http://eurlex.europa.eu/LexUriServ/LexUriServ.do?uri=OJ:L:2003:184:0035:0039:EN:PDF. 
21. European Centre for Disease Prevention and Control (ECDC). Indicator-based surveillance. [Accessed 24 November 2015]; Available from:

http://ecdc.europa.eu/en/activities/surveillance/Pages/index.aspx.

22. European Commission. Directive 2003/99/EC of the European Parliament and of the Council of 17 November 2003 on the monitoring of zoonoses and zoonotic agents, amending Council Decision 90/424/EEC and repealing Council Directive 92/117/EEC. Official Journal of the European Union. Luxembourg: Publications Office of the European Union. 12.12.2003:L325. Available from: Available from: http://eurlex.europa.eu/LexUriServ/LexUriServ.do?uri=OJ:L:2003:325:0031:0040:EN:PDF.

23. European Food Safety Authority, European Centre for Disease Prevention and Control. The European Union summary report on trends and sources of zoonoses, zoonotic agents and food-borne outbreaks in 2013. EFSA Journal. 2015;13(1):3991. $162 \mathrm{pp}$. Available from: http://www.efsa.europa.eu/en/efsajournal/pub/3991.htm doi:10.2903/j.efsa.2015.3991.

24. European Commission. Commission regulation 16/2011 of 10 January 2011 laying down implementing measures for the Rapid alert system for food and feed. Official Journal of the European Union. Luxembourg: Publications Office of the European Union. 11.1.2011:L6/7. Available from: http://eur-lex.europa.eu/legalcontent/EN/TXT/PDF/?uri=CELEX:32011R0016\&from=EN.

25. European Commission. RASFF - Food and Feed Safety Alerts. [Accessed 22 September 2015]; Available from: http://ec.europa.eu/food/safety/rasff/index en.htm.

26. World Health Organization. Strengthening health security by implementing the International Health Regulations (2005) [cited 201522 September]; Available from: http://www.who.int/ihr/en/.

27. World Health Organization (WHO). International Food Safety Authorities Network (INFOSAN). [Accessed 24 November 2015]; Available from: http://www.who.int/foodsafety/areas work/infosan/en/.

28. World Health Organization (WHO) and Food and Agriculture Organization of the United Nations (FAO). INFOSAN Activity report 2013. Geneva, Switzerland 2014.

29. World Health Organization, Food and Agriculture Organization. INFOSAN Connecting Food Safety Authorities to Reduce Foodborne Risks.

30. Gossner C. ECDC launches the second version of the EPIS-FWD platform. Euro Surveill. 2013;18(27).

31. Gossner C.M, Johansson K, Kotila S, Takkinen J, Coulombier D. Event-based surveillance for food-and water-borne diseases and zoonoses in the European Union: The key role of the Epidemic Intelligence Information System (EPIS-FWD). Submitted.

32. European Centre for Disease Prevention and Control (ECDC). Weekly Communicable Threat Report (CDTR), week 30, 21-27 Jul 2013. . Stockholm: ECDC;2013.

33. Gossner CM, Severi E, Danielsson N, Hutin Y, Coulombier D. Changing hepatitis A epidemiology in the European Union: new challenges and opportunities. Euro Surveill. 2015;20(16). 
34. European Centre for Disease Prevention and Control (ECDC). Specification of an online questionnaire tool for foodborne outbreak investigations Stockholm 23-24 February 2015. Stockholm: ECDC, 2015.

35. Centers for Disease C, Prevention. Outbreak of Salmonella serotype Saintpaul infections associated with multiple raw produce items--United States, 2008. MMWR Morb Mortal Wkly Rep. 2008 Aug 29;57(34):929-34.

36. Ethelberg S, Smith B, Torpdahl M, Lisby M, Boel J, Jensen T, et al. An outbreak of Verocytotoxin-producing Escherichia coli O26:H11 caused by beef sausage, Denmark 2007. Euro Surveill. 2007 May;12(5):E070531 4.

37. Guzman-Herrador B, Jensvoll L, Einoder-Moreno M, Lange H, Myking S, Nygard K, et al. Ongoing hepatitis A outbreak in Europe 2013 to 2014: imported berry mix cake suspected to be the source of infection in Norway. Euro Surveill. 2014;19(15).

38. Jalava K, Selby K, Pihlajasaari A, Kolho E, Dahlsten E, Forss N, et al. Two cases of food-borne botulism in Finland caused by conserved olives, October 2011. Euro Surveill. 2011;16(49):20034.

39. Franklin K, Gossner C.M, Gardhouse C, Nguyen T-A, de Jong B, Wise M.E, et al. Criteria to consider when declaring the end of an enteric illness outbreak. Submitted.

40. Wattiau P, Boland C, Bertrand S. Methodologies for Salmonella enterica subsp. enterica subtyping: gold standards and alternatives. Appl Environ Microbiol. 2011 Nov;77(22):7877-85.

41. Grimont PAD, Weill FX. Antigenic formulae of the Salmonella serovars, 9th ed. Paris: World Health Organization Collaborating Center for Reference and Research on Salmonella, Institut Pasteur2007.

42. Guibourdenche M, Roggentin P, Mikoleit M, Fields PI, Bockemühl J, Grimont PA, et al. Supplement 2003-2007 (No. 47) to the White-Kauffmann-Le Minor scheme Res Microbiol. 2010;161(1):26-9. doi: 10.1016/j.resmic.2009.10.002.

43. Issenhuth-Jeanjean S, Roggentin P, Mikoleit M, Guibourdenche M, de Pinna E, Nair S, et al. Supplement 2008-2010 (no. 48) to the White-Kauffmann-Le Minor scheme. Res Microbiol 2014;165(7):526-30. doi:10.1016/j.resmic.2014.07.004.

44. Herikstad H, Motarjemi Y, Tauxe RV. Salmonella surveillance: a global survey of public health serotyping. Epidemiol Infect. 2002 Aug;129(1):1-8.

45. Muller L, Kjelso C, Frank C, Jensen T, Torpdahl M, Soborg B, et al. Outbreak of Salmonella Strathcona caused by datterino tomatoes, Denmark, 2011. Epidemiol Infect. 2016 Feb 5:1-10.

46. Kerouanton A, Marault M, Lailler R, Weill FX, Feurer C, Espie E, et al. Pulsed-field gel electrophoresis subtyping database for foodborne Salmonella enterica serotype discrimination. Foodborne Pathog Dis. 2007 Fall;4(3):293-303.

47. Larsson JT, Torpdahl M, Petersen RF, Sorensen G, Lindstedt BA, Nielsen EM. Development of a new nomenclature for Salmonella typhimurium multilocus variable number of tandem repeats analysis (MLVA). Euro Surveill. 2009;14(15). 
48. Torpdahl M, Sorensen G, Lindstedt BA, Nielsen EM. Tandem repeat analysis for surveillance of human Salmonella Typhimurium infections. Emerg Infect Dis. 2007 Mar;13(3):388-95.

49. Hopkins KL, Peters TM, de Pinna E, Wain J. Standardisation of multilocus variable-number tandem-repeat analysis (MLVA) for subtyping of Salmonella enterica serovar Enteritidis. Euro Surveill. 2011;16(32).

50. Fabre L, Zhang J, Guigon G, Le Hello S, Guibert V, Accou-Demartin M, et al. CRISPR typing and subtyping for improved laboratory surveillance of Salmonella infections. PLoS One. 2012;7(5):e36995.

51. Lemon SM, Jansen RW, Brown EA. Genetic, antigenic and biological differences between strains of hepatitis A virus. Vaccine. 1992;10 Suppl 1:S40-4.

52. Costa-Mattioli M, Di Napoli A, Ferre V, Billaudel S, Perez-Bercoff R, Cristina J. Genetic variability of hepatitis A virus. J Gen Virol. 2003 Dec;84(Pt 12):3191-201.

53. European Centre for Disease Prevention and Control. Annual epidemiological report 2014 - food- and waterborne diseases and zoonoses. Stockholm: ECDC2014.

54. European Centre for Disease Prevention and Control (ECDC). Survey of National Reference Laboratory (NRL) capacity for six food-and waterborne diseases in EU/EEA countries: Stockholm 2012.

55. Ashton PM, Peters T, Ameh L, McAleer R, Petrie S, Nair S, et al. Whole Genome Sequencing for the Retrospective Investigation of an Outbreak of Salmonella Typhimurium DT 8. PLoS currents. 2015;7.

56. Centers for Disease Control and Prevention. Next Generation PulseNet, PulseNet USA strategy to meet the challenge of Culture Independent Diagnostic Methods. Atlanta: CDC; [updated 6 August 201320 January 2016]; Available from: http://www.cdc.gov/pulsenet/next-generation.html.

57. den Bakker HC, Allard MW, Bopp D, Brown EW, Fontana J, Iqbal Z, et al. Rapid whole-genome sequencing for surveillance of Salmonella enterica serovar enteritidis. Emerg Infect Dis. 2014 Aug;20(8):1306-14.

58. Leekitcharoenphon P, Nielsen EM, Kaas RS, Lund O, Aarestrup FM. Evaluation of whole genome sequencing for outbreak detection of Salmonella enterica. PLoS One. 2014;9(2):e87991.

59. Dunn JR. Whole-Genome Sequencing: Opportunities and Challenges for Public Health, Food-borne Outbreak Investigations, and the Global Food Supply. J Infect Dis. 2015 May 20.

60. Hoffmann M, Luo Y, Monday SR, Gonzalez-Escalona N, Ottesen AR, Muruvanda T, et al. Tracing Origins of the Salmonella Bareilly Strain Causing a Food-borne Outbreak in the United States. J Infect Dis. 2015 May 20.

61. European Centre for Disease Prevention and Control. Expert Opinion on the introduction of next-generation typing methods for food- and waterborne diseases in the EU and EEA. Stockholm: ECDC; 2015.

62. European Centre for Disease Prevention and Control. Terms of references Working Group "FWD CRESP" on development of operational procedures for FWD molecular surveillance and cluster response. Stockholm: ECDC; 2015. 
63. Iwamoto M, Huang JY, Cronquist AB, Medus C, Hurd S, Zansky S, et al. Bacterial enteric infections detected by culture-independent diagnostic tests--

FoodNet, United States, 2012-2014. MMWR Morb Mortal Wkly Rep. 2015 Mar $13 ; 64(9): 252-7$.

64. Centers for Disease Control and Prevention. Foodborne Illness and CultureIndependent Diagnostic Tests (CIDTs). [updated 14 May 201512 Jan 2016];

Available from: http://www.cdc.gov/foodnet/reports/cidt-questions-and-answers$\underline{2015 . h t m l}$. 


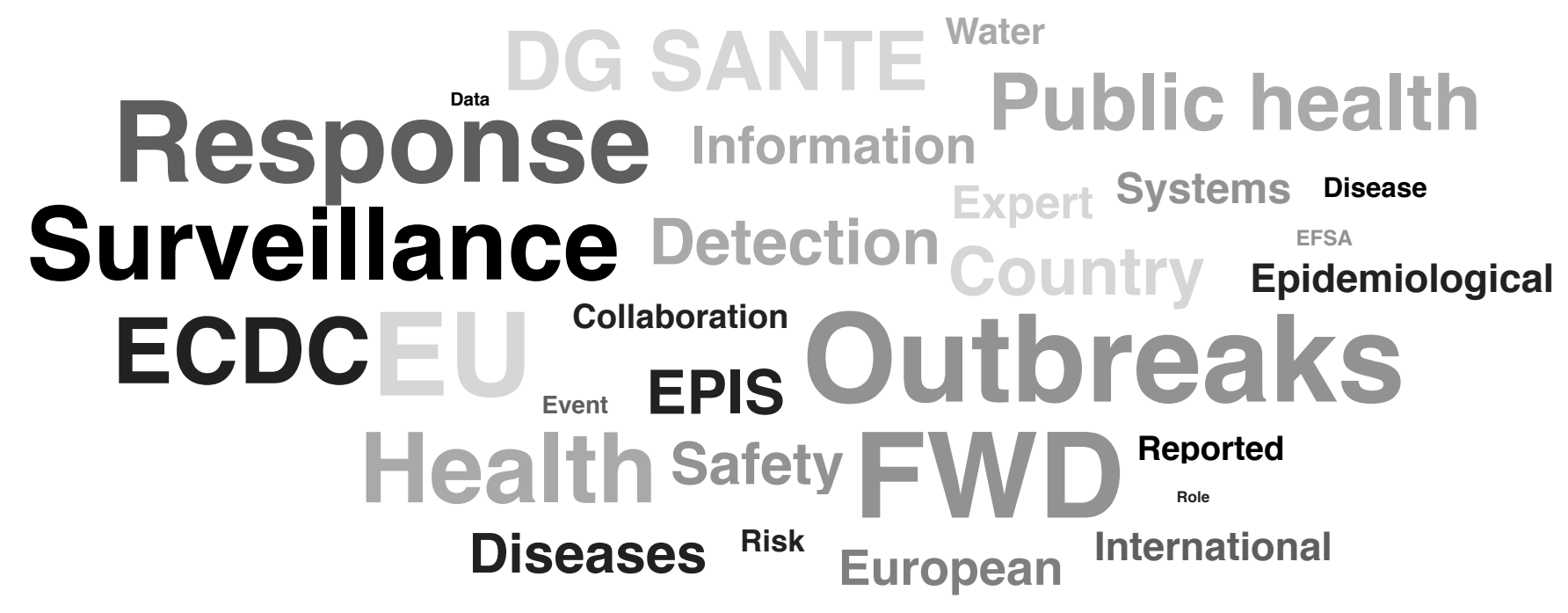

\section{SUMMARY \& SAMENVATTING}




\section{SUMMARY}

The aim of the thesis is to provide an understanding of food- and water-borne diseases (FWDs) surveillance and outbreak response in the European Union (EU) and to investigate possible ways to strengthen related processes and information technology systems.

\section{SECTION I - INTRODUCTION}

Section I provides an introduction to this thesis, describing the general concepts of surveillance and outbreak response to FWDs in the EU.

Chapter 1 introduces some basics on surveillance and outbreak response, presents the scope of this thesis, and provides an overview of the most common pathogens and epidemiological situation regarding FWD diseases infections and outbreaks in the EU.

Food- and water-borne diseases regroup more than 200 diseases that are transmitted predominantly through the ingestion of contaminated food or water. The world Health Organization estimates that two million people are dying every year from diarrhoeal FWDs worldwide. There are 18 FWDs that are subject to mandatory notification in the EU. Among those diseases, campylobacteriosis and salmonellosis are the two predominant diseases, representing 83\% of all cases of notifiable FWD. In 2012, there were 5363 food-borne outbreaks in the EU accounting for 55453 human cases.

As international trade of food items and movements of people (i.e. travels) are constantly increasing, the likelihood of having dispersed multi-country FWD outbreaks is increasing too. In this context, it is crucial to ensure that surveillance and response systems in place at the supra-national level can capture those outbreaks and allow a timely and coordinated response.

Chapter 2 describes the Salmonella naming scheme and its impacts on the salmonellosis surveillance. Traditionally, most Salmonella serotypes (93\%; $1475 / 1585)$ are named after geographical locations, referred as geo-serotypes. Germany, the United Kingdom and the United States are the three countries with most geo-serotypes. Other serotype names are referring to individuals' names, animals, tribes, food items or are a composition of symptoms and host. In the current era of fast development of whole genome sequencing, the Salmonella serotypes naming scheme should remain a reference.

\section{SECTION II - EVENT-BASED SURVEILLANCE AT THE EUROPEAN UNION LEVEL}

Section II introduces the EPidemic intelligence Information System for Food- and Water-borne Diseases and zoonoses (EPIS-FWD) as an EU tool for event-based.

Chapter 3 briefly describes the two major updates made in 2013 to EPIS-FWD in order to strengthen inter-sectorial collaboration: first, the introduction of an area for the assessment of multi-country microbiological clusters of Salmonella, Shiga toxinproducing Escherichia coli (STEC) and Listeria monocytogenes infections detected through The European Surveillance System (TESSy); second, the possibility to invite experts that are not from the public health sector to contribute to the assessment of event (e.g. food-safety experts, veterinarians, environmental experts) . 
Chapter 4 provides an in-depth analysis of the FWD events, also called Urgent Inquiries (UIs), assessed by the European Centre for Disease Prevention and Control (ECDC) between 2008 and 2013. During this period, there were 215 UIs, the majority of them $(135 ; 63 \%)$ being related to salmonellosis. For $110(51 \%)$ UIs, a potential food vehicle of infection was identified, with vegetables being the most reported category $(34 ; 31 \%)$. A total of $28 \%(n=60)$ of the outbreaks reported had an international dimension, involving at least two countries. The UI allowed early detection of multi-country outbreaks, facilitated the identification of the suspected vehicles and consequently contributed to the timely implementation of control measures.

In addition, chapter 2 showed that the introduction of EPIS-FWD in 2010 facilitated the timely exchange of information between public health authorities of the participating countries.

\section{SECTION III - DETECTION AND RESPONSE TO FOOD- AND WATER- BORNE DISEASES OUTBREAKS IN THE EUROPEAN UNION}

Section III gathers examples of food-borne disease outbreaks to present the process of outbreak detection and response, including investigation mechanisms and development of a response strategy.

Chapter 5 describes a national outbreak of salmonellosis that occurred in France in 2011 which highlights how outbreak detection, investigation and reporting to the international level are conducted in the EU Member States. To investigate this outbreak, supermarket loyalty cards were used as a new epidemiological tool and dried pork sausage from one producer was identified as the most likely source of the outbreak. Despite the absence of positive food samples, control measures including withdrawal and recall were implemented showing the strong inter-sectorial collaboration between public health and food safety risk assessors and risk managers. The international dimension of this outbreak was assessed through EPIS-FWD and the event notified through the Early Warning and Response System (EWRS).

Using three multi-country outbreaks of hepatitis A that occurred simultaneously in 2013, chapter 6 presents how EPIS-FWD supports the rapid detection of multicountry outbreaks and the collection of epidemiological and microbiological data used for the investigations. EPIS-FWD allowed the early detection of the multinational dimension of these outbreaks. The system supported the rapid exchange of information among the experts from participating countries and easy access to upto-date epidemiological and microbiological results. EPIS-FWD was also used as a document repository for the line listings, questionnaires and protocols, and rapid risk assessments prepared by ECDC.

In addition, chapter 6 highlights the importance of international collaboration but also cross-sectorial collaboration, including exchange of information gathered through complementary surveillance systems in the EU.

As a response to the wave of food related hepatitis A outbreaks described in chapter 2, ECDC launched a review of the hepatitis A epidemiological situation in the EU. Chapter 7 demonstrates how surveillance data is supporting such mid-term outbreak response, underlying the limitations encountered due to the incompleteness of the data reported to TESSy (e.g. disease severity) and due to the complexity of 
investigating hepatitis A outbreaks: long incubation period of the disease leading to food consumption recall bias and difficulties to isolate the virus in food samples making it challenging to ascertain hypothesis about food vehicle.

\section{SECTION IV - DETECTION AND RESPONSE TO FOOD- AND WATER- BORNE DISEASES OUTBREAKS BEYOND THE EUROPEAN UNION \\ LEVEL AND CLOSURE OF OUTBREAKS}

Section IV extends the scope of outbreak detection and response beyond the EU level and provides guidance on closure of FWD outbreaks.

Using the 2008 melamine incident which is one of largest deliberate food contamination incidents ever described, chapter 8 illustrates the complexity of international trade of food products and ingredients and the role of the World Health Organization (WHO) in responding to global food safety incident. Forty-seven countries received melamine-contaminated products and 300,000 Chinese infants and young children suffered kidney and urinary tract effects. WHO gathered evidence for the assessment of the situation, issued advice on laboratory issues and communicated results to public health and food safety authorities. This incident highlighted the need to rapidly report food safety events to mitigate the impact on public health.

Declaring the end of a FWD multi-country outbreak is a key step of an outbreak investigation that is unfortunately often neglected. Chapter 9 provides criteria to guide the decision to declare FWD multi-country outbreaks over. Three criteria were developed: determining that illnesses have returned to baseline levels (criterion 1), identifying the last time that individuals may have been exposed to the outbreak source (criterion 2) and allowing enough time to pass to allow these individuals to become ill and be reported to public health (criterion 3). Having been validated against several food-borne disease outbreaks in Canada, the United States and Europe, these criteria provide an objective and scientifically based approach to determining when FWD outbreak is over.

\section{SECTION V - GENERAL DISCUSSION}

Section $\mathbf{V}$ is a general discussion to this thesis. Chapter $\mathbf{1 0}$ discusses the main findings presented earlier in this thesis, highlights some of the challenges of the FWD surveillance and response mechanisms, and provides some avenues for strengthening such mechanisms. Four key topics of discussion rose from the articles presented in this thesis: importance and challenges of collaboration among public health experts but also between experts from different sectors at the national and the EU level; the multiple independent systems in place for surveillance and outbreak response at the EU level and the possibilities to expand their scope and better integrate them; epidemiological methods for detection, reporting and investigation of outbreaks with their challenges and potential new tools that could be developed; laboratory methods for detection and investigation of outbreaks, with their limitations and new technologies that may change radically the current surveillance processes.

Out of this discussion, ten key recommendations are suggested to strengthen eventbased surveillance and response to FWD outbreaks in the EU. 
1. ECDC, the European Food Safety Authority (EFSA), the European Commission (EC) Directorate General for Health and Food Safety - Public health, country knowledge, crisis management directorate (DG SANTE C) and the EC Directorate General for Health and Food Safety - Crisis management in food, animals and plants directorate (DG SANTE G) should consider clarifying their roles and responsibilities during outbreak investigation and further develop standard operating procedures to facilitate their collaboration. In addition, they should consider developing an information sheet, for national experts and the general public, summarising the EU response mechanisms to FWD outbreaks. This information sheet should cover the complementary role of the International Food Safety Authorities Network (INFOSAN) and could include some case scenarios and success stories of outbreak investigations.

2. ECDC, EFSA, DG SANTE C and DG SANTE G should consider organising joint multidisciplinary simulation exercises and trainings in order to test procedures and continuously train experts on different aspects of surveillance and outbreak response. Post outbreaks lessons learned workshop could also be organised in order to debrief on experiences and identify possible improvements. Reducing reporting delays and appropriately using EU surveillance and outbreak response systems should be topics of discussion during these exercises/trainings/workshops.

3. ECDC, EFSA, DG SANTE C and DG SANTE G should consider developing guidelines for reporting and investigating potential multi-country outbreaks to the EU level, including information sharing through EPIS-FWD and other EU surveillance systems. On the public health side, ECDC and DG SANTE C should play a more active role in monitoring notifications through EPIS-FWD and EWRS and provide guidance to Member States when events are not reported through the appropriate system.

4. ECDC, EFSA, DG SANTE C and DG SANTE G should consider revising EU systems for surveillance and outbreak response to streamline the flow of information. The central role of EPIS-FWD in linking risk assessors and risk managers from the public health sector and the food safety and veterinary health sector should be confirmed.

5. ECDC should consider revising the list of descriptive variables in TESSy in order to improve completeness of the data while still meeting the established surveillance objectives.

6. ECDC and Member States should consider preparing a "Best Practices" document on new epidemiological methods for outbreaks investigation (i.e. use of debit/credit cards and loyalty cards).

7. ECDC should consider developing a questionnaire tool for trawling and case control studies interviews during multi-country outbreaks. The tool would allow the rapid development of multi-languages questionnaires and take into consideration the food diversity in the EU.

8. When multi-country outbreaks that have been investigated are considered over, ECDC, EFSA, DG SANTE C and DG SANTE G should systematically issue a joint closure statement following agreed criteria applied in a systematic way. 
9. ECDC should continue supporting EU Member States laboratories in enhancing their capacity to perform molecular characterisation of the most common food-borne pathogens and promote the use of common protocols and expertise sharing among Member States laboratories.

10. ECDC should continue supporting Member States laboratories through Whole Genome Sequencing (WGS) transition and consider revising surveillance systems in the light of the generalisation of WGS and culture-independent diagnostic tests (CIDTs). 


\section{SAMEnVATting}

Het doel van dit proefschrift is inzicht te krijgen in de surveillance en outbreakrespons van voedsel- en watergerelateerde ziekten binnen de Europese Unie (EU) en om te onderzoeken of er mogelijkheden zijn om gerelateerde processen en informatietechnologische systemen te versterken.

\section{SECTIE I - INTRODUCTIE}

Sectie 1 levert een introductie op dit proefschrift door de algemene concepten van surveillance en outbreakrespons van voedsel- en watergerelateerde ziekten binnen de EU te beschrijven.

Hoofdstuk 1 introduceert enkele basispunten van surveillance en outbreakrespons, het laat de volledige scope van dit proefschrift zien en levert een overzicht van de meeste gangbare pathogenen en de epidemiologische situatie van infecties en uitbraken door voedsel- en watergerelateerde ziekten in de EU.

Voedsel- en watergerelateerde ziekten bestaan uit meer dan 200 ziekten die hoofdzakelijk worden overgedragen door het innemen van besmet drinkwater of voedsel. De WHO schat dat jaarlijks, wereldwijd twee miljoen mensen sterven door diarree veroorzaakt door voedsel- en watergerelateerde ziekten. In de EU zijn 18 voedsel- en watergerelateerde ziekten meldingsplichtig. Van deze meldingsplichtige voedsel- en watergerelateerde ziekten zijn campylobacteriose en salmonellose met $83 \%$ de meest voorkomende ziekten. In 2012 waren er 5.363 voedselgerelateerde uitbraken in de EU, verantwoordelijk voor 55.453 gevallen.

Omdat internationale handel van voedingswaren en migratie van mensen (bijv. reizen) steeds meer toenemen, is het waarschijnlijk dat daardoor ook grensoverschrijdende uitbraken van voedsel- en watergerelateerde ziekten toenemen. In deze context is het cruciaal ervoor te zorgen dat de aanwezige surveillance- en responssystemen op nationaal overstijgend niveau deze uitbraken in beeld krijgen en zorgen voor een tijdige en gecoördineerde respons.

Hoofdstuk 2 beschrijft de Salmonella-benamingen en haar effect op de salmonellose surveillance. De meeste Salmonella serotypes (93\%; 1476/1586) worden traditioneel vernoemd naar geografische locaties, zogenaamde geo-serotypes. De drie landen met de meeste geo-serotypes zijn Duitsland, Groot Brittanië en de Verenigde Staten. Andere serotype-namen verwijzen naar namen van individuen, dieren, stammen, voedselitems of een compositie van symptomen en gastheer. In de huidige tijd van snelle ontwikkeling van whole genome sequencing zou het namen benamingensysteem van Salmonella als referentie moeten blijven dienen.

\section{SECTIE II - EVENT-BASED SURVEILlanCE OP EU NIVEAU}

Sectie II introduceert het EPidemic intelligence Information System for Food- and Water-borne Diseases and zoonoses (EPIS-FWD) als een EU-tool voor event-based surveillance.

Hoofdstuk 3 beschrijft in het kort de twee grootste updates uit 2013 van EPIS-FWD met als doel de intersectoriale samenwerking te versterken: ten eerste de introductie 
van een plek om grensoverschrijdende, microbiologische clusters van Salmonella, Shiga toxine-producerende Escherichia coli (STEC) en Listeria monocytogenesinfecties gedetecteerd door The European Surveillance System (TESSy) in kaart te brengen; ten tweede de mogelijkheid om experts die niet uit de public health sector komen uit te nodigen om bij te dragen aan het in kaart brengen van een event (bijv. voedselveiligheidexperts, veterinairen, miliekundige experts).

Hoofdstuk 4 levert een diepgaande analyse van de events van voedsel- en watergerelateerde ziekten, ook Urgent Inquiries (UIs) genoemd, tussen 2008 en 2013 in kaart gebracht door het European Centre for Disease Prevention and Control (ECDC). Gedurende deze periode waren er 215 UIs, het overgrote deel daarvan (135; $63 \%$ ) gerelateerd aan salmonellose. Voor 110 (51\%) UIs was een potentiële voedselinfectiebron geïdentificeerd, met groenten als de meest gerapporteerde categorie $(34 ; 31 \%) .28 \%(\mathrm{n}=60)$ van de gerapporteerde uitbraken hadden een internationaal karakter waar minimaal 2 landen bij betrokken waren. De UI zorgde voor een vroege detectie van grensoverschrijdende uitbraken, faciliteerde de identificatie van verdachte bronnen en droeg daardoor bij aan de tijdige implementatie van controlemaatregelen.

Bovendien toonde hoofdstuk 2 dat de introductie van EPIS-FWD in 2010 de tijdige informatie-uitwisseling tussen public health autoriteiten van de deelnemende landen faciliteerde.

\section{SECTIE III - DETECTIE EN RESPONS OP VOEDSEL- EN WATERGERELATEERDE UITBRAKEN IN DE EU}

In Sectie III zijn voorbeelden verzamelt van voedselgerelateerde uitbraken om het proces van uitbraakdetectie en respons te tonen, inclusief onderzoeksmethodes en ontwikkeling van een responsstrategie.

Hoofdstuk 5 beschrijft een nationale uitbraak van salmonellose in Frankrijk in 2011 die belicht hoe uitbraakdetectie, onderzoek en rapportage op nationaal niveau wordt afgehandeld in de EU-lidstaten. Om deze uitbraak te onderzoeken werden de supermarkt klantenkaarten gebruikt als een nieuwe epidemiologische tool en gedroogde varkensworst van één bepaalde producent werd gezien als de hoogstwaarschijnlijke bron van de uitbraak. Ondanks dat er geen positieve voedingsmonsters ter beschikking waren, werden er controle maatregelen geïmplementeerd waaronder het product uit de markt halen en terugroepen, en werd de sterke intersectorale samenwerking tussen public health en voedselveiligheidspecialisten en risicomanagers getoond. De internationale dimensie van deze uitbraak werd door EPIS-FWD onderzocht en het event werd via het Early Warning and Response System (EWRS) gemeld.

Met behulp van drie grensoverschrijdende uitbraken van hepatitis A die tegelijkertijd plaatsvonden in 2013, laat hoofdstuk 6 zien hoe EPIS-FWD de snelle detectie van grensoverschrijdende uitbraken en de verzameling van voor de onderzoeken gebruikte epidemiologische en microbiologische data ondersteunt. EPIS-FWD zorgde voor een vroege detectie van de grensoverschrijdende dimensie van deze uitbraken. Het systeem ondersteunde de snelle informatie-uitwisseling van de experts van deelnemende landen en makkelijke toegang tot up-to-date epidemiologische en microbiologische resultaten. Bovendien werd EPIS-FWD gebruikt voor 
documentopslag van de lijsten, vragenlijsten en protocollen en snelle risk assessments opgesteld door ECDC.

Bovendien belicht hoofdstuk 6 het belang van internationale samenwerking, maar ook van intersectorale samenwerking, inclusief informatie-uitwisseling die verzameld werd door de diverse surveillancesystemen in de EU.

In antwoord op de golf van voedselgerelateerde hepatitis A-uitbraken in hoofdstuk 2, lanceerde ECDC een overzicht van de epidemiologische situatie van hepatitis A in de EU. Hoofdstuk 7 toont hoe surveillance-data zo'n tussentijdse outbreakrespons ondersteunt, ondanks de beperkingen vanwege de incomplete data gerapporteerd aan TESSy (bijv. ernst van de ziekte) en vanwege de complexiteit van onderzoek van hepatitis A-uitbraken. Een lange incubatietijd van de ziekte kan leiden tot twijfel over wat men zich herinnert te hebben gegeten en het kan lastig zijn om het virus in voedselmonsters te isoleren. Dit kan het bevestigen van een vermoedelijke voedselbron tot een uitdaging maken.

\section{SECTIE IV - DETECTIE EN RESPONS BIJ VOEDSEL- EN WATERGERELATEERDE ZIEKTE-UITBRAKEN OP EU-NIVEAU EN AFSLUITING VAN UITBRAKEN}

Sectie IV breidt de reikwijdte van uitbraakdetectie en respons uit naar het EU-niveau en biedt richtlijnen aan over het afsluiten van voedsel- en watergerelateerde ziekteuitbraken.

Met behulp van het melamine incident in 2008, wat één van de grootste, opzettelijke voedselcontaminatie-incidenten ooit beschrijft, toont hoofdstuk 8 de complexiteit van internationale handel van voedselproducten en ingrediënten en de rol van de World Health Organization (WHO) in handelen op globale voedselveiligheidsincidenten. Zevenenveertig landen ontvingen melamine-besmette producten en 300.000 Chinese zuigelingen en jonge kinderen werden getroffen door nier- en urinewegproblemen. De WHO verzamelde bewijslast om de situatie in kaart te brengen, gaf advies over laboratoriumvraagstukken en communiceerde de resultaten met public health- en veiligheidsautoriteiten. Dit incident toonde de noodzaak tot snelle rapportage van voedselveiligheidsvoorvallen aan om de impact op public health beperkt te houden.

Verklaren dat een grensoverschrijdende voedsel- en watergerelateerde ziekte-uitbraak is beëindigd, is een cruciale stap in een uitbraakonderzoek die helaas vaak wordt vergeten. Hoofdstuk 9 levert criteria om te komen tot het besluit om een voedsel- en watergerealteerde ziekte-uitbraak als beëindigd te verklaren. Er werden drie criteria ontwikkeld: vaststellen dat ziektes zijn gedaald tot het basisniveau (criterium 1), bepalen wanneer individuen mogelijk voor het laatst zijn blootgesteld aan de uitbraakbron (criterium 2) en voldoende tijd voorbij laten gaan dat deze individuen (mogelijk) ziek kunnen worden en er voldoende gelegenheid is geweest dit te melden aan de public health autoriteiten (criterium 3). Deze criteria, gevalideerd bij diverse voedselgerelateerde ziekte-uitbraken in Canada, de Verenigde Staten en Europa, bieden een objectieve en wetenschappelijk onderbouwde aanpak om te bepalen wanneer voedsel- en watergerelateerde ziekte-uitbraken voorbij zijn. 


\section{Sectie V - Algemene discussie}

Sectie V bevat de algemene discussie van dit proefschrift. Hoofdstuk 10 behandelt de belangrijkste bevindingen die eerder in dit proefschrift zijn gepresenteerd, belicht een aantal van de uitdagingen van de FWD-surveillance- en responsmechanismen en levert een aantal wegen om deze mechanismen te versterken. Er kwamen vier hoofdthema's uit de in deze thesis gepresenteerde artikelen naar boven voor discussie: belang en uitdagingen van samenwerking tussen public health professionals, maar ook tussen professionals uit andere sectoren op nationaal en EU-niveau; de vele, bestaande, onafhankelijke systemen voor surveillance en outbreakrespons op EUniveau en de mogelijkheden om hun bereik te vergroten en beter te integreren; epidemiologische detectiemethodes, rapporteren en onderzoek van uitbraken met hun uitdagingen en mogelijk nieuwe tools die zouden kunnen worden ontwikkeld; laboratoriummethodieken voor detectie en onderzoek van uitbraken met hun beperkingen en nieuwe technologieën die wellicht de huidige surveillanceprocessen radicaal zouden kunnen veranderen.

Uit deze algemene discussie worden tien hoofdaanbevelingen gedaan om eventbased surveillance en respons op FWD-uitbraken in de EU te versterken.

1. ECDC, de European Food Safety Authority (EFSA), de European Commission (EC) Directorate General for Health and Food Safety - Public health, country knowledge, crisis management directorate (DG SANTE C) en het EC Directorate General for Health and Food Safety - Crisis management in food, animals and plants directorate (DG SANTE G) kunnen hun rol en verantwoordelijkheden tijdens een uitbraakonderzoek verduidelijken en ze kunnen ook standaard werkprocedures ontwikkelen om hun samenwerking te faciliteren. Daarnaast kunnen zij ten behoeve van de nationale professionals en het algemene publiek een informatiebrochure ontwikkelen met daarin samengevat de EU-responsmechanismen bij FWD-uitbraken. Deze informatiebrochure zou ook de aanvullende rol van het internationale Food Safety Authority Network (INFOSAN), voorbeeld scenario's en verhalen van succesvol outbreakonderzoek moeten bevatten.

2. ECDC, EFSA, DG SANTE C en DG SANTE G kunnen op regelmatige basis samengestelde multidisciplinaire simulatie-oefeningen en trainingen organiseren om de procedures te testen en professionals continu te trainen op diverse aspecten van surveillance en outbreakrespons. Post-outbreak-lessonslearned-workshops kunnen ook worden georganiseerd om terug te kijken op de opgedane ervaringen en het identificeren van verbeteringen. Het terugbrengen van vertragingen in rapportage en het juiste gebruik van EU surveillance en outbreakrespons zouden als thema's moeten worden besproken in deze workshops.

3. ECDC, EFSA, DG SANTE $C$ en DG SANTE $G$ kunnen richtlijnen ontwikkelen voor rapportage en onderzoek van 'multi-country outbreaks' op EU niveau, inclusief het delen van informatie met EPIS-FWD en andere EU surveillance systemen. Vanuit de kant van de public health zouden ECDC en DG SANTE $C$ een meer actieve rol kunnen spelen in het monitoren van meldingen via EPIS-FWD en EWRS en het begeleiden van lidstaten wanneer events niet gemeld worden. 
4. ECDC, EFSA, DG SANTE C en DG SANTE G kunnen de EU surveillanceen outbreakresponssystemen herzien om de informatiestroom te stroomlijnen. De centrale rol van EPIS-FWD om de risicobeoordelaars en risicomanagers uit de public health en de voedselveiligheids- en veterinaire gezondheidssector te linken kan worden vastgelegd.

5. ECDC kan de lijst van beschrijvende variabelen in TESSy herzien om de volledigheid van data te verbeteren terwijl toch de afgesproken surveillance doeleinden worden bereikt.

6. ECDC en lidstaten kunnen gezamenlijk een 'best practices' document van nieuwe epidemiologische methodieken voor uitbraakonderzoek (bijv. gebruik van debet-/creditkaarten en klantenkaarten) ontwikkelen.

7. ECDC kan een vragenlijsttool ontwikkelen voor volgsysteem- en case control onderzoekinterviews gedurende grensoverschrijdende uitbraken. Deze tool zou dan snel vragenlijsten met verschillende talen kunnen ontwikkelen en rekening kunnen houden met de voedsel diversiteit binnen landen.

8. Bij de nabeschouwing van grensoverschrijdende uitbraken die zijn onderzocht, kunnen ECDC, EFSA, DG SANTE C en DG SANTE G systematisch op gestructureerde wijze een 'einde-uitbraak-verklaring' laten uitgaan conform overeengekomen systematische criteria.

9. ECDC kan EU-lidstaten ondersteunen in het verbeteren van de capaciteit om de meest voorkomende voedselgerelateerde pathogenen moleculair te karakteriseren en zij zou het gebruik gestandaardiseerde protocollen en uitwisseling van expertise op dit gebied kunnen stimuleren.

10. ECDC zou EU-lidstaten kunnen ondersteunen in het verbeteren van de capaciteiten om whole genome sequencing (WGS) in te zetten en moeten overwegen surveillance systemen aan te passen op grond van nieuwe inzichten door whole genome sequencing en andere kweek onafhankelijke diagnostiek. 



\section{DG SANTE Water \\ Response Information Public health \\ Surveillance Detection Expert Systems olosese ECDC EU Eveven EPIS Outbreaks Health Safety FWD ${ }^{\text {Reported }}$ Diseases Risk European International}

\section{VALORISATION,}

LIST OF ABBREVIATIONS,

ACKNOWLEDGMENTS \&

CURRICULUM VITAE 


\section{VALORISATION}

\section{Political relevance}

The first record of international health cooperation between countries that are now part of the EU can be traced-back to the middle of the ninetieth century. Prompted by the cholera threat, the first International Sanitary Conference took place in Paris in July 1851 and aimed at the establishment of harmonized maritime quarantine requirements. Following the Second World War, WHO was created to reinforce international cooperation on health matters. At the EU level, it is in 1998 that the European Parliament and the European Council approved the decision to set up a European network for epidemiological surveillance and control, the EWRS. The emergence of the severe acute respiratory syndrome (SARS) coronavirus in 2003 and the threat it posed to the EU highlighted the need to reinforce the coordination of EU public health authorities' activities towards common threats. Subsequently, in 2005 ECDC was created with the mandate "to identify, assess and communicate current and emerging threats to human health from communicable diseases". As demonstrated in this thesis, both ECDC and WHO have been playing key roles in the detection of the international aspect of major food- and water-borne disease outbreaks and events and in the coordination of the response. Multi-sectorial collaboration at national but also EU level was shown to be crucial. The review of the event-based surveillance and outbreak response presented in this thesis is important in terms of EU politics as it could in theory influence EU strategy for public health and food safety.

\section{Societal and economical relevance}

In 2014, about 386000 cases of food- or water-borne infections were reported in the EU. The number of outbreaks for 2014 has not yet been published by EFSA but following data from previous years, it is expected that the number of outbreaks in 2014 would be above 5000. In 2013, there were 5196 outbreaks of food- or waterborne infections in the EU. These outbreaks accounted for 40726 human cases among which 5935 were hospitalized and 10 had a fatal outcome. Aside from the most common gastro-intestinal discomfort, long term health outcomes may occur (e.g. neuromuscular paralysis, kidney diseases).

In parallel, food-borne infections and outbreaks often create direct repercussion on the food industry. The outbreak of shiga-toxin-producing Escherichia coli (STEC) O104:H4 that started in Germany in May 2011 and led to the well-known "Spanish cucumber" scandal caused an estimated loss for EU farmers in the fruit and vegetable sector of at least EUR 812 million.

The main focus of this thesis is to identify opportunities to strengthen event-based surveillance and outbreak response at the EU level in order to timely detected multicountry outbreaks of FWD and to rapidly respond to such outbreaks while ensuring an overall coordination of the response between affected Member States. Through the identification of avenues to strengthen outbreak detection and response mechanisms, this thesis aims at minimizing both the societal impact and the economical cost of food-and water-borne infections and outbreaks in the EU.

In addition, this thesis aims at facilitating the work of EU public health and food and veterinary institutions by addressing the challenges of inter-sectorial collaboration, 
highlighting the limitations of the systems they have put in place and describing new epidemiological and microbiological methods for outbreak detection and investigation they should consider for future updates of their systems. By optimizing event-based surveillance and outbreak response at the EU level, one can combine resources and avoid duplication of efforts, which ultimately save EU tax payers' money.

\section{Target groups}

This thesis primarily targets EU institutions and national authorities in EU Member States working in the fields of public health and food safety and veterinary health. This group includes ECDC, EFSA, DG SANTE C and DG SANTE G, ministries of health, ministries of agricultures, public health institutes and food safety and veterinary health institutes. This thesis presents some clear recommendations to address the current challenges faced by EU institutions and national authorities in terms of event-based surveillance and outbreak response.

This thesis also targets Members of the Parliament and Members of the Council of the EU as they have legislative and budgetary authority at the EU level and could therefore influence the activities of the EU institutions.

More broadly, this thesis could be of interest to anybody interested in learning how EU institutions working on public health and food safety and veterinary health matters are leading and coordinating event-based surveillance and outbreak response at EU level. This group may include not only national or regional authorities from non-EU Member States working on public health and food safety and veterinary health matters, but also universities (researchers and students), food industries and press/media.

FWD outbreaks could be the results of accidental contamination or deliberate contamination for economical purposes or bioterrorism. Therefore this thesis could also be of interest to EU or national Intelligence Services who would like to know how is organized event-based surveillance and response to multi-country FWD outbreaks.

\section{Next steps...}

Additional studies could be designed to strengthen event-based surveillance for FWD and outbreak response. For instance, this thesis identified the need to further integrate ECDC tools for indicator-based surveillance and event-based surveillance, TESSy and EPIS-FWD respectively. A comparative study on retrospective salmonellosis data collected through TESSY and EPIS-FWD has just been initiated. Algorithms for the detection of salmonellosis outbreak signals based on serotype information have been developed and applied to 2008-2015 data collected through TESSy. The signals detected will be compared to the events reported in EPIS-FWD. The results remain to be analyzed and will be made public. Considering the delay in reporting case-based data to TESSy (quarterly reporting), signal detection in the prospect to detect ongoing multi-country outbreak has so far been limited. Therefore, ECDC, together with EU Member States, is currently revising the reporting protocol to increase the frequency of the reports of serotype information. Ultimately, ECDC aims at using serotype information collected through TESSY to detect potential multi-country outbreaks that are not detected or not reported by Member States to EPIS-FWD. Serotype 
information would however be of limited use for detection of outbreak of very common serotypes such as Typhimurium and Enteritidis. In such cases, further characterization would be required.

To facilitate the response to FWD multi-country outbreaks, ECDC initiated a new project on outbreak investigation questionnaires. The aims of this project is to develop a pool of questions for descriptive and analytic studies that would be already translated in different languages and could be easily used to rapidly build questionnaires in multiple languages. Though a system of coding of questions, results from several countries could be analyzed at a central level which should facilitate the interpretation of the results. The creation of the pool of questions started in May 2016 and the first set of translations should be made public early 2017.

The results presented in this thesis may be used by ECDC in the context of the ongoing revision of its surveillance systems. ECDC aims at strengthening its data collection process and facilitating the joint analysis of the indicator- and event-based surveillance data. The strengths and weaknesses of FWD surveillance and outbreak response tools highlighted in this thesis will be considered while defining future systems requirements.

\section{Innovation and challenges}

While investigating the outbreaks presented in this thesis, I perceived that there were many misunderstandings and confusions about the roles and responsibilities of the different EU stakeholders and the systems in place for outbreak detection and response. This reflects the absence of such review in the past and the innovative aspect of this thesis, not on the methodological level but rather on the topic and the EU level angle. The mapping of the stakeholders and tools presented in this thesis would be very valuable to clarify to a large audience how event-based surveillance and outbreak response at the EU level is organized. Potentially, to reach as many experts as possible, the publication of a synthesis of this thesis in a peer-reviewed journal targeting public health experts and food safety and veterinary health experts could be considered.

To strengthen event-based surveillance and outbreak response, ten recommendations were proposed. Considering that changes at the EU level take time, it is unlikely that those recommendations would be implemented in the immediate future. Those changes will require willingness from all the stakeholders but also empowerment from the strategic leaders at the EU level. Additionally, to implement these recommendations, some financial and human resources will be necessary. 


\section{LIST OF ABBREVIATIONS}

CIDT: Culture-Independent Diagnostic Tests

DCF: Data Collection Framework

DG SANTE C: Directorate General for Health and Food Safety - Public health, country knowledge, crisis management directorate

DG SANTE G: Directorate General for Health and Food Safety - Crisis management in food, animals and plants directorate

DNA: Deoxyribonucleic acid

EC: European Commission

ECDC: European Centre for Disease Prevention and Control

EEA: European Economic Area

EFSA: European Food Safety Authority

EPIS: EPidemic intelligence Information System

EU: European Union

EWRS: Early Warning and Response System

FWD: Food- and Water-borne Diseases

HAV: Hepatitis A virus

INFOSAN: International Food Safety Authorities Network

RASFF: Rapid Alert System for Food and Feed

RNA: Ribonucleic acid

STEC: Shiga-toxin-producing Escherichia coli

TESSy: The European Surveillance System

WGS: Whole Genome Sequencing

WHO: World Health Organization 


\section{ACKNOWLEDGEMentS}

Many are those who deserve my deep and sincere gratitude for this work, and I fear the space allowed here is too limited to cover everyone in detail. I must, however, start acknowledging my two supervisors who have guided and advised me on my path to greatness, whether from close or far. Christian Hoebe have been an amazing off site support from Maastricht University giving critical guidance and feedback on form and content - often at an eyes blink. Birgitta de Jong has provided the day to day support, feedback and guidance in her dual role of supervisor and line manager. I must also extend my gratitude to my co-authors for the papers included in this thesis. It would clearly not have been possible to produce these data, analysis and results without you. I must thank my many colleagues at the European Centre for Disease Prevention and Control (ECDC) and its Member State National Focal Points that laid the foundation on which the work is based on daily. Too many to cover by name, but you know who you are. I would like to thank the former director of ECDC, Marc Sprenger, for allowing me to do a PhD while working for the center. I would also like to thank Johanna Takkinen, Thomas Van Cangh and Daniel Palm for reviewing specific parts of the thesis.

There are three persons in particular that I would like to mention with special gratitude. Denis Coulombier who is always keeping his door open for an open and mutual discussion, regardless if the topic is sailing, sewing or EU surveillance. Pelle for being the best partner one can ask for in life - always helping to see a topic from a new angle, and finally the most important person of them all Tuva Louise. You have been a part of me and extended me in ways I did not believe possible. The first nine months literally part of me and now for more than nine months being a constant companion in life. I have not met a person more understanding of EU wide surveillance and concepts involved!

My deepest gratitude to all of you! 


\section{CURRICULUM VITAE}

\section{Introduction}

Céline M. Gossner is a doctor in veterinary medicine who graduated from the veterinary school of Toulouse (France) in 2004. She pursued her studies with a Master's in Risk Management in Agricultural and Agro-food Industries (MSc) at SupAgro, Montpellier (France) and worked for a couple of years in the pet food industry in Portugal.

Then, she enrolled in a Master in Business Administration (MBA) specialized in International Organizations and Non-Governmental Organizations at the University of Geneva (HEC Genève) (Switzerland) and worked for the World Health Organization until 2009, when she joined the European Centre for Disease Prevention and Control, ECDC, in Stockholm (Sweden). Céline is working as an epidemiologist specialized in food-borne and zoonotic infections.

At ECDC, Céline coordinates the development of outbreak response tools including the EPidemic intelligence Information Systems (EPISs) and contributes to eventbased surveillance and response to food- and water-borne diseases and zoonoses outbreaks. Together with the European Food Safety Authority, she is leading various projects to strengthen the collaboration at the animal-human interface at the European Union level.

\section{List of peer-reviewed publications in scientific journals}

1. Gossner CM, Le Hello S, De Jong B, Rolfhmare P, Faensen D, Weill FX, et al. Around the world in 1475 Salmonella geo-serotypes. Emerg. Infect Dis. In press 2016.

2. Muller L, Kjelso C, Frank C, Jensen T, Torpdahl M, Soborg B, et al. Outbreak of Salmonella Strathcona caused by datterino tomatoes, Denmark, 2011. Epidemiol Infect. 2016 Feb 5:1-10.

3. Sane J, MacDonald E, Vold L, Gossner C, Severi E, Outbreak Investigation Team. Multistate foodborne hepatitis A outbreak among European tourists returning from Egypt--need for reinforced vaccination recommendations, November 2012 to April 2013. Euro Surveill. 2015;20(4).

4. Pesola AK, Parn T, Huusko S, Perevoscikovs J, Ollgren J, Salmenlinna S, et al. Multinational outbreak of Salmonella Enteritidis infection during an international youth ice hockey competition in Riga, Latvia, preliminary report, March and April 2015. Euro Surveill. 2015;20(20).

5. Gossner CM, Severi E, Danielsson N, Hutin Y, Coulombier D. Changing hepatitis A epidemiology in the European Union: new challenges and opportunities. Euro Surveill. 2015;20(16).

6. Gossner CM, de Jong B, Hoebe CJ, Coulombier D, European F, Waterborne Diseases Study Group C. Event-based surveillance of food- and waterborne diseases in Europe: urgent inquiries (outbreak alerts) during 2008 to 2013. Euro Surveill. $2015 ; 20(25)$. 
7. Westrell T, Monnet DL, Gossner C, Heuer O, Takkinen J. Drug-resistant Salmonella enterica serotype Kentucky in Europe. Lancet Infect Dis. 2014 Apr;14(4):270-1.

8. Kinross P, van Alphen L, Martinez Urtaza J, Struelens M, Takkinen J, Coulombier D, et al. Multidisciplinary investigation of a multicountry outbreak of Salmonella Stanley infections associated with turkey meat in the European Union, August 2011 to January 2013. Euro Surveill. 2014;19(19).

9. Gossner C, Severi E. Three simultaneous, food-borne, multi-country outbreaks of hepatitis A virus infection reported in EPIS-FWD in 2013: what does it mean for the European Union? Euro Surveill. 2014;19(43).

10. Gossner C, Danielson N, Gervelmeyer A, Berthe F, Faye B, Kaasik Aaslav K, et al. Human-dromedary camel interactions and the risk of acquiring zoonotic Middle East Respiratory Syndrome Coronavirus infection. Zoonoses and public health. 2014 Dec 27.

11. Adlhoch C, Gossner C, Koch G, Brown I, Bouwstra R, Verdonck F, et al. Comparing introduction to Europe of highly pathogenic avian influenza viruses $\mathrm{A}(\mathrm{H} 5 \mathrm{~N} 8)$ in 2014 and A(H5N1) in 2005. Euro Surveill. 2014;19(50).

12. Rebolledo J, Garvey P, Ryan A, O'Donnell J, Cormican M, Jackson S, et al. International outbreak investigation of Salmonella Heidelberg associated with inflight catering. Epidemiol Infect. 2013 Jul 26:1-10.

13. Gossner C. ECDC launches the second version of the EPIS-FWD platform. Euro Surveill. 2013;18(27).

14. Gossner CM, van Cauteren D, Le Hello S, Weill FX, Terrien E, Tessier S, et al. Nationwide outbreak of Salmonella enterica serotype 4,[5],12:i:- infection associated with consumption of dried pork sausage, France, November to December 2011. Euro Surveill. 2012;17(5).

15. Jones J, Gastellu-Etchegorry M, Stenz FK, Baudon C, Bloem SJ, Bondonneau $\mathrm{M}$, et al. Epidemiology, surveillance and control of infectious diseases in the European overseas countries and territories, 2011. Euro Surveill. 2011;16(29).

16. Gossner CM, Van Cangh T, Coulombier D. Public health in the European overseas countries and territories: new perspectives for Europe. Euro Surveill. 2011;16(29).

17. Gossner CM, Schlundt J, Ben Embarek P, Hird S, Lo-Fo-Wong D, Beltran JJ, et al. The melamine incident: implications for international food and feed safety. Environ Health Perspect. 2009 Dec;117(12):1803-8.

18. European Centre for Disease Prevention and Control (ECDC) Technical Emergency Team. Initial epidemiological findings in the European Union following the declaration of pandemic alert level 5 due to influenza A (H1N1). Euro Surveill. 2009 May 7;14(18). 


\section{List of contributions to reports}

1. European Food Safety Authority (EFSA). Scientific report on drivers for occasional spillover event of Ebola virus. EFSA Journal 2015;13(6):4161, 46 pp. doi:10.2903/j.efsa.2015.4161. 2015.

2. European Food Safety Authority (EFSA). Risk related to household pets in contact with Ebola cases in humans. EFSA Journal 2014;12(12):3930, 12 pp doi:102903/jefsa20143930. 2014.

3. European Food Safety Authority (EFSA), European Centre for Disease Prevention and Control (ECDC), European Medicines Agency (EMA). Scientific Opinion on the possible risks posed by the Influenza $\mathrm{A}(\mathrm{H} 3 \mathrm{~N} 2 \mathrm{v})$ virus for animal health and its potential spread and implications for animal and human health. EFSA Journal. 2013;11(10):3383. 64 pp. doi:10.2903/j.efsa.2013.3383

4. World Health Organization. Disease risk assessment and interventions, Gaza Strip. Geneva: WHO; 2009.

\section{List of abstracts and oral presentation to conferences}

1. Warns-Petit E, Gervelmeyer A, Gossner C. ECDC-EFSA collaboration at the animal-human interface on non-foodborne zoonotic and potential zoonotic diseases. 3rd international One Health congress; Amsterdam, the Netherlands; 2015.

2. Fonteneau L, Le Hello S, Bertrand S, Mattheus W, Fabre L, Torpdahl M, et al. Multinational Salmonella Chester outbreak associated with travel to Morocco, 2014. European Scientific Conference on Applied Infectious Disease Epidemiology (ESCAIDE); Stockholm, Sweden; 2015.

3. Gossner C.M., Takkinen J. Indicator- and event-based surveillance for detection and assessment of emerging zoonotic infections. Annual Scientific Conference and the Annual General Meeting of the European College of Veterinary Public Health; Copenhagen, Denmark; 2014.

4. Sane J, MacDonald E, Vold L, Gossner C.M, Severi E. Lack of vaccination for hepatitis A among European travel-related cases to all-inclusive resorts in Egypt observations from a multi-state outbreak (on behalf of the International Outbreak Investigation Team). European Scientific Conference on Applied Infectious Disease Epidemiology (ESCAIDE) Stockholm, Sweden; 2013.

5. Johansson K, Van Walle I, Ködmön C, Martinez-Urtaza J, Palm D, Gossner C.M, et al. Molecular surveillance at the European level: Strategy and pilot for integration of molecular typing data into EU-level surveillance and epidemic preparedness. European Scientific Conference on Applied Infectious Disease Epidemiology (ESCAIDE) Stockholm, Sweden; 2013.

6. Gossner CM, Bertrand S, Kanitz E, Martinez-Urtaza J, Kinross P, Takkinen J, et al. Multistate outbreak of Salmonella Stanley infection in the European Union, 2011-2012: investigations from fork to farm. . I3S Conference, International symposium on Salmonella and salmonellosis; Saint Malo, France; 2013.

7. Franklin K, Gossner C.M, de Jong B, Gardhouse C, Currie A. Collaborative development of criteria to consider when declaring the end of a food-borne illness 
outbreak. European Scientific Conference on Applied Infectious Disease Epidemiology (ESCAIDE) Stockholm, Sweden; 2013.

8. $\quad$ Eibach D, Gossner C.M., Westrell T., Martinez-Urtaza J., Takkinen J., Jasir A. Monophasic Salmonella Typhimurium in the EU: Emerging pathogen or increased awareness? European Scientific Conference on Applied Infectious Disease Epidemiology (ESCAIDE) Stockholm, Sweden; 2013.

9. Müller L, Kjelsoe C, Frank C, Jensen T, Torpdahl M, Søborg B, et al. European outbreak of Salmonella Strathcona caused by small tomatoes, August November 2011 European Scientific Conference on Applied Infectious Disease Epidemiology (ESCAIDE) Edinburgh, The United Kingdom; 2012.

10. Gervelmeyer A, Gossner C. Improved collaboration at the animal-human interface A European initiative to facilitate early detection and joint rapid risk assessments of outbreaks of non-foodborne zoonoses International Meeting on Emerging Diseases and Surveillance (IMED) Vienna, Austria; 2012.

11. Gossner C, Lenglet A, De Jong B, Leitmeyer K. Strengthening the multidisciplinary approach for early warning and response to food- and waterborne outbreaks at European level through the Epidemic Intelligence Information System (EPIS). GRF One Health Summit; Davos, Switzerland; 2012. 

